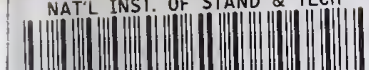

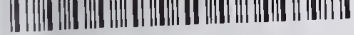 \\ 719
}

$462,00$.

Al1106 03961?

NBSIR 75-642

NIST

PUBLICATIONS

PROJECT SUMMARIES

of the Center for Building Technology

National Bureau of Standards 1974-75

\section{JANUARY, 1975}

QC 100 nal Bureau of Standards 456 ington, D.C. 20234

$75-642$

1975

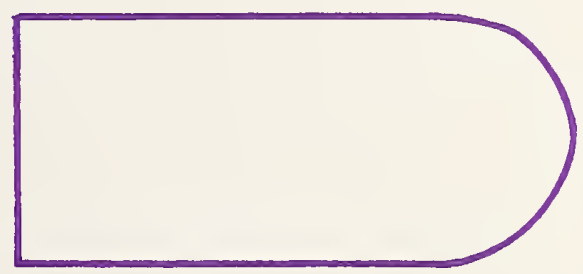

DEPARTMENT OF COMMERCE

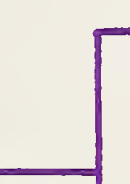




\section{PROJECT SUMMARIES OF THE CENTER FOR BUILDING TECHNOLOGY NATIONAL BUREAU OF STANDARDS $1974-75$}

Lillian T. Slovic, Editor

Center for Building Technology

January, 1975

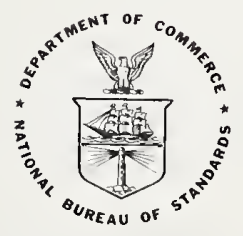

U. S. DEPARTMENT OF COMMERCE, Frederick B. Dent, Secretary NATIONAL BUREAU OF STANDARDS, Richard W. Roberts, Director 

This report provides a project-by-project account of the work of the Center for Building Technology. It describes each onqoina and recently completed research project; in turn, the project descriptions when taken together offer a comprehensive view of the Center's overall program.

"Project Summaries" serves as a management tool and as an informational service to the Center's research professionals, functioning in the latter instance as a means of keeping researchers abreast of one another's work. At the same time, this report is beina shared with peers in the building community and, for informational and coordinative purposes, with the Federal agencies concerned with building. In this connection, it is to be remembered that this report is essentially an internal or "business" document and as such departs from the editorial standards associated with formal publications of the National Bureau of Standards.

"Project Summaries" FY 74-75 covers projects concluded in Fiscal Year 1974 (a Federal fiscal year runs from mid-year to mid-year and is designated by the year in which it ends; e.g. FY 75 ends in July of 1975). It also includes projects launched with the start of Fiscal Year 1975 as well as projects bridgina both years. The projects of this report are grouped according to the research issue addressed, i.e. standards and codes, housing, etc. They are spread across the Center's organizational units (see organizational chart, next paqe).

The summaries of many of the projects contained herein make reference to various publications, some of which are not formal citations of open literature documents. The user of this report is accordingly cautioned against assuming availability of all documents referenced. The user is also advised that the kevwords used in this report are those suggested by the National Bureau of Standards Keyword Index; "impact" keywords were developed at NBS in a fledgling effort to delineate the primary areas of impact of the Bureau's programs as they relate to major national needs or societal goals, and "technical" keywords are those employed by the Smithsonian Science Information Exchange.

The Center for Building Technology's mission is to advance the nation's building technology and facilitate its implementation for the public benefit. In addition to the laboratory and field projects described in this report, the Center also engages in cooperative projects with several foreign research organizations. 


\section{CENTER FOR BUILDING TECHNOLOGY}

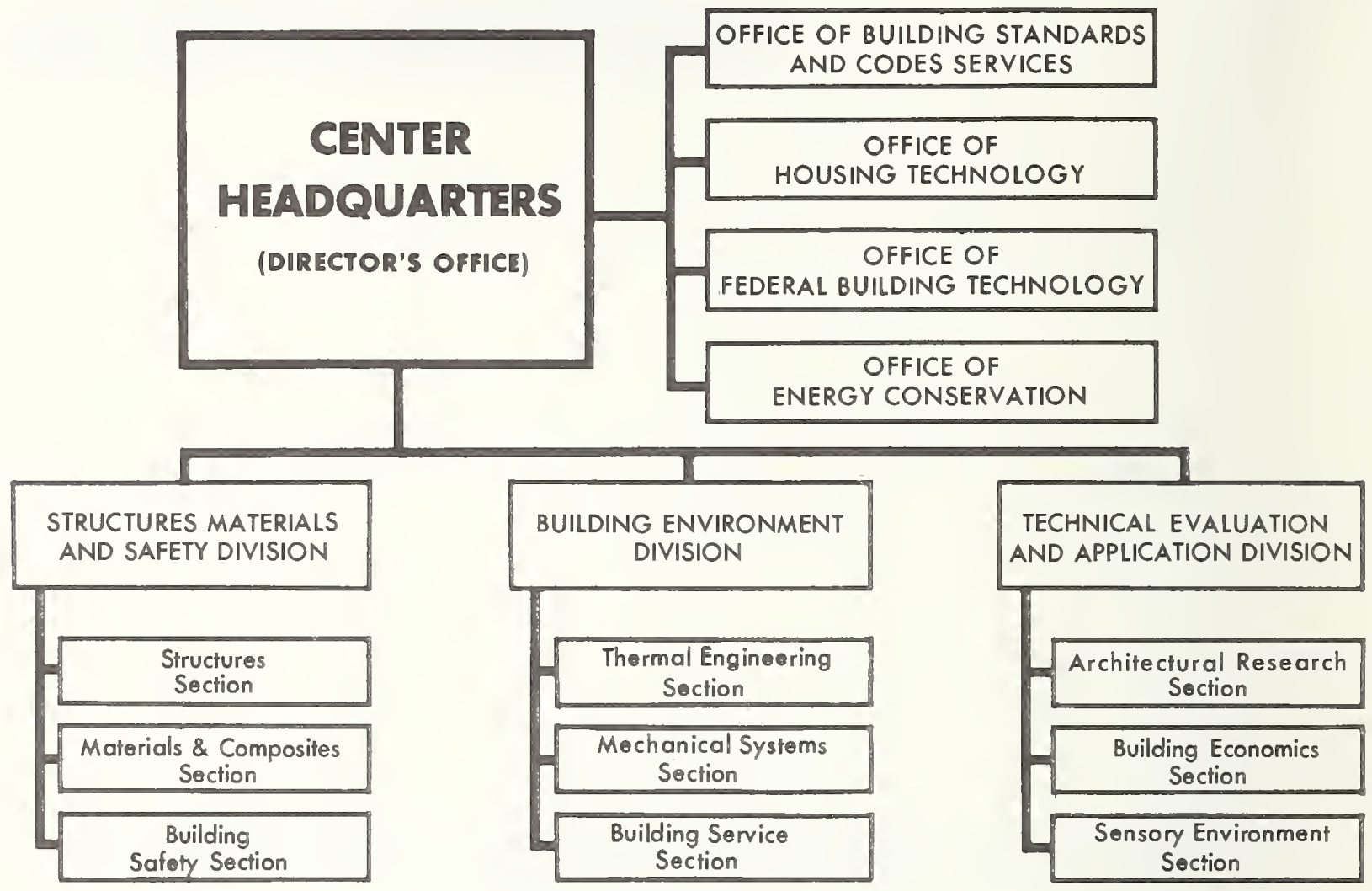


STANDARDS, CODES

FEDERAL BUILDING

STRUCTURES
Standards and Codes ........................ . . . . 2 National Conference of States on Building Codes and Standards (NCSBCS). . . 3 Coordinated Evaluation System (CES) . . . . . . . . . . . . . . . 4 Laboratory Evaluation and Accreditation Program (LEAP) . . . . . . . . . 5 Housing Technology . . . . . . . . . . . . . . . . . . . . . 6 HUD Long Range Research . . . . . . . . . . . . . . . . . . . . . . . . . 6 Solar Energy Demonstration Program . . . . . . . . . . . . . . . . 7 Performance Standards--Special and Innovative Construction . . . . . . . 8 Impact of Metrication on U.S. Housing . . . . . . . . . . . . . . . . . 8 HUD--Lead Paint Hazards . . . . . . . . . . . . . . . . . . . 9 Building Concepts Used in Operation BREAKTHROUGH . . . . . . . . . . . . . 10 BREAKTHROUGH Housing Systems Producers Evaluation and Certification . . . 10 Compendium of Test Methods Used in Operation BREAKTHROUGH . . . . . . . . 11 Fire Compendium for Operation BREAKTHROUGH . . . . . . . . . . . . . . 11 Shelley Building Smoke Test . . . . . . . . . . . . . . . . . 12 Transportation and Handling Equipment--Operation BREAKTHROUGH . . . . . . 12 Failure Identification and Analysis--Mobile Homes . . . . . . . . . . . . 13 Federal Building Technology . . . . . . . . . . . . . . . . 14 Simulated Solar Radiation Tests on Air Support Shelters . . . . . . . . 15 Fire and Live Loads on Buildings . . . . . . . . . . . . . . . . . . . 16 Building Practices for Disaster Mitigation . . . . . . . . . . . . . . 17

Air Mobility Shelter Systems . . . . . . . . . . . . . . . . 18

High Wind Study for Developing Countries . . . . . . . . . . . . . 19 Paper Honeycomb Technology. . . . . . . . . . . . . . . . . . . 20 Model Study of a Parking Garage Collapse . . . . . . . . . . . . . . . . . 21 Data Acquisition Development . . . . . . . . . . . . . . . . . 21 HUD Long Ranqe Research--Structural Test Methods . . . . . . . . . . . . 22 HUD Long Range Research--Progressive Collapse . . . . . . . . . . . . . 23 Strength of Existing Masonry Walls . . . . . . . . . . . . . . . 24 Occupancy Loads on Buildings . . . . . . . . . . . . . . . . . . 24 Wind Loads on Structures . . . . . . . . . . . . . . . . 25 Hurricane Effects on Port Facilities . . . . . . . . . . . . . . 26 Design Criteria for Masonry . . . . . . . . . . . . . . . . . 27 Inelastic Response of Buildings and Structural Restoration . . . . . . 28 
Selection and Maintenance of Floor Coverings . . . . . . . . . . . . 29

Simulated and Actual Exposure of Building Materials . . . . . . . . . . 30

Building Stone Preservatives . . . . . . . . . . . . . . . 31

Rheology of Organic Building Materials . . . . . . . . . . . . . . . 32

Test Methods--Joints in Plastic Pipe . . . . . . . . . . . . . . 33

Viscosity Grading Criteria for Roofing Asphalt . . . . . . . . . . . . . 33

Polymer Impregnated Mortars and Concretes . . . . . . . . . . . . . 34

Performance of Roofing . . . . . . . . . . . . . . . . . . . . . . . . . . . . . 35

Corrosion of Metals . . . . . . . . . . . . . . . . . . . . . . . 36

Non-Metallic Coating for Concrete Reinforcing Steel . . . . . . . . . 37

Organic Coatings . . . . . . . . . . . . . . . . . . . 38

Inorganic Building Materials . . . . . . . . . . . . . . . . . 39

Durability Prediction Methodology . . . . . . . . . . . . . . . . . 40

Evaluation of Plastic Wall Covering Materials . . . . . . . . . . . . 41

Corrosion Control--Piping--Military Facilities . . . . . . . . . . . . . . . 41

Field Survey of Roofing . . . . . . . . . . . . . . . . . . . . . 42

Porcelain Enamel Institute Research Associateship . . . . . . . . . . . . 42

HUD Lonq Range Research--Graffiti . . . . . . . . . . . . . . . . . 43

HUD Long Range Research--Accelerated Aging . . . . . . . . . . . . . . . . . . 44

HUD Long Range Research--Waterproofing . . . . . . . . . . . . . . . . . 45

HUD Long Range Research--Innovative Coating Systems . . . . . . . . . . . 45

Building Joint Sealants . . . . . . . . . . . . . . . . . . . 46

Aluminum bire and Grounding . . . . . . . . . . . . . . . . . . . . . . . . . . . 47

SAFETY

Consumer Product Safety Commission--Architectural Glass . . . . . . . . . 47

Safety in Construction and Occupancy of Buildings . . . . . . . . . . . . 48

Slip Resistance of Flooring . . . . . . . . . . . . . . . . . . . . . . . 49

Safety Research on Stairs, Ramps and Landings . . . . . . . . . . . . . . . . . . . 50

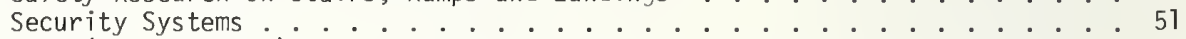

CPSC (Door Studies)

ENERGY Modular Integrated Utility Systems Programmatic Support . . . . . . . . . . 53

Modular Integrated Utility Systems Design, Analys is and Technical Support 54

Modular Integrated Utility Systems Feasibility Demonstration . . . . . . . 55

Modular Intearated Utility Systems Project Management . . . . . . . . . . . 57

Retrofit Plan, Energy Conservation, NBS Campus . . . . . . . . . . . . . . . . . 58

Conservation of Energy Program . . . . . . . . . . . . . . . . . . . . . . . . . . 59

Energy Conservation Information . . . . . . . . . . . . . . . . . . . . . . . . . . . 60

Industrial Energy Conservation . . . . . . . . . . . . . . . . . . . 61

Performance Standard for Eneray Conservation . . . . . . . . . . . . . . . . . . . 62

Contract Management (Energy Conservation) . . . . . . . . . . . . . . . 63

Industry Energy Use Research Associateship, Dow Chemical Company . . . . . . 63

Evaluation of Solar Heating, Ventilating and Air-Conditioning Systems : . 64

Energy Demonstration Office Building . . . . . . . . . . . . . . . 65

New Building Energy Design . . . . . . . . . . . . . . . . . . . . . . . . . . . . . . 66

HUD Long Range Research - Thermal Performance of Whole Buildings . . . . . 67

Appliance Enerğy Labeling . . . . . . . . . . . . . . . . . . . 68

Attic Ventilation ....................... . . . . . . 68

Retrofit of Housing to Save Energy-Mobile Homes . . . . . . . . . . . . . 69

GSA Energy Profile for Federal Buildings . . . . . . . . . . . . . . . . . . 70

Bowman House . . . . . . . . . . . . . . . . . . . . . . . . . 70

Retrofit of Housing to Save Energy, Bowman House . . . . . . . . . . . . . . . . . . . . 71

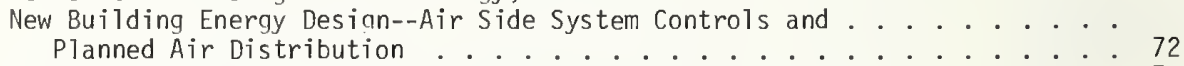

Existing Buildings' Energy Analys is . . . . . . . . . . . . . . . . . . . . . . . . . . . . 73

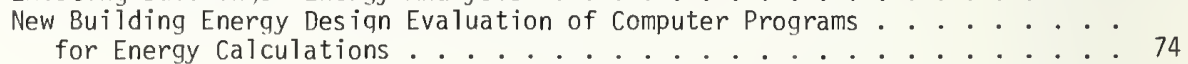


ENVIRONMENTAL

BUILDING SERVICES

ARCHITECTURAL

ECONOMICS

COMMUNICATION
Insulation in Refrigerated Warehouses . . . . . . . . . . . . . . 74

Efficiency of HVAC Equipment . . . . . . . . . . . . . . . 75

Measurement of Indoor Radiation - Pilot . . . . . . . . . . . . 76

Heat Pump Specification ................... . . . . . 76

Underground Plastic Pipe Systems . . . . . . . . . . . . . . . . 77

Measurement Technology...................... . . . . 78

Integrated Solar Energy Systems . . . . . . . . . . . . . . . 79

People and Building Fire Safety--Monitor . . . . . . . . . . . . . 80

Signal Lighting . . . . . . . . . . . . . . . . . 81

Light Nuality: Veiling Reflectance. . . . . . . . . . . . . . . 32

Noise In and Around Buildings (CBT) . . . . . . . . . . . . . . . 83

Emergency Equipment Standards . . . . . . . . . . . . . . . . 84

Thermal "Comfort" Measures in Buildings . . . . . . . . . . . . . . . . 85

Color and Appearance . . . . . . . . . . . . . . . . . . 86

Exterior Envelope Design-Fenestration . . . . . . . . . . . . . . 87

Visual Environment ...................... . . . 89

Plumbing Systems Design Criteria... . . . . . . . . . . . . . 90

Criteria for Backflow Preventers . . . . . . . . . . . . . . . 91

Criteria for Reduced-Size Venting . . . . . . . . . . . . . . . . . 92

Computer Evaluation of Building Plumbing Systems . . . . . . . . . . . . 93

Measurement Technology: Utility Loads . . . . . . . . . . . . . . . 94

Residential Aerobic Waste Water Treatment . . . . . . . . . . . . . . 94

HUD Long Range Research-Innovative Electrical Connections . . . . . . . 95

Electrical Service Quality Measurement . . . . . . . . . . . . . . 96

HUD Long Range Research -- Innovative Piping Materials . . . . . . . . . . 97

Service Systems Data Processing . . . . . . . . . . . . . . . . . 99

Vacuum Drainage .. . . . . . . . . . . . . . . . . . 100

Utility Load Measurements . . . . . . . . . . . . . . . . . 101

American Institute of Architects/NBS Research Architect . . . . . . . . 102

Construction Research . . . . . . . . . . . 102

Medical Facility Design . . . . . . . . . . . . . . . . . . . 103

Architectural Research .. . . . . . . . . . . . . . . . . 104

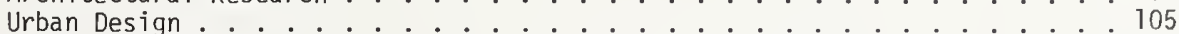

Building Design Theory .. . . . . . . . . . . . . . . . 106

Project Feedback . . . . . . . . . . . . . . . . . . . . . 106

Methodology Handbook .. . . . . . . . . . . . . . . . 107

Interdisciplinary Decision Making in Design . . . . . . . . . . . . . 108

Architectural Psychology . . . . . . . . . . . . . . . . . . . . . . . 108

Feedback on Jersey City, Operation BREAKTHROUGH . . . . . . . . . . . 109

Economic Indicators of Construction Cost Trend . . . . . . . . . . . . . . . . . 110

Techniques for Economic Evaluation . . . . . . . . . . . . . . . 111

CBT Microstudies . . . . . . . . . . . . . . . . . . . . 112

Building Practices for Disaster Mitigation--Financial Loss . . . . . 112

Economics of Abandonment and Rehabilitation ............. . . 113

Economics of Energy Conservation . . . . . . . . . . . . . . . . . . . 114

Economic Evaluation of Roof and Wali Sections . . . . . . . . . . . . . . . . 114

Alternative Financing Methods, Non-Plant Sewage Treatment . . . . . . . 115

Building Technology Information Systems ................. 115

Conferences and Seminars . . . . . . . . . . . . . . . . . 116

International Building Research . . . . . . . . . . . . . 116

Liaison With the Building Community ................ . . . 117

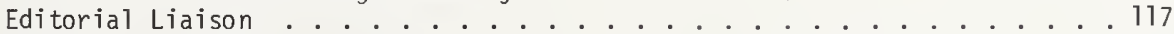

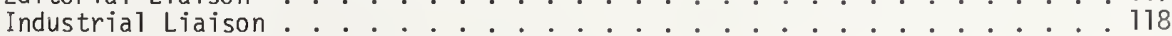




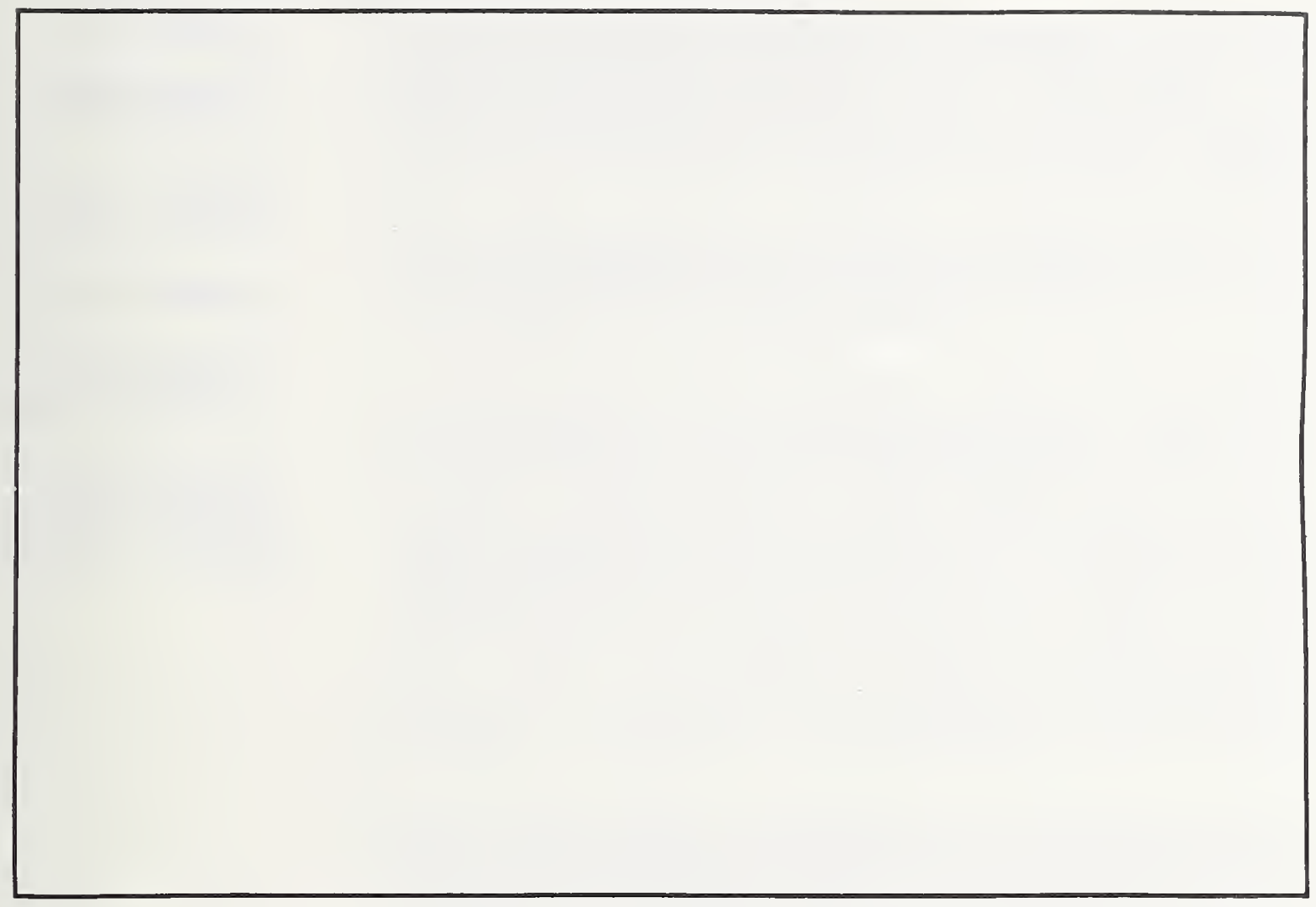

PROJECT DESCRIPTIONS 
No fully coordinated effort exists for determining national building standdards needs. Code enforcement officials often fill such qaps in their regulations by developing their own non-standard reaulations. This program will attempt to utilize CBT expertise operating with consensus committees, in the development of national building standards to satisfy the needs of regulatory officials, manufacturers, designers, and consumers--in short, the nation's entire building community.

The objective of this project is to determine the nation's building standards needs using the building requlations as source material, and to carry out the bujlding standards objectives and priorities established by the CBT Standards Council utilizing the most appropriate CBT staff members (selected with the aid of the CBT talent bank) as standards committee participants.

The assembly and maintenance of complete state and model code files plus the yearly list of proposed code changes will provide the basis for jdentifying regulatory needs not adequately covered by existing national consensus standards. This information, processed through the CBT Standards Council for CBT priority determination, will establish the the basis for involving CBT staff in selected national consensus committee in order to carry out these CBT standards objectives. All pertinent details regarding the resulting standards will be made known to the appropriate code enforcement officials to enable their timely consideration and adoption. A more detailed description can be obtained from the program description approved at the June 7, 1974, meeting of the CBT Standards Council. International buildina standards activities will be monitored and support given to those considered important by the CBT Standards Council.

Both phases, codes and standards, are actually continuing CBT programs but never before coordinated as proposed here.

The state and model code plan files should be completed by September 1 , 1974. The analyses of these code documents will be of a continuous nature. As these analyses are completed and standards needs established, the informidion will be presented at the regularly scheduled meetinas of the CBT Standards Council. Reactivation of the CBT talent bank will be completed by September 30,1974 . The assignment of CBT staff to selected committees will be done on a continuing basis and is not readily subject to milestone determinations. Standards development, especially through the use of outside consensus committees, is also not subject to milestone determinations, at least not at this time. The delivery of the completed standards to the appropriate code officials is time dependent on the development speed of the committees involved.

The following were a result of this oroject: "Design and Evaluation Criteria for Enerny Conservation in New Buildincs, "February 27, 1974, National Conferences of States on Bujlding Codes and Standards; Robert $S$ Wyly, Lawrence S. Galowin and Charles T. Mahaffey collaborated in the formation and presentation of NBS views on a performance code for plumbing under the American National Standards Institute (ANSI) procedures; Peter F. Colwel1, "The Economics of an Energy Standard," speech qiven to the Fovernor's Task Force on Eneray Conservation, the Massachusetts State Building Code Commission, the University of Massachusetts Extension Services, and the Museum of Science.

\section{Project Status Continuing}

Project Leader Charles T. Mahaffey 301 921-3447

Sponsor National Bureau of Standards

Project Number $46 \overline{01740}$

Impact Keywords Building design; construction; effective regulation.

Technical Keywords Codes and Standards, construction; Codes and Standards, design; desian, general. 


\section{NATIONAL CONFERENCE OF STATES ON BUILDING CODES AND STANDARDS (NCSBCS)}

Project Status

Continuing

Project Leader

Sandra A. Berry

301 921-3447

\section{Sponsor}

National Bureau of

Standards

Project Number $46 \overline{01130}$

Impact Keywords Building design; construction; ; new federal ism.

Technical Keywords Codes and standards; improvement of buildings.
The building regulatory system increasingly a State function, represents the public interest in the design, construction and operation of the built environment. NCSBCS is the means by which CBT research output can reach the regulatory agencies with minimum delay. Moreover, NCSBCS is a vehicle for helping to identify needed building research. This is an effective means for cooperative participation of all levels of government in reaching decisions regarding supportive assistance, research, financing, etc.

The objective of this period is to provide a forum of the States for discussion of problems related to the administration of programs pertaining to building as carried on by regulatory officers of the States and to provide a mechanism for the exchange and development of solutions to problems identified by the Conference.

The Secretariat responds to needs of NCSBCS as expressed to NBS through its Executive and Standing Committees. Technical Assistance will maintain direct contact with and participation in Standing Comittees of NCSBCS as assianed by the Office Chief throuah the Conference Coordinator. The Secretariat will provide technical and secretarial services to NCSBCS as requested. This includes development and dissemination of the proaram outline for NCSBCS; about 40 mass mailinas to about 200 persons each; technical assistants to participate in standina Committee meetings and informal consultations between these meetings; and legal assistance provided by $\mathrm{DOC}$.

During FY 74 approximately 45 individual mailings to an average of 200 persons were made. Support to the various Standing and Special NCSBCS Committees including assistance in development and dissemination of the 1973-74 Outline was continued; Constitution and Bylaws; arrangements and details for 3 Committee Weeks and one Annual Conference, (Des Moines, Boston, Salt Lake City, Austin). were printed.

During FY 75 the following meetings will be arranged: Executive Committee, Washington, D.C., post committee mailings three weeks after, pre-committee week mailings three weeks ahead; Northeastern Reqional Meeting, Providence, R.I., post committee mailing three weeks after, pre-committee week mailings three weeks ahead; Midwestern Regional Meeting, Minneapolis, Minnesota, post committee mailing three weeks after, pre-committee week mailing three weeks ahead; Southern Reqional Meeting, New Orleans, Louisiana, Post-committee mailing three weeks after, pre-annual conference mailing four to five weeks ahead; and eighth Annual Conference Meetina, Santa Fe, New Mexico. Before each meeting arrangements are made for hotels, meeting rooms, mailings, registration. Technical staff is available at each meeting. 


\section{COORDINATED EVALUATION SYSTEM (CES)}

In 1971, the Executive Office of the President asked NBS to develop specific programs which would asist in removing or reducing barriers created by building regulatory process. On the recommendation of the National Conference of States on Building Codes and Standards (NCSBCS), the CES project was established to develop model documents to serve the needs of many state regulatory agencies and to minimize duplications and delays experienced by a producer in.obtaining regulatory approvals.

The long range objective of the project is to assist the states in developing their building regulatory activities and functions, primarily by developing model informational documents and associated information flows that will assist state building regulatory agencies in establishing a coordinated and uniform evaluation, approval and inspection system.

The current objective is to develop model rules and regulations for the model mobile home act and further develop, based on the above rules, model documents for the regulation of mobile homes. The format would be similar to the model documents already developed (FY 74) for the regulation of manufactured buildings.

During FY 75, CES will develop through background research and past experience, model documents including model rules and regulations relating to mobile homes. This will include visiting some states to study different systems of certification, e.g. state, third party or contract agent. Project staff will also undertake a program of direct technical assistance to uses of the prototype model documents in building regulatory programs around the nation.

Preliminary reports were completed pertaining to model documentation for the regulation of manufactured buildings (one and two family dwelling units). This model documentation was made available for use by all state regulatory agencies, private evaluation and inspection agencies, and the manufactured building industry. Also completed in FY 74 were reference summary reports outlining the status of state building regulatory programs and enforcement processes related to manufactured buildings and mobile homes. In addition, three related contractor reports were released to NTIS. Some states are in the process of adopting CES model documents and the response to the summary tables has been encouraging.

During FY 75 model documents for evaluating and approving manufactured buildings will be written (Final revision of NBS Interagency Report

(NBSIR) 73-278 for publication as Technical Note); state reference summary reports (computerized format) outlining the status of building regulatory programs and enforcement processes relating to manufactured buildings and mobile homes will be completed; comprehensive overview of statewide preemptive building codes (computerized format) applicable to conventional construction will be completed; sampling plan for manufactured buildings and mobile homes will be developed; model rules and regulations for mobile home act will be formulated; and model documents for evaluation and approval of mobile homes will be created.
Project Status

Project Leader

Patrick W. Cooke

301 921-3447

\section{Sponsor}

National Bureau of

Standards

Project Number $46 \overline{01132}$

Impact Keywords construction; effective requlation; qual ity control.

Technical Keywords codes and standards; manufacturing; mobile homes. 


\section{LABORATORY EVALUATION AND ACCREDITATION PROGRAM (LEAP)}

Project Status Continuing

Project Leader Robert n. Dikkers 301 921-3447

\section{Sponsor \\ Nationa 1 Bureau of Standards}

\section{Project Number $46 \overline{01131}$}

Impact Keywords Construction; effective regulation; quality control.

Technical Keywords Codes and standards; design, other; mobile houses; testing.
The LEAP project was established in FY 72 in direct response to a formal request from the National Conference of States on Building Codes and Standards (NCSBCS). This request sought assistance in the development of a technical foundation for the evaluation of laboratories and/or agencies engaged in the certification of manufactured building, mobile homes, and building components. The development and implementation of such a laboratory evaluation and accreditation program would greatly benefit regulatory agencies, manufacturers and users in the interstate acceptance of buildings and building products by assuring a creditable source of examination and evaluation services to government and to industry.

The objective of the project is to develop the institutional mechanism and associated standards research needed to evaluate and accredit laboratories to perform engineering analysis, testing, and compliance assurance functions required by building regulatory authorities.

Project LEAP has prepared in FY 73 (with contract support) five research documents, NBS Interaqency Reports (NBSIR), relating to criteria and methodolony for evaluating laboratory capabilities in regard to manufactured building certification functions (evaluation, testing, and inspection). This work has resulted in the creation of a voluntary consensus standard committee (ASTM E32) to further process the LEAP documents into final standards for national use.

LEAP staff have actively participated in ASTM Committee E32 and has prepared an initial draft of "Criteria for Evaluating Agencies Engaged in Systems Analysis and Compliance Assurance for Manufactured Building." Subsequent drafts were formally considered by the E32 Committee in FY 74. LEAP staff has also actively participated in ASTM Committee E36. This committee is preoaring generic criteria pertaining to testing and/or inspection agencies as distinguished from the specific (manufactured building) criteria under E32. The staff has also participated in NBS preliminary planning relating to a national laboratory accreditation program.

During FY 75, LEAP will continue active participation in ASTM E32 and E36 committee work. LEAP, as a major activity, will also initiate, with at least two states (Maryland and Massachusetts), pilot and study demonstration projects relating to laboratory evaluation programs. The purpose of these pilot projects will be to further develop the institutional and documentation mechanisms necessary for intrastate and interstate laboratory accreditation. The preliminary documentation of results of the intrastate study programs are to be completed early in FY 76. In FY 75, the previous documents prepared by LEAP (NBSIR-73-186,195,224,225) will be also edited and combined into one formal NBS publication. 
The housing technology effort is directed toward the exploration of areas which are most useful in meeting critical housing needs. These areas include: (1) a need for the identification of research projects of a high priority nature; (2) the development of a plan for mobile home research; and (3) the planning for research efforts to be undertaken in support of a solar energy program. The FY 74 activities concentrated on refining high priority research projects for housing, advancing mobile home research planning, and continued investigatory activities for solar energy.

Continued liaison with The Department of Housing and Urban Development (HUD) and other orqanizations is expected to be instrumental in developing new high priority projects as part of a total research package for housing technology. Detailed planning will be instituted for those projects of mutual interest to CBT and HUD so that schedule and funding levels can be proposed. It is anticipated that HUD will fund a number of mutually developed high priority projects during FY 75.
Project Status

Continuing

Project Leader James G. Gross $301921-3126$

\section{Sponsor \\ National Bureau of Standards \\ Project Number 4608160}

Impact Keywords Building design; consumer protection; enerny--solar, geothermal and other.

Technical Keywords Codes and standards; components general; mobile homes; piping systems; solar-heat-radiation

\section{HUD LONG RANGE RESEARCH}

\begin{abstract}
A Department of Commerce - Department of Housing and Urban Development Secretary-to-Secretary level agreement signed several years ago states that NBS would provide technical support to HUD in carrying out HUD's research responsibilities. The scope of this research includes planning, evaluating, conducting, and managing selected projects which would be relevant and timely in the general area of housing. Projects selected would generally run two to four years and would be oriented toward solving high priority research needs as identified jointly by NBS and HUD. This effort is of a continuous nature with many projects already completed; others, started in previous fiscal years, still ongoing; and additional projects to be started in FY 75. This particular work scope provides the necessary planning to assure that the projects identified and selected for implementation are relevant, fall within the general expertise of NBS, and can be accomplished with the available manpower. A list of high priority projects is continually updated and reviewed by NBS and HUD. Several projects presently in work were chosen to fill technical gaps in the Evaluation Criteria developed by NBS for use by HUD in evaluating innovative housing. Other projects in work or contemplated are designed to add to the solution of problems of national interest in the area of housing such as the use of plastic pipe, innovative electrical distribution systems, and fire safety activities. Periodic reports are provided to HUD on each active project to show overall summary status. Reorientation and replanning of projects are accomplished as required.
\end{abstract}

The following are under the overall management of this project: Progressive Collapse, Structural Test Methods, Graffiti, Waterproofing, Accelerated Aging, Innovative Coating System, Thermal Performance of Whole Buildings,
Project Status

continuing

Project Leader

James G. Gross

301 921-3281

Sponsor

Department of Housing and Urban Development

Project Number $46 \overline{08403}$

Impact Keywords construction.

Technical Keywords Testing. 
Innovative Piping Materials and Innovative Electrical Connections. Summaries of these projects are located under the operating unit conducting the research. The Fire Technology Division is supervising the research on Smoke and Flame Spread, Fire Loads, and Sprinkler Systems.

\section{SOLAR ENERGY DEMONSTRATION PROGRAM}

\author{
Project Status \\ New \\ Project Leader
}

Robert D. Dikkers

$301921-3126$

\section{Sponsor}

Department of Housing

and Urban Development

Project Number

\section{$46 \overline{06500}$}

Impact Keywords

Energy, geothermal and other.

Technical Keywords
An interdisciplinary team of CBT staff members will generate interim performance criteria for accomplishing the objectives set forth in the Solar Heating and Cooling Demonstration Act of 1974. The criteria, to the extent allowed by the state-of-the-art, will be performance oriented. . NBS will use the talents of other organizations, both Federal and non-Federal, to draw input for the generation of the criteria. An advisory group, drawn from experts in the solar energy field, will be established to critique to the draft criteria during its formulative stages as well as in its later more finalized state. The approach in developing the design and evaluation criteria will be to establish both system and subsystem component requirements. This will require setting levels of acceptance for the thermal performance of the total solar heating system design and also establishing guidelines for components and other hardware items. The presentatjon of the material will be in the format of requirement, criterion, evaluation and commentary to permit use by designers and evaluators and allow future change where needed. Requirements will also be established for the buildings which will employ the solar heating systems. The FHA Minimum Property Standards will be used as one of the source documents for the building design requirements. Special thermal requirements, structural considerations, and basic architectural design constraints may be required to assure an attainable and potentially acceptable end product. 


\section{PERFORMANCE STANDARDS-- SPECIAL AND INNOVATIVE CONSTRUCTION}

The draft documents which were submitted to the Department of Housing and Urban Development (HUD) in July 1973 have been revised to indicate those parts of the performance standards which are directly referable to the Minimum Property Standards, and those parts which are new requirements needed to assure acceptable performance of innovative materials and designs. Additional work will be required when agreement between NBS/HUD is reached on how the final document is to be applied. When the final format is selected several sessions will be scheduled with industry groups to gain concurrence on levels of acceptability presented in the draft document. CBT staff members representing different technical disciplines will meet with the industry aroup to discuss and present reasons for selection of stated levels of performance. The draft document will be modified to reflect the industry/CBT changes. $\frac{\text { Project Status }}{\text { Continuing }}$

Project Leader

Thomas K. Faison

$301921-3126$

Sponsor

Department of Housing and Urban Development

Project Number $46 \overline{08510}$

Impact Keywords construction; effective regulation

Technical Keywords rodes and standards; design; fire considerations; safety; structural; testing

\section{IMPACT OF METRICATION ON U.S. HOUSING}

The U.S. Metric Study, undertaken in an attempt to determine possible impacts of metrication on various sectors of the U.S. economy, resulted in recommendations by the Secretary of Commerce that the United States adopt the metric system. Although this was a major study in terms of scope and impact, only limited attention could be paid to some of the industries which were examined. The original study included a broad survey of the potential effects of metrication of the domestic housing industry, but additional efforts should be initiated to focus on the effects of metri= cation on builders, suppliers, contractors, unions, etc., in an attempt to uncover potential problem areas calling for early solution or amelioration. This study and the resulting report provide a summary analysis of potential impacts on the housing community, both short-term and long-term, as a result of the adoption of the metric system. In addition, recommendatir is $f r$ in-depth studies to resolve specific problems have been developec.

A publication, "An Overview of the Factors Impacting Metrication of the U.S. Housing Industry," NBS Interaqency Report 73-421, by Robert Henderson and Donald Corrigan, resulted from this study.
Project Status concluded

Project Leader Joseph Greenberg $301921-3126$

Sponsor

Department of Housing and Urban Development

Project Number $4 6 \longdiv { 0 8 4 1 4 }$

Impact Keywords International competitiveness;

international standards; productivity enhancement.

Technical Keywords codes and standards; manufacturing. 


\author{
Project Status \\ Continuing
}

Project Leader Harvey Berger

301 921-3281

Sponsor
National Bureau of
standards
$46 \frac{\text { Project Number }}{400}$
Conpact Keywords
hazards in the home.

Technical Keywords Barrier coatings; safety; testing; walls; windows
The objective of this Housing and Urban Development (HUD) sponsored Lead Based Paint Program is the identification and evaluation of technology which might be applied to elimination and/or prevention of lead poisoning in children below 7 years of age which may be caused by the availability of dried, aged lead-based paint on residential surfaces.

Under the management of the Center for Building Technology, personnel from CBT, with the support of the Analytical Chemistry, Technical Analysis and Applied Mathematics Divisions, conducted work in the following areas: 1) an estimation of the extent of lead paint poisoning incidence; 2) the identification and evaluation of techniques for the detection of lead in paint; 3) the identification and evaluations of techniques for the elimination of the lead paint hazard in housing.

In FY 74 the Lead Paint Poisoning Project accomplished the following major tasks: 1) conducted a pilot demonstration of deleading methods in dwellina units made available by the National Capitol Housing Authority; 2) developed plans and methodologies for HUD's Experimental Hazard Elimination Program which will involve the deleading of 250 dwellings distributed through 4 cities across the Nation; 3) developed survey plans, techniques and analytical methodologies for a survey of 4,000 dwellings in the City of Pittsburgh for lead paint hazards and for elevated blood-lead levels in children living in that housing; 4) prepared the technical content of HUD's "Requests for Proposals" for improved lead detection systems and for management of the Experimental Hazard Elimination Program.

The following resulted from project research: "Analytical Methods for the Detection of Toxic Elements in Dry Paint Matrices: Literature Survey," NBS Interagency Report (NBSIR) 73-251; "Report on a Pretest of a Survey Plan for Estimating Incidence of Lead-Based Paint," NBSIR 73-407; "Survey Plans and Data Collection and Analysis Methodologies: Results of a Pre-Survey for the Maanitude and Extent of Lead Based Paint Hazard in Housing," NBSIR 73-426; "Pilot Demonstration of Lead Based Paint Hazard Elimination Methods: Report on Field Survey No. 2," NBSIR 73-438; "Potential Systems for Lead Hazard El imination: Evaluations and Recommendations for Use," Technical Note 808. Talk qiven at the University of Pittsburgh, School of Medicine, Division of Continuing Education June 6, 1974, "Environmental Aspects of Lead Paint Poisoning in Housing."

In FY 75 the Lead Paint Poisoning Project wi11: 1) support HUD's monitoring of their development contracts; 2) evaluate the conduct and results of the Experimental Hazard Elimination Program; 3) monitor and evaluate the results of the Pittsburgh housing/children survey; 4) conduct chemical analyses and physical testing of aversive coatings; 5) participate in further efforts to identify and evaluate innovative lead paint hazard elimination methods; 6) initiate an information dissemination program; 7) develop a plan to survey HUD associated housina for lead paint hazards; 8) design an experiment for evaluating alternative strategies for lead paint poisoning control. 


\section{BUILDING CONCEPTS USED IN OPERATION BREAKTHROUGH}

This project was originated to document the various new ideas and techniques used by the Housing System Producers selected under the Operation BREAKTHROUGH Program. The document is organized into nine sections and describes concepts in the areas of 1) Enclosed Spaces; 2) Structure; 3) Exterior Enclosure; 4) Interior Enclosure; 5) HVAC; 6) Plumbing; 7) Electrical; 8) Elevators; and 9) Hardware, Specialties, and Appliances. The document is highly illustrated and oriented toward a wide ranging audience which includes all sectors of the housing community interested in industrialized housing. Work was started in FY 73 and completed during FY 74. The document, "Feedback: Operation BREAKTHROUGH, U.S. Department of Housing and Urban Development, A Compendium of Building Concepts," Volume 2, was published by the Department of Housing and Urban Development (HUD) and widely distributed under the HUD operation BREAKTHROUGH Feedback program.
Project Status Concluded

Project Leader James Pielert 301 921-3126

\section{Sponsor} Department of Housing and Urban Development

Project Number 4608405

Impact Keywords Disaster mitigation; housing; safety

Technical Keywords Fire considerations; high rise buildinas; safety; testing.

\section{BREAKTHROUGH HOUSING SYSTEMS PRODUCERS EVALUATION AND CERTIFICATION}

In support of the Department of Housing and Urban Development (HUD) in their demonstration program, Operation BREAKTHROUGH (OBT), the Office of Housina Technology (OHT) provided the technical evaluation of the system designs for the 22 housing system producers participating in phase 1 of the program. The evaluations of the designs were made at various staqes of completion--50 percent, 95 percent, 100 percent-with the evaluations beina based upon the OBT Guide Criteria developed earlier by the Center for Building Technology. As evaluation of the designs indicated potential problem areas or insufficient data were available to arrive at a sound judgment, special evaluative tests were required. Testing at NBS and monitoring of tests conducted at other laboratories were provided in support of the evaluation process. Ful1scale testing was required of some of the more innovative systems where prediction of system performance could not be made with adequate confidence. Life safety reviews were made as a final effort to assure that all matters dealing with the safety of the eventual occupants of the buildinas had been identified and transmitted to HUD. A1] pertinent information used in the evaluation process was documented and filed for future use. In an effort to advance performance standards the Guide Criteria was used as a base for generating performance standards for single family and multifamily dwellings.
Project Status Concluded

Project Leader Thomas K. Faison

Sponsor

Department of Housing and Urban Development

Project Number $46 \overline{00400}$

Impact Keywords Building design; consumer protection; productivity enhancement.

Technical Keywords codes and standards; construction; residential, safety; testing. 


\section{COMPENDIUM OF TEST METHODS USED IN OPERATION BREAKTHROUGH}

Project Status

Continuing

Project Leader David Waksman

301 92T-3281

\section{Sponsor}

Department of Housing and Urban Development

Project Number $4 6 \longdiv { 0 8 4 1 6 }$

Impact Keywords construction; safety

Technical Keywords Testing
Operation BREAKTHROUGH was established by Department of Housing and Urban Development (HUD) to stimulate the development of residential construction concepts that would increase the housing production rate and thus help to meet the nation's housing needs. Since many of the systems proposed by industry were innovative in nature, extensive laboratory testing was required during the design and development phase of the BREAKTHROUGH program in order to judge whether or not the innovative designs would provide satisfactory performance during the life of the structure. In many cases existing standard test methods could not be used and it was necessary to develop new Taboratory procedures. The purpose of this project is to identify the laboratory test methods used in Operation BREAKTHROUGH and document them in such a manner that they will be of use to the housing industry.

A compilation of test methods used by NBS and other laboratories for evaluation in Operation BREAKTHROUGH including tests run at NBS and at other Taboratories is being developed. Test methods are being organized by function and discipline, and the testing philosophy and rationale are being included along with specific tests descriptions.

Progress during FY 74 consisted of a review of pertinent test reports.

Anticipated progress during FY 75 includes: (1) preparation of a preliminary summary outline including typical sections; (2) preparation of a draft manuscript of typical sections, including art work in a form ready for printing; (3) preparation of a draft manuscript of the entire compendium; and (4) submission of the entire document including art work to the sponsor, HUD, in a form ready for printing.

\section{FIRE COMPENDIUM FOR OPERATION BREAKTHROUGH}

\author{
Project Status \\ continuing \\ Project Leader \\ David Waksman \\ 301 921-3281
}

Sponsor

Department of Housing and Urban Development

Project Number $4 6 \longdiv { 0 8 4 7 5 }$

Impact Keywords Disaster mitigation; fire research; housing construction.

Technical Keywords Fire considerations; testing.
Operation BREAKTHROUGH was established by Department of Housing and Urban Development (HUD) to stimulate the development of residential construction concepts that would increase the housing production rate and thus meet the Nation's housing needs. Since many of the systems proposed by industry were innovative in nature, and there was a lack of information available concerning their fire hazard performance, considerable fire testing was conducted under the auspices of the BREAKTHROUGH Program. A compendium describing in detail the materials and system designs evaluated and the types of tests performed is being prepared. In addition to being of value to groups directly concerned with fire hazard performance, it will also be of value to the housing construction industry as a whole since the compendium describes the performance of many innovative construction systems, and the data presented can be used to evaluate similar systems without conducting a comprehensive testing program.

Progress during FY 74 included: (1) the collection, assimitation of all relevant test reports; (2) the preparation of a preliminary summary outline submittal to the sponsor, HUD, for approval; and (3) the preparation of a draft manuscript containing typical sections of each chapter of the compendium.

Plans for FY 75 include: (1) preparation of a draft manuscript of typical sections including artwork in a form ready for printing to be submitted to the sponsor for approval; (2) preparation of a draft manuscript of the entire compendium; and (3) preparation of the entire document including art work in a form ready for printing by the sponsor. 


\section{SHELLEY BUILDING SMOKE TEST}

Early in the BREAKTHROUGH Program, the Shelley Company asked for a waiver of the criteria requiring the corridor dead-ends not exceed 20 feet and that a maximum of two exits be provided, spaced at least one-half corridor length apart. Shelley requested that they be permitted to place the required stairways at the ends of the building. This was granted provided certain conditions were met. The tests were to confirm the soundness of the alternate requirements.

Field measurements were made to determine the effectiveness of the smoke detection system and the smoke movement characteristics within the building under simulated fire conditions during the third quarter of FY 74. As a result of the findings with respect to the performance of the smoke proof tower, modifications to the tower were suggested to the sponsor to insure better performance. A draft report was prepared for section review.
Project Status

concluded

Project Leader James Pielert 301 921-3146

Sponsor

Department of Housing and Urban Development

Project Number $46 \overline{08470}$

Impact Keywords

Fire research, housing; safety

Technical Keywords Fire considerations; high rise buildings; safety; testing

\section{TRANSPORTATION AND HANDLING EQUIPMENT-- OPERATION BREAKTHROUGH}

The Office of Housind Technology (OHT) conducted a survey to gather information to be used in the preparation of a documentary of transportation techniques and handling processes used in Operation BREAKTHROUGH. The firm of Reidelbach-Simpson Inc. was contracted for preparation of draft text and layout of the material. OHT staff made significant contributions to the text through rathering of technical material and redrafting the orininal composition. Valuable input was made by the Department of Housina and Urban Development (HUD)government technical representative during revision of the draft material leading to the final manuscript, "Transportation and Handling systems Used in Operation BREAKTHROUGH" which was submitted to HUD, July, 1974.

\author{
Project Status \\ Concluded \\ Project Leader \\ Thomas K. Faison \\ $301 \quad 921-3126$
}

Sponsor

Department of Housing and Urban Development

Project Number 4608406

Impact Keywords Highways; railroad; tracking

Technical Keywords Loading-unloading; packing; railroads; regulations; storage; transportation. 


\section{FAILURE IDENTIFICATION AND ANALYSIS-- MOBILE HOMES}

Project Status

continuing

Project Leader James Pielert

$301921-3146$

Sponsor

Department of Housing and Urban Development

Project Number $4 6 \longdiv { 0 8 5 2 0 }$

Impact Keywords construction; consumer protection

Technical Keywords codes and standards; construction; low-cost housing; manufacturing; mobile homes; transportation.
Mobile homes represent one-fifth of all housing units produced in each of the past five years. In 1972 they constituted 43 percent of the sales of all new single family units and 96 percent of those selling for less than $\$ 15,000$. Recently, the effectiveness of mobile homes in providing safe, adequate, and low-cost shelter has been questioned by consumer groups, members of Congress and others. The American National Standards Institute (ANSI) A119.1 Standard for Mobile Homes has gained wide acceptance as a requlatory document with 43 states usinn it or variations thereof.

The objective of this project is to (a) identify significant mobile home performance problems; (b) relate identified problems and provisions of: (1) American National Standards Institute (ANSI) A119.1 Standard for Mobile Homes, (2) Inspection, Quality Assurance and Requlatory Programs, (3) Mortaage Insurance Requirements.

During FY 75 existing mobile home performance data from the Department of Housing and Urban Development (HUD) (Agnes disaster units) other government agencies and the private sector will be collected, orqanized and analyzed. Mobile homes will be physically inspected by an interdisciplinary team from NBS to determine causes of failures identified in Task $I$ and II. The results from the physical inspection and data collection will be summarized and related to the project objectives. Also, a study of state regulatory programs will be completed under this task.

During FY 74 maintenance files for 9,000 mobile homes used for Agnes disaster housing by HUD in Wilkes-Barre, Pa. were brought to NBS and analysis was begun. Mobile home performance data was obtained from the files of concerned state agencies and the Veterans Administration. The states from which data were obtained are Virginia, Texas, California, Washinaton, Georqia, and Alabama.

Two hundred thirty-five HUD mobile homes were inspected at Wilkes-Barre, $\mathrm{Pa}$. Also 20 privately owned mobile homes in southern Maryland were inspected. A study of state mobile home regulatory programs was begun. 
Some 35 Federal agencies are involved in the design and construction of buildings. In addition, and even more importantly, the Federal agencies have a very great impact on all construction in the U.S. through safety standards (such as issued by the Occupational Safety and Health Administration, the Consumer Product Safety Commission and Health Administration, the Consumer Product Safety Commission and others), through minimum standards issued for conditions of participation in Federal programs (such as Medicare/Medicaid, Hill-Burton Program, Minimum Property Standards, etc.) and through a number of other mechanisms. And although the construction industry is such a large portion of the total U.S. economy and although the various Federal agencies have a great impact on this construction; little money is expended for research in comparison to other fields of industry. Further, the great number of Federal agencies being involved and the even greater number of state and local agencies being involved, have a great impact on the construction industry through a multiplicity of rules and regulations. Many of these rules and requlations are established on sound research results, however, many are not. This project acts as a Federal coordination or focal point for the various Federal agencies involved in construction. It also provides these Federal agencies with a source for research assistance and technical information for the improvement and enhancement of their building programs.

The objective of this project is to serve as a focal point for providing research assistance and technical information and guidance to other Federal agencies engaged in building related activities.

The approach taken on this project is threefold: (1) direct assistance to Federal agencies on specific building technology questions and problems, (2) conduct Federal agency workshops on select building technology topics for representatives from all Federal agencies and (3) participate in organizations representing the interests and views of a number of Federal agencies.

CBT's Office of Federal Building Technology (OFBT) hosted a number of Federal agency workshops in FY 74 on buildina science and technology. OFBT also hosted several specialty conferences and training sessions for the various representatives of the Federal agencies. These meetings permitted an exchange of views, ideas and problems of common concern to the various Federal agencies, thus improving communication between members both within the Federal agencies and in the private sector. These meetings also permitted the dissemination of the latest research findings and results of building research projects undertaken by CBT and by other Federal agencies.

The OFBT staff also provided review of other Federal agency project manuscripts, papers, legislation, and other documents related to building activities. Consultation and technical information was provided to these Federal agencies through meetings, conferences, telephone queries and through other means. The OFBT staff also actively interacts on a continuous basis with the BRAB Federal Construction Council (FCC). The OFBT staff also interacts with National Science Foundation and other programs of interest to more than a single Federal agency. In addition, the OFBT staff developed detailed research plans to meet specific Federal agency objectives, provided technical monitoring of the execution of those plans, prepared progress review meetings and other activities related to ongoing research activity management. Finally, OFBT monitored legislative matters that had potential impact on CBT, INBS and other Federal agencies (such as the Solar Energy Heating and Cooling Demonstration Act of 1974). During FY 74 OFBT sponsored the following Federal Agency Workshops: September 4, Integrated Utility Systems; October 2, Medical Facility Program Roundtable; November 7, Human Factors in Buildings; December 4, Abnormal Loading on Buildings; January 8, Laboratory Evaluation and Accreditation Program; February 5, Security for Buildings; March 5, Materials, Adhesives and Sealants; April 2, Natural Hazards Evaluation of Existing Buildings; May 7, Mobile Homes;
Project Status Continuing

Project Leader

Samuel Kramer

$301921-3233$

\author{
Sponsor \\ National Bureau of \\ Standards \\ Project Number \\ $46 \overline{03191}$ \\ Impact Keywords \\ Buildina desian; \\ personal security; \\ utilization \\ Technical Keywords \\ Design, general; \\ improvement of buildings; \\ methods
}


June 4, Solar Energy. In addition, reports addressed to specific agency problems were developed. Assistance through telephone inquiries, technical assistance to field personnel, review of other agency reports and other assistance was provided.

It is expected that during FY 75 NBS/CBT will provide to other requesting aqencies identification of their problem areas, formulation of common interest groups with similar problems, development of methodology to provide appropriate research and generation of technical memorandum and reports as required. It is also expected that ten Federal Agency workshops will be conducted at NBS during FY 75 in addition to a number of speciality conferences and training sessions. In FY 75, analys is of legislative matters impacting on building technology is expected to increase along with increased coordination necessary for emerging research programs sponsored by Federal Energy Agency, Environmental Protection Agency, Occupational Safety and Health Administration, Consumer Product Safety Commission and other agencies.

\section{SIMULATED SOLAR RADIATION TESTS ON AIR SUPPORT SHELTERS}

\author{
Project Status \\ Concluded \\ Project Leader \\ Larry W. Masters \\ 301 921-3233
}

\section{Sponsor \\ U.S. Army Natick Laboratories}

Project Number $46 \overline{04416}$

Impact Keywords Defense; disaster mitiqation

Technical Keywords shelters; solar heat; testing.
Five assembled air support shelters were tested one at a time in the NBS environmental chamber using an array of infrared lights to simulate solar radiation. The surface temperature of each shelter was cycled from ambient to $200^{\circ} \mathrm{F}$ and abnormal behavior of the shelter was documented and measured. Surface temperatures and air pressures in the structures were recorded. Simulated solar radiation test results of five production line shelters were obtained to assist in evaluating causes of failures of shelters in service. The results of this study were presented in a final report published as NBS Interagency Report 74-467, "Simulated Solar Heat Tests on Medical Unit, Self-Contained Transportable (M.U.S.T.) Air-Inflatable. Double-Wall Hospital Ward Shelters," dated May 1974. "Simulated Solar Heat Tests on M.U.S.T. Air-Inflatable, Double-Wall Hospital Ward Shelters," NBS Interagency Report 74-467, was completed. 
The objectives of this program are to collect fire load and live load data and to apply probabilistic models for predicting loads in office and school occupancies. The office fire load and live load program will survey approximately 10,000 rooms chosen from about 100 buildings selected in a statistical manner. Based on surveyed room factors, interior finish, and the type, quantities and distribution of combustible contents and other live loads, a statistical model will be devised to predict the fire and live loads to be expected in buildings.

The design of safe economical structures requires consideration of loading and structural resistance. Although most building codes currently treat the design problem in a deterministic fashion, the trend in code development in the United States and abroad involves explicit consideration of the variability of these factors. Results obtained from this survey would lead to improved understanding of the factors affecting loads in buildings and design values based on the probabilistic nature of the loading for incorporation in national model codes and consensus standards. This will contribute to improved building safety and reduce life and property loss due to fires.

Survey techniques based on weight inventorying and data collection procedures wi11 be developed. Characteristics such as height, age, location, etc., of office buildings in the U.S. will be determined and used to select a statistical sample of buildings to be surveyed. Special data processing techniques and computer programs will be developed for data analysis purposes.

In FY 74 the survey techniques were developed. The 25 buildings for the first phase of the project were selected. A new procedure to computer input building geometry and spatial distribution of areas within a building was also developed. In addition the following were presented: C.A. Cornel1, "Office Live Loads Proqram Formulation," report to NBS, Apri1, 1974; Charles Culver, "Methodology for Conducting Fire Live Loads Survey," talk presented Apri1 3, 1974 to the Building Research Advisory Board Advisory Commi ttee.

In FY 75 it is anticipated that the 100 office buildings will be surveyed and complete analysis of the data will be carried out. In addition, the scope of the survey for educational facilities will be defined.
Project Status

Continuing

Project Leader Charles G. Culver $301 \quad 921-3233$

Sponsor

National Academy of Science, Building Research Advisory Board

Project Number $4 6 \longdiv { 0 5 5 0 6 }$

Impact Keywords Building design; fire research.

Technical Keywords Codes and standards; fire considerations; structural design. 


\section{Project Status \\ continuing}

Project Leader Charles G. Culver $301 \quad 921-3231$

\section{Sponsor}

National Bureau of Standards, National Science Foundation.

Project Number $4 6 \longdiv { 0 5 1 9 0 }$

Impact Keywords Building design.

Technical Keywords Design, other; safety.
Property losses from natural disasters in the United States have averaged approximately one billion dollars per year in recent years and are increasing in constant dollars at an annual rate of 1.7 per cent. Property losses are the most easily measured but perhaps the least important part of disaster losses. Losses from human suffering, disruption of productive activities and expenditures in disaster relief are difficult to quantify but magnify disaster losses many fold.

The Cooperative Federal Program in Building Practices for Disaster Mitigation initiated in the spring of 1972 seeks to integrate extensive activities and resources in Federal agencies and work with professional organizations, private practitioners, and state and local governments in support of improved building practices. The objectives of the program are: (1) to synthesize current knowledge and develop improved building practices for insuring the safety of new and existing buildings with substantial human occupancy and; (2) to make this knowledge available in usable form to assist Federal, State and local agencies and officials in effecting land-use planning and building regulation to mitigate the effects of natural disasters.

Federal concern with building practices for disaster mitigation arises from major statutory responsibilities. Approximately 37 per cent of all new construction is directly or indirectly Federally supported; good practices protect these investments and responsibilities. Outputs from the program including manuals of practice, code provisions, and design criteria and procedures will present improved building practices for implementation by Federal agencies, code groups, and the engineering design profession. Implementation of the results of the program will lead to a reduction in the increasing losses resulting from natural disasters.

The program will focus on practice which gives integrated consideration to natural disasters from earthquakes, hurricanes, tornadoes, other extreme winds and flooding.

Projects included in the program are: improved measures of the intensity of natural hazards; natural hazards evaluation of existing buildinas; development of comprehensive seismic desian provisions; development of post-disaster investiqation procedures; and leadership in post-disaster investiqations.

In FY 74 NBS/CBT (1) developed a methodology for natural hazards evaluation of existing buildings (2) worked with practicing structural engineers from California in developing preliminary seismic desian rules based on the latest state-of-the-art and applied these rules to the redesian of 11 existing buildings to examine improved safety and economic ramifications, (3) completed planning for a project with nation-wide involvement directed toward developing nationally applicable seismic design provisions, (4) participated in a joint effort with the National Science Foundation in developing improved procedures for conducting post-disaster investigations to maximize the learning from these events, (5) conducted a post-disaster investigation following the military Personnel Records Center Fire to evaluate the structural performance, (6) conducted a post-disaster investigation of the collapse of a portion of the Bond Court Hotel in Cleveland, Ohio, and (7) conducted post-disaster evaluation of consulting work with Department of Commerce and Organization of American States relative to the rebuilding of Manaqua, Nicaragua. Plans for FY 75 include developing a first draft of the seismic design provisions. Approximately 90 individuals including university researchers, professional practitioners, and local, state and national requlatory officials will be involved in the activity. The following output resulted from this project: "Definition of Scope, Organization Methodology and Research Plan for the Development of Comprehensive Seismic Design Provisions," May 1974; Charles Culver "Comprehensive Seismic Design Provisions for Buildings," talk presented at Sixth Joint Meeting on the U.S. Japan Panel on Wind and Seismic Effects, May 1974; Samuel Kramer, Charles Culver, NBS Activities on Earthquake Engineering, talk presented to meeting of Advisory Committee for U.S. 
Geological Survey, June 1974; Charles Culver, Hai Sang Lew, Gary Hart, Clarkson Pinkham, "Natural Hazards Evaluation of Existing Buildings," in review process; "An Evaluation of a Response Spectrum Approach to Seismic Design of Buildings, "May 1974, in publication process; Charles Culver, Robert Crist, "The Military Personnel Records Center Fire," Talk presented to the American Concrete Institute National Meeting, Ottawa, Canada, Oct. 1973.

\section{AIR MOBILITY SHELTER SYSTEMS}

The principal objective of this project was to evaluate the effects of in-service loads, aging and weathering of the sandwich panels used in Air Force shelters. A secondary objective was to suggest methods of improving the in-service performance of the shelters.

Air-mobile shelters are in general use by Department of Defense in large numbers and hundreds more are being purchased every year. Many of the she1ters have not given satisfactory service.

About 25 shelters were thoroughly inspected in the field at various Air Force Bases in order to observe and document conditions or physical defects which might have caused unsatisfactory performance. Two shelters were dismantled in the laboratory and thoroughly inspected for design or fabrication defects, for degradation of material properties, and for causative factors in the degradation. A number of different tests were performed on specimens cut from the sandwich panels in the shelters.

Reports were prepared indicating that degradation of the adhesive bond in the sandwich panels can be attributed to the effect of water within the panels.
Project Status Concluded

Project Leader Thomas Reichard 301 921-3233

Sponsor U.S. Air Force

Project Number $4 6 \longdiv { 0 5 4 7 0 }$

Impact Keywords Building design; defense.

Technical Keywords Military; shelters; testing. 


\section{HIGH WIND STUDY FOR DEVELOPING COUNTRIES}

\author{
Project Status \\ Continuing
}

Project Leader

Richard D. Marshall

Sponsor

Agency for International

Development

Project Number

4605502

Impact Keywords

Building design; effective regulation.

Technical Keywords Design; safety; wind loads.
The research will develop improved design criteria for low-cost/low-rise buildings to better resist extreme winds. This project originated from recognizing that a need exists for additional research to supplement the limited amount of existing data of wind effects of low-rise buildings. Existing criteria for wind loads do not make provisions for steady and fluctuating wind pressures along the edges of roofs and walls where separate flows occur. The wind flow along these regions are one of the primary contributors to building damages. Thus, such research possesses a potentia] for attaining high benefits in reducing building damages in the U.S. and in other high wind geographic areas.

The approach is to analyze wind loadings on a sample of seven low-rise buildings in three statistically independent sites in the Philippines. Wind-tunnel modeling of the seven test buildings will be performed with the appropriate correlation analysis. Climatological and housing information (including socio-economic and architectural data from developing countries) will be analyzed.

In FY 74 NBS/CBT (1) selected the second and third of 3 statistically independent field test sites for full-scale building (the first was selected in FY 73); (2) instrumented 5 of 7 test houses at the 3 sites ( 4 houses by NBS/CBT staff and 1 by Filipino technicians); (3) instrumented the University of Philippines (UP) wind tunnel facility; (4) awarded short-term contracts with two professionals, one from Bangladesh, the other from Jamaica thus providing a two-way transfer of information mechanisms between other high wind geographic areas; (5) conducted and participated in an International Workshop in Manila during November 1973 on assessing the state-of-the-art of low-rise buildings against extreme winds (developed 31 recommendations), (6) analyzed wind loading data from two Philippine storms in 0ctober 1973; and (7) continued close working relationship with the Philippine Advisory Committee, U.S. Agency for Internationa] Development (AID) Mission Manila and AID Washington.

It is expected the following activities will be performed in FY 75; (1) instrument the remaining 2 test houses (July 74); (2) validate wind tunnel modeling techniques (simulated natural winds) with representative measurements obtained from full-scale buildinas, (3) analyze wind loads on the seven full-scale field buildinas; (4) develop wind risks map, for the Philippines, (Jan. 75); (5) monitor the progress of NBS trained Filipino technicians from the University of Philippines and Weather Bureau, (6) develop draft design criteria report (Mar. 75); and (7) present the draft report to an international audience of professionals--engineers, architects, regulatory officials to be hosted by the Philippine Advisory Committee in Manila (May 75).

During the course of this project the following were completed: Noel $\mathrm{J}$. Raufaste and Richard D. Marsha11, "FY 73 Proqress Report on Design Criteria and Methodology for Construction of Low-Cost Housing to Resist Typhoons and Hurricanes," NBS Interaqency Report (NBSIR) 74-582, July 1973; Noel J. Raufaste and Richard D. Marsha11, "FY 74 Progress Report on Desian Criteria and Methodology for Construction of Low-Cost Housing to Resist Typhoons and Hurricanes," NBSIR 74-567, July, 1974; Noel J. Raufaste and Richard D. Marsha11, "FY 74 Interim Project Status Report Design Criteria and Methodology for Construction of Low-Cost Housing to Resist Typhoons and Hurricanes," February, 1974; Noel J. Raufaste and Richard D. Marsha]] (ed.), "Proceedings - Workshop in Design for Extreme Winds," Manila, Phillippines, November 14-17, 1973 Buildina Science Series 56; Oral presentations given at November, 1973 workshop - Noel J. Raufaste, "Backoround of Research Project," Manila Phillippines; Richard D. Marshal1, "Aerodynamics of Structures and Wind Tunnel Modeling"; Edward 0. Pfrang, "Lessons Learned from Past Wind Disaster Investigations"; Oral presentation at AID Contractors Coordination Meeting, January 1974, Denver, Colorado - Noel J. Raufaste, "NBS/AID Wind Research Activities." 
Al] branches of the military utilize liahtweight, air-liftable structures which serve as combination shipping containers and shelters. Most of the shelters now being used are fabricated from either paper honeycomb sandwich panels for plastic foam and beam panels. From the overall performance requirements the honeycomb sandwich panels are considered to be the most satisfactory for the shelters. Unfortunately, the durability of some of the honeycomb shelters has been unsatisfactory.

In an effort to improve the performance of honeycomb panel shelters, critical properties of honeycomb panel material will be identification and an effort made to help industry improve their products.

With the cooperation of the honeycomb industry, the shelter fabricators and the military users the performance requirements for the core materia] wil] be thoroughly reassessed. Quantities of core material made to the new requirements will be obtained and evaluated. It is expected that certain properties not now specified will be shown to be important and methods for testing these properties will be developed.

During FY 74 a Technical Working Group on Honeycomb Sandwich Pane] Core was established with NBS/CBT serving as Chairman and Secretary. This joint government/industry group held technical sessions on April 23 and 24, 1974 and June 18 and 19, 1974. In FY 74 miscellaneous testing of honeycomb material was also performed. Presentations was made to the Technical Working Group on Honeycomb Sandwich Panel Core, Apri1, 23-24, 1974, NBS Gaithersburg, Md.; and to the Forest Products Laboratory, Madison, Wisconsin, June 18 and $19,1974$.

In FY 75 additional testing will be performed. The Technical Working Group will continue to meet (next session schedule for August 27 and 28, 1974) and other milestones will be attained as follows: (a) statement of requirements for honeycomb cores; (b) development of new test methods; (c) procurement of trial-run honeycombs; and (d) evaluation of new type honeycombs.
Project Status

continuing

Project Leader

Samue] Kramer

$301 \quad 921-3233$

\section{Sponsor \\ U.S. Army Natick \\ Laboratories}

Project Number $46 \overline{05570}$

Impact Keywords Defense; materials utilization.

Technical Keywords Defects in materials genera ]; honeycomb. 


\section{MODEL STUDY OF A PARKING GARAGE COLLAPSE}

\author{
Project Status \\ continuing \\ Project Leader \\ Edgar V. Leyendecker \\ $301921-3475$
}

Sponsor

National Bureau of

Standards

Project Number

$4 6 \longdiv { 1 5 1 3 8 }$

Impact Keywords

Construction; effective regulation.

Technical Keywords Model studies; concrete structures; codes and standards.
Unbonded post-tensioned concrete is a relatively new type of construction that is being widely used because of economy. However, because of its newness, there is not a wide technical base for current design and construction standards. Thus, the recent catastrophic collapse in Fairfax County, Va. of a parking garage using this type of construction has raised a fundamental question within the enqineering design profession (by organizations such as the American Concrete Institute and the Prestressed Concrete Institute), namely "Did the garage collapse occur simply because the structure was overloaded or did the collapse occur because of some unknown weakness in design standards governing unbonded post-tensioned construction.

The answer to this question can have a significant impact on codes and Standards.

The project is being conducted to study the behavior and determine the mode of failure of the parking garage. These data will add to the technical base used for the design of unbonded post-tensioned concrete and for the evaluation of this type of construction by building regulatory systems.

An experimental investigation will be conducted using direct structural model testing. The direct structural model is essentially a true-to-scale analogue computer for the direct solution of an actual structural system. This type of model emphasizes agreement between prototype and model physical characteristics and boundary conditions. The model may be used to document elastic, inelastic, and ultimate load behavior.

During FY 74 planning of the model test program was developed. Most of the modelling material was located and obtained. In addition a talk was given by Edgar V. Leyendecker, "Engineering Aspects of the Skyline Plaza Collapse," to the National Capital Chapter of the American Concrete Institute, Rockville, Maryland, March 26, 1974.

\section{DATA ACQUISITION DEVELOPMENT}

Project Status

continuing

Project Leader

James Shaver

301 921-3475

Sponsor

National Bureau of

Standards

Project Number $4 6 \longdiv { 1 5 1 3 9 }$

Impact Keywords

Housing.

Technical Keywords Data generation.
The research engineers capacity for analytical analysis of experimental data can be increased by the development of an interactive remote terminal geared to his needs.

Researchers are confronted with a current and increasing need to utilize the computer in many situations during ongoing laboratory and field studies for experimental data acquisition and analysis.

The project will develop capability for research engineers to use a remote demand terminal and explore the feasibility of utilizing existing minicomputer as a satellite terminal to the NBS 1108 system. It will also acquire and/or develop operational software packages which increase the research engineers capacity for analytical analysis of experimental data.

During FY 75 plans are to develop operational software packages for aid in analytical and data analysis utilizing remote demand processing; engineer's user manual for demand processing; and a feasibility study of utilizing existing mini-computer as a satellite terminal to the IIBS 1088 system. 


\section{HUD LONG RANGE RESEARCH - STRUCTURAL TEST METHODS}

Emerging performance criteria, building codes, construction standards and various inspection and approval organizations often require that building components be tested for assurance of acceptability or to establish a rating of the component's performance. Furthermore, the use of new construction materials and new construction approaches makes performance testing a virtually mandatory step in the evaluation process. In order that structural test methodology can stay abreast of the needs of builders, evaluators and designers basic research is necessary. By focusing the research on the development of standard procedures for performing the evaluative tasks, the entire building profession can be the beneficiary.

The objective of this project is to provide HUD with a state-of-the-art summary of structural test methods for building components; to derive several improved structural test methods for building components and to provide guidelines useful in the interpretation of the test resuits obtained from these methods; and to drive some guidelines to be employed in the simulated environmental conditioning of test specimens prior to testing.

The actual research work is to be preceded by a state-of-the-art summary, which is to be generated after: (1) studying the literature relating to structural test methods, (2) establishing liaison with voluntary standards associations, (3) reviewing NBS test experience in Operation BREAKTHROUGH (4) reviewing test requirements stated in various standards and codes, (5) distributing a questionnaire to members of American Society for Testing and Materials (ASTM) Committee E-6. As a result of the information gathered in the survey, recommendations for research programs aimed at improving structural test methods can be derived. The approach toward test method development consists of employing laboratory techniques to investigate the most important parameters and complimenting this activity with available analytical techniques. To derive guidelines for simulated environmental conditioning of test samples, the steps are as follows: (1) review applicable ASTM, foreign and international standards; (2) review case studies of conditioning procedures; (3) establish 7 iaison with industry associations and (4) derive user-oriented tables describing recommended procedures.

During FY 74 the state-of-the-art survey was completed and the final draft of a manuscript summarizing the findings was prepared for publication.

Most of the laboratory investigation work planned to enable the development of an improved test method for in-plane compression testing of wall panel prototypes was completed. The laboratory work was supplemented by computeraided analytical work, the results of which will be included in the proposed standard test method. A first draft of the standard test method was submitted for task group review to ASTM Subcommittee E06.1.2 (concerned with the performance of vertical components).

An evaluation of the presently accepted standard for performing racking tests on wall prototypes was undertaken to establish which parameters were in the most critical need of investigation. Several parameters were identified as a result of the study.

Information germane to the subject of pre-test environmental conditioning was gathered, studied and summarized. Some preliminary organizations work was performed toward categorizing building components according to their use and to building materials that are used in forming these composites.

During FY 75 plans are to publish the state-of-the-art summary; complete a review draft of a report containing guidelines for environmental conditioning of test specimens; prepare a second draft of "Test Method for In-Plane Compression on Wall Panel Specimens"; complete laboratory investigation of racking test method; prepare a report on the results of a questionnaire sent to members of ASTM Committee E-6; and prepare a final report on test method development.
Project Status continuing

Project Leader James G. Gross $301 \quad 921-3475$

Sponsor

Department of Housing and Urban Development

Project Number $4 6 \longdiv { 0 8 4 0 3 }$

Impact Keywords

Construction; productivity enhancement.

Technical Keywords codes and standards. 


\section{HUD LONG RANGE RESEARCH--PROGRESSIVE COLLAPSE}

\author{
Project Status \\ continuing \\ Project Leader \\ Edgar V. Leyendecker \\ $301 \quad 921-3475$
}

\section{Sponsor}

Department of Housing and Urban Development

Project Number $4 6 \longdiv { 1 8 4 8 8 }$

Impact Keywords Construction; effective regulation.

Technical Keywords Design, structural; improvement of buildings; codes and standards.
A series of catastrophic collapses or narrowly averted failures of multistory buildings in the USA, Canada, France, Spain, and England have focused international attention on the need to study the risk to structures from loadings that hitherto have received little attention by designers. These loadings are referred to as abnormal loadings.

The objectives of this project are to develop design criteria to increase the resistance of buildings to progressive collapse and to determine the sources of abnormal loads on buildings.

The catastrophic or progressive collapse of a major portion of a building due to an abnormal loading (such as a gas explosion) could cause many deaths and injuries. Such a progressive collapse could seriously hinder the development of industrialized housing in this country. It is, therefore, essential that the risk of progressive collapse to these and other buildings be fully assessed and criteria for resistance be developed as soon as possible.

The project has been divided into four phases. Phase I is a study of the state-of-the-art. Phase II is a study of the magnitude-distribution-time relationship of abnormal loads on buildings in the U.S. Phase III is a study of building response to abnormal loading and the identification of any needed experimental work. Phase IV is the development, submittal for national comment, and final recommendation of design criteria to increase resistance against progressive collapse.

During the reporting period abnormal loadings on buildings and their frequency of occurrence were studied. Four documenting reports have been issued and a summary report is in preparation: Norman F. Somes, "Abnormal Loadings on Buildings and Progressive Collapse, "NBS Interagency Report (NBSIR) 73-221, May, 1973; Eric Burnett, Norman F. Somes and Edqar V. Leyendecker, "Residential Buildings and Gas-Related Explosions," NBSIR 73-208, June, 1973; Stuart Fribush, Deborah Bowser, and Robert Chapman, "Estimates of Vehicular Collisions with Multistory Residential Buildings," NBSIR 73-175, Apri1, 1973; Wayne Steele, Deborah Bowser, and Robert Chapman, "The incidence of Hazardous Material Accidents During Transportation and Storage," NBSIR 73-412, November, 1973. Studies of response of buildings to abnormal loadings are under way with draft reports completed on masonry and flat plate buildings. In addition several talks were given: Norman F. Somes, "Loading and Safety" talk given at the American Concrete Institute Symposium on Industrialized Construction, Ottawa, Canada, October, 1973;

Edgar V. Leyendecker, "Progressive Collapse in Buildings," talk aiven for NBS-In-Action Series, January 1974; Eric Burnett, Edqar V. Leyendecker, and Norman F. Somes, "bnormal Loadina and Buildina Safety," American Concrete Institute Symposium on Industrialized Construction, San Francisco, California, Apri] 1974; and Edgar Leyendecker, "Pronressive Collapse of Masonry Structures," National Structural Enaineering Meeting, American Society of Civi] Enaineers, Cincinnati, Ohio, Apri1 1974.

The objective of achieving a progressive collapse design criteria is expected to be completed by the middle of the fiscal year with the completion of Phase III above. Phase IV should also be completed by the end of the fiscal year. 
This project constitutes an extension in scope of the FY 72 NBS study on behalf of the Veterans Adminstration (VA) to develop procedures for evaluating strength and stiffness properties of masonry wall elements in existing VA hospital building facilities to determine their adequacy in earthquakes.

Topics investigated in FY 74 included (a) development of alternate flexure test methods using small specimens retrieved from existing construction, (b) deflection limitations of non-structural partitions and, (c) numerical calculations for analysis of typical masonry building under earthquake loading.

The approach used was essentially the same as in the original FY 72 study; synthesis of information on masonry pertinent to the subject of interest and available through NBS and other sources, and recommendation of procedures for the specified task in the scope.

The findings of the FY 74 study were merged with those initially investigated in FY 72 into a final report titled "Structural Properties of Masonry in Existing Buildings." Another report, "Evaluation of Structural Properties of Masonry Walls in Existing Buildings," is in review.

\author{
Project Status \\ concluded \\ Project Leader \\ George Fatta 1 \\ 301 921-3475
}

\author{
Sponsor \\ veteran's Administration \\ Project Number \\ $4 6 \longdiv { 5 4 0 8 }$ \\ Impact Keywords \\ Building design; \\ construction. \\ Technical Keywords \\ Codes and standards.
}

Project Status concluded incidental local loads induced by occupants.

The approach to this project is: (1) to establish parameters which idencify potential abuse conditions leading to local damage of dry-wall construction; (2) to determine whether the stipulated local loads are adequate; and (3) to determine load levels that can be resisted by currently-used building subsystems.

Based on visits to military installations and discussions with base personnel during FY 73 it was found that local damage to dry-wall construction in military housing is most often caused by body impact, kicking and striking with a fist. The task for FY 74 was to develop a test procedure for determining the characteristics of occupant induced impact loads on walls in the laboratory and use this procedure to measure the load characteristics produced by body impact, kicking and hitting with a fist. These data are to be presented in an NBS report to the sponsor.

\section{OCCUPANCY LOADS ON BUILDINGS}

\section{Project Leader James Shaver $301 \quad 921-3475$}

Sponsor

Tri-Services of the Department of Defense

Project Number $4 6 \longdiv { 5 4 0 4 }$

Impact Keywords construction.

Technical Keywords Codes and standards. 


\author{
Project Status \\ Continuing \\ Project Leader \\ Richard Marsha 17 \\ 301 921-3475
}

\section{Sponsor \\ National Bureau of \\ Standards}

Project Number $4 6 \longdiv { 1 5 1 3 2 }$

Impact Keywords Building design; construction; consumer protection.

Technical Keywords codes and standards; safety.
There is an urgent need for more refined models of the behavior of buildings and other structures subjected to wind forces. Recent trends in design philosophy, use of new materials and innovative construction details have lead to structures with an increased sensitivity to wind effects. As Secretariat of American National Standards Institute Committee A58.1, the NBS has a vital interest in the development of suitable criteria which will ensure the design of buildings which will perform satisfactorily under wind conditions likely to occur during the anticipated life of the structure. The objective of this project is to document the effects of wind on structures and to use this information as the basis for design criteria for inclusion in building codes and standards.

The project involves the use of experimental data currently available and the collection of additional data, either by the use of wind tunnel mode1ing or by direct measurement in full scale. Along with this, theoretical models will be developed and checked against experimental results.

Results achieved last year include completion of a report on ful1-scale and wind tunnel measurements of mean and fluctuating pressures on a lowrise building (Montana), completion of study on adequacy of current probabilistic approach to definition of design wind speeds, completion of study on expression of atmospheric turbulence spectra to be used in building design, completion of study on adequacy of methods for determining alongwind response incorporated in modern codes standards, completion of improved automated procedure for determining alongwind response, completion of draft report on variation of mean wind with height in hurricanes, exchanges of technical information with Scientific and Technical Building Center (CSTB) Nantes, and installation of an electro-optical deflection measuring system in the Government Printing Office Tower in London under the Joint Complementary Research Program with the British Research Establishment. In addition the following output resulted from this project: "Wind Spectra and Alongwind Structural Response," paper presented at the New York National Environmental Engineering Meeting, American Society of Civil Engineers, October, 1973; "Wind Loading and Modern Building Codes," and "Wind Research at the National Bureau of Standards" papers presented at Cincinnati National Structural Engineering Meeting, Apri1, 1974; "Probability Distributions of Extreme Wind Loads," paper submitted for possible publication in the Journal of the Structural Division, American Society of Civil Engineers; "A Study of Wind Pressures on a Single-Family Dwelling in Model and Full Scale," paper presented at the International Symposium on Full Scale Measurements of Wind Effects on Tall Buildings and Other Structures, London, Ontario, June, 1974. 
To develop the modern design criteria which are the ultimate objective of the project, research and development work is required which involves original contributions to the state of the art and independent, non-routine assessments of available information with the potential of being applied to the needs of the project.

The project requires constant standby readiness for hurricane landfall which the private sector or other agencies do not supply. It is also necessary that an unbiased group without special interests assimilate and evaluate data and existing design criteria. The high level of competence in the wind load area is also a firm foundation for CBT participation.

Progress last year included: (a) identification of ports interested in participating in the program; (b) port surveys and selection of anemometer sites; (c) selection of anemometers and masts to be installed by ports, selection and development of portable field equipment to be used by NBS; (d) liaison with National Weather Service and procedure for alerting NBS staff in the event of a hurricane watch; (e) elements of procedure for evaluating various code provisions on design for wind; and ( $f$ ) operating procedure for instrumentation team in case a hurricane watch is issued.

In addition the following output resulted: Emil Simiu and Richard D. Marsha11, "Wind Loading and Modern Building Codes," presented at American Society of Civil Engineers Structural Meeting, Cincinnati, Ohio, Apri1, 1974; Emil Simiu, "Variation of Mean Winds with Height in Hurricanes," Journal of the Engineering Mechanics Division, American Society of Civit Engineers, Vol. 100, August, 1974; V.C. Patel and J.F. Nash, Technical Report prepared under contract 4-35831, June 30, 1974; Interim Project Status Report, March 1, 1974.

During FY 75 plans are to: (a) collect and analyze field data in the event of a landfall and of the successful completion of mission by NBS instrumentation team and (b) further develop procedures for evaluating code provisions on design for wind. Results obtained that are of general interest to the engineering community will be presented in technical papers. The completion of two such papers is anticipated.
Project Status Continuing

Project Leader Emi] Simiu

301 921-3475

Sponsor

Maritime Administration

Project Number $4 6 \longdiv { 1 5 4 0 9 }$

Impact Keywords Buitding design.

Technica 1 Keywords Tropical cyclones and hurricanes. 


\section{DESIGN CRITERIA FOR MASONRY}

Project Status

Continuina

Project Leader

FeTix Yokel

301 921-3475

Sponsor

National Bureau of

Standards; Nationa 1

Concrete Masonry

Institute; Brick

Institute of America;

Masonry Institute of America; Tri-Service Building Materials Investiqational Proaram of the Department of Defense.

Project Number $4 6 \longdiv { 1 5 1 3 0 }$

Impact Keywords Building design; consumer protection; disaster mitigation.

Technical Keywords Earthquake; improvement of buildinas; concrete structures, reinforced.
A Cooperative Program of Research between Industry and the Federal Government has been established by NBS to develop improved procedures for the design of masonry structures in seismic regions. This project responds to the need for more information on the response of masonry structures to earthquake loads, in order to develop design criteria similar to those presently used for steel and concrete construction.

The work comprises several tasks for which NBS provides management, technical quidance and coordination of the research of the laboratories of NBS, the Brick Institute of America (BIA), the National Concrete Masonry Association (NCMA), and of technical input from NBS, BIA, NCMA and Masonry Institute of America (MIS).

The project has three phases: (1) a state-of-the-art study to compare existing standards, codes, and informal design practice with the state of the art, compile test information, identify gaps in knowledge and information that must be filled by additional research, and develop interim design recommendations; (2) a test program, designed to develop information on such parameters as strenqth, stiffness, ductility and damping and evaluate the performance of various design details; and (3) the synthesis of results and development of design criteria that can be proposed for adoption in codes and standards.

A draft state of the art report on masonry shear walls was completed. A report on "Strength of Masonry WalTs Under Rocking Loads," which includes input from a doctoral student at Brigham Young University who is in the process of summarizing analytical phases. An analytical study was constructed comparing the calculated dynamic response of masonry building to earthquake load with requirements of the Uniform Building Code.

In FY 75 the report entitled "A Failure Hypothesis for Masonry Shearwalls," will be completed and submitted to the Structural Journal of the American Society of Civil Engineers for publication.

The report "Strength of Masonry Walls Under Flexure and Compression," will be published as a Building Science Series (BSS) report. A draft state of the art report on the analysis of coupled shearwalls will be prepared; the planned test program will be conducted; interim design recommendations will be considered. The summary of products is as follows: (1) a BSS report on "Strength of Masonry Walls Under Flexure and Compression," (2) a report on the "Strength of Masonry Walls Under Racking Load," (3) a report on "A FaiTure Hypothesis for Masonry Shearwal7s;" (4) an expanded draft of the state of the art report; (5) execution of a limited test program; and (6) interim design recommendation. 


\section{INELASTIC RESPONSE OF BUILDINGS AND STRUCTURAL RESTORATION}

A 3-phase project for as many years was envisaged as follows: (1) search and synthesis of existing knowledge on hysteretic behavior of structural elements and on methods of repair; (2) planning and execution of testing-repairtesting program sequence, and; (3) documentation of inelastic response criteria and structural repair procedures.

The project in its original concept was discontinued at the end of January, 1974, primarily as a result of consideration of the following factors: (1) need of additional subsidy and manpower allocation to meet obligations in other ongoing activities, (2) problems involved in reconciling objectives of the two studies relating to hysteretic behavior and repair, and (3) anticipated curtailment of project activities for the balance of current FY due to extended sick leave of key project personnel.

At the time of project termination (January, 1974), 30 percent of the project funds had been expended as fol lows: (1) 20 percent of the effort had been expended (George Fattal) on existing literature search and preparation of test plan, (2) 10 percent of the effort had been expended (E.V. Leyendecker and Chod) on reduction of test data on precast concrete beam-column connections loaded in the inelastic range. The remaining 70 percent of the effort was diverted as follows: an allocation was made to the masonry program to meet oblications relating to items described under 12(a) and 12(b); an allocation was made to previous oblications on concluding 10-year research (Reichard) on creep and drying shrinkage of lightweight and normal weight concrete.

The following reports were completed during FY 74: George Fattal, Richard Jolley, and Felix Yokel, "Cooperative Masonry Project Status Report," submitted to participating Brick Institute of America, Masonry Association organizations on June 1974 and composed of the following reports: (a) Research Needs in Masonry; (b) Strength of Masonry Walls, a-state-of-theart report; (c) Response of Masonry Buildings to Earthquake Loads; (d) Draft of NBS Racking Test Report; George Fattal and Louis Cattaneo, "Strength of Masonry Walls Under Compression and Flexure," in review. 


\author{
Project Status \\ Concluded \\ Project Leader \\ Gerald A. Sleater \\ 301 921-3371
}

\section{Sponsor}

National Bureau of

Standards

Project Number $4 6 \longdiv { 1 6 1 6 6 }$

Impact Keywords Construction, materials.

Technical Keywords Inorganic chemistry.
Two important aspects of a material's microstructure are its porosity and its heterogeneity. The contribution of both to a material's performance is realized, but how, and through what mechanisms this occurs is not completely understood. Improved understanding of the relationships between microstructure and performance should lead to improved criteria for the selection of building materials.

The objective of this project is to develop quantitative information about relationships between microstructure and the performance and durability of inorganic building materials. These materials include natural stone, concrete, and clay products.

The first types of materials to be investigated will be from available specimens of weathered concrete and natural stone. The porosity of these materials will be characterized through procedures such as lightand scanning electron-microscopy, mercury porosimetry, and X-ray diffraction analysis. When possible, cooperative work will be carried out with other groups at NBS having similar interests. Aging of specimens will be done by accelerated. laboratory procedures and by natural weathering.

Nine types of natural stone were obtained, and their pore volume and pore size distributions were obtained through mercury porosimetry. Scanning electron photomicrographs were made of the stones, and their deterioration by air pollutants was simulated in the laboratory. The project has been terminated since the objectives can be met through more specific projects, e.g. Building Stone Preservatives and Inorganic Materials.

\section{SELECTION AND MAINTENANCE OF FLOOR COVERINGS}

\section{Project Status Concluded}

Project Leader Robert G. Mathey $301921-3407$

\author{
Sponsor \\ Naval Civil \\ Engineering \\ Laboratory \\ Project Number \\ $4 6 \longdiv { 6 4 4 1 }$
}

Impact Keywords Construction; materials.

Technical Keywords Floors.
The Naval Civil Engineering Laboratory (NCEL) has requested that the Center for Building Technology determine the state-of-the-art of information for the selection and maintenance of floor coverings and to prepare a comprehensive plan to provide information which is not available.

During FY 74 pertinent information presently available was updated, organized, and submitted in the form of a state-of-the-art report, "State-of-the-Art for Selection and Maintenance of Floor Coverings," along with project proposals for further research. Such information included first cost installed, maintenance cost at various appearance levels, and expected service life of various types of floor coverings for various locations and degrees of service. The state-of-the-art of test methods relating to appearance, function, and cost of floor coverings was also included in the report. 


\section{SIMULATED AND ACTUAL EXPOSURE OF BUILDING MATERIALS}

The deterioration of building materials through natural weathering is a serious loss to the national economy. One approach to determining the durability of materials to weathering is to expose samples of the materials in various climates and natural environments known to cause degradation. As the duration of such natural exposure tests is often prohibitively long, a second approach to durability testing is to simulate the more deleterious aspects of weathering in the laboratory, at an accelerated rate. A meaningful building materials test program must include both approaches to the understanding and evaluation of materials durability.

The objective of the project is to provide information about the relationships between the effects of natural weathering and accelerated laboratory weathering on building materials and to make available and maintain the facilities for making weathering tests.

Seven natural weathering exposure stations have been set-up and are maintained by the section. Located at sites from Alaska to Puerto Rico, they encompass a variety of climates and environments deleterious to building materials. Specimens of innovative and traditional building materials from other projects are exposed at these stations. Specimens of the same materials are subjected to accelerated aging in the laboratory. Comparison between the results of natural and accelerated weathering lead to improved understanding of the usefulness and limitations of accelerated weathering tests.

During FY 74 a continuous effort was needed to maintain the exposure stations, to develop optimum specimen transfer to and from the exposure stations, and to set-up on-site monitoring systems--especially for ultraviolet radiation and time of wetness. Accelerated aging apparatus in the laboratory was maintained and updated. Increased knowledge of materials testing was obtained through exchange of information with similar test facilities. Such data was disseminated through NBS reports.

During FY 75 the following accomplishments are expected (1) completion of state-of-the-art report on natural weathering, (2) continued extension of weathering monitoring equipment to additional exposure stations and (3) continued updating of exposure stations and methods of shipping specimens. 


\section{BUILDING STONE PRESERVATIVES}

\section{Project Status \\ Continuing}

Project Leader Gerald A. Sleater $301 \quad 921-3371$

Sponsor National Park Service of the Department of the Interior

Project Number $4 6 \longdiv { 1 6 4 3 7 }$

Impact Keywords Construction; materials.

Technical Keywords coatings, general.
Deterioration of historic buildings and monuments has become a serious worldwide problem. Faced with incidents of stone decay in this country, the National Park Service asked the NBS to develop performance criteria for the evaluation of commercial materials (stone preservatives) intended to protect stone against decay. Such criteria will be important to the National Park Service (NPS) in selecting materials for the preservation of national monuments.

Through knowledge of past efforts in stone preservation, the causes of stone decay are learned, thereby enabling choice of proper test parameters for testing the efficacy of preservatives. Various types of stone, treated and untreated with preservatives, are tested in an accelerated laboratory test program incorporating these parameters. The change, or lack of change, in the test specimens is evaluated and the data is used in the establishment of performance criteria (specifications) for stone preservatives.

Background research in the field was used to draw-up a report on stone preservation, as well as to design a test program. Laboratory testing is concentrated on a special test chamber in which cyclic testing of a number of test stone specimens can be carried out; this chamber was constructed and installed in FY 74. Eight and a half tons of stone have been purchased for use in the tests and over 30 different stone preservatives have been obtained from commercial suppliers.

Plans are to (1) complete the laboratory test program, and based upon these results, issue a report to the sponsor listing criteria for the evaluation of stone preservatives and, (2) issue a Building Science Series publication of the test program carried out at NBS and the performance criteria arrived at thereby. Several talks will also be qiven: "Large Scale Testing of Stone Preservatives," 1974 ann 1 meeting of the Geological Society of America, Miami, November 18-20, 1974; talk, "Testing Stone Preservatives," the International Symposium on the reservation of Stone, Bologna, Italy, June 19-21, 1974; talk, "Testing of Stone and Measurement of Stone Deterioration," International Union of Testing and Research Laboratories for Materials and Structures, Committee 25, Berlin, Germany, October, 1974. 
The largest class of materials used for roofing in the U.S. is the class of roofing bitumens including both asphalts and coal tar pitches. The asphalt industry is under pressures from the oil shortage and increasing labor and shipping costs which have resulted in changes in the product. Only very limited quality control and consumer specifications have been used in the past and the industry has not advanced its methods of characterization and specification sufficiently rapidly to keep up with the changes in the products. Consequently, roofing problems which have arisen may be due to inadequate purchase specifications. All parties involved in building (manufacturer, builder and buyer) will benefit from accurate, reliable test methods, adequate criteria, and meaningful specifications. Benefits in direct costs and in energy conservation should result from improved specifications and test methods through better controlled processing, good workmanship made easier by use of a uniform product, and longer, more predictable product 7 ife.

The objective of the project is to develop means and methods for characterizing roofing bitumens by rheological measurements.

Simple, rapid methods for measuring the viscosity, viscosity-temperature relationship and viscosity-shear rate dependency of bitumens wi]l be developed. Studies will be made on a wide range of samples of roofing bitumens with the new methods to give a picture of the range of values to be expected. Correlation will be sought between these values and performance to provide a basis for the establishment of reasonable criteria. The criteria, test procedures, and product property specification wi]l be submitted for acceptance by the roofing industry.

During FY 74 data was collected from participating members in the round robin test of the NBS roofing bitumen viscosity method. A means for estimating the absolute viscosity from a series of flow tests is being developed. The temperature coefficient of the flow is also being investigated. An informal report to the American Roofing Manufacturer's Association on results to date of round robin test was presented.

Plans for FY 75 are (1) to investiqate the feasibility of evaluating viscosity, deviation from Newtonian flow, and the flow-temperature coefficient values for a roofing bitumen with three, single measurements; and (2) to check the accuracy of the NBS roofing bitumen viscosity method against other, well-established methods.
Project Status

Continuing

Max Tryoject Leader
$301921-3441$

Sponsor

Nationa] Bureau of

Standards

Project Number $4 6 \longdiv { 1 6 7 6 0 }$

Impact Keywords Conservation; quality control.

Technica] Keywords Rheological properties. 


\section{TEST METHODS--JOINTS IN PLASTIC PIPE}

New

Project Status

Project Leader

Max Tryon

$301927-3441$

Sponsor

Tri-Services of the Department

of Defense

Project Number $4 6 \longdiv { 1 5 4 4 5 }$

Impact Keywords

Construction;

materials; safety

Technical Keywords

Pipina systems.
Various plastic pipe systems are presently in use, or proposed for use, in transmitting natural gas, sewage, and steam condensate in power plants at several military installations. Present testing procedures for joint quality is limited to various types of pressure tests upon relatively large sections of installed systems. Numerous failures of systems after passing the existing tests have occurred resulting in high costs and hazards. Many of these failures have been caused by faulty joint construction.

The objective of this project is to provide guidelines and methods for the nondestructive evaluation of plastic pipe joints used in gas, sewer, or steam condensate lines at military installations.

A rapid nondestructive field test for pipe joint quality, especially in cemented joints, would greatly reduce the time of testing and improve the reliability of the piping system. The nondestructive testing approach will include investigation of sonic tests, thermal conduction tests, and thermographic scanning.

Plans are to (1) survey the piping systems and materials used by the military; (2) examine nondestructive test procedures such as sonic tests, thermal conduction tests; etc., for feasibility of joint evaluation; (3) correlate test results with actual burst or leak tests on various joint systems; and (4) report on results with preliminary recommendation for testing joints.

Further work will be needed in the future to test the recommended procedures in the field.

\section{VISCOSITY GRADING CRITERIA FOR ROOFING ASPHALT}

\author{
Project Status \\ Project Leader \\ Max Tryon \\ $301 \quad 927-3441$
}

Sponsor

Tri-Services of

the Department

of Defense

Project Number $4 6 \longdiv { 1 5 4 4 4 }$

Impact Keywords Construction; materials.

Technical Keywords Roofs.
The objective of this project is to develop a viscosity grading specification for roofing asphalt as an aid to (a) better quality control and (b) improved application procedures.

The present specifications for roofing asphalt are inadequate to assure that satisfactory roofing asphalts will be supplied for built-up roofing. Recent shortages in asphalt supply and resulting changes in asphalt quality have emphasized the need for tighter specifications. Since the military is presently spending about $\$ 30$ million dollars per year on new roof construction, adequate specifications are essential to them.

The road industry is already using viscosity grading for specification purposes. While the system is not directly applicable to roofing needs, it should be adaptable. Quantitative evaluation of the viscosity properties of roofing asphalts in present use, as well as the correlation of these properties with the viscosity at the time of application, will be carried out to establish the viscosity grading criteria.

The program will be carried out through the following series of tasks: (1) a survey of asphalt sources and collection of asphalt types used by the military will be made; (2) test panels will be constructed to military specification for field exposures on asphalts received; (3) viscosity-temperature studies will be performed on each of the asphalts received; and (4) a report giving preliminary recommended criteria and specification data for roofing asphalt for military roofs will be prepared. 


\section{POLYMER IMPREGNATED MORTARS AND CONCRETES}

Polymer impregnated mortars and concretes are a new class of building materials which have great potential as cost effective building materials. They are also, possible substitutes for potentially more expensive and scarce materials such as steel and wood. However, performance criteria must be established before these materials are widely utilized in building construction. This project will contribute to the knowledge required to establish performance criteria.

The objective of this project was to identify the important microstructural properties which affect the mechanical properties and durability of polymer impreanated mortars and concretes and to develop models to interpret the relationships observed.

The effects of the microstructure of mortars on the performance of the polymer impregnated mortars have been emphasized in the research approach. Specimens with a wide range of microstructural features were prepared by: (1) varying the water to cement ratio; (2) varying the curing conditions and times prior to impregnation; and (3) using different cements. The microstructural properties of unimprennated and impregnated materials have been determined by such techniques as: porosity and polymer-loading measurements; and scanning electron microscopy. Strength and fracture mechanics studies have been performed using small specimens.

Polymer impregnated materials were found to have compressive and flexural strengths, and moduli of elasticity, which were 3 to 4 times greater than the corresponding unimpregnated materials. The fracture toughness of impregnated mortars were also about 4-fold greater than unimpregnated mortars. The porosities of hardened cement pastes and mortars were substantially decreased through the impregnation process.

The following were also completed: James clifton and James Fearn, "Porosity and Pore Size Distribution of Unimpregnated and Impregnated Hardened Cement Pastes and Mortars," to be submitted to Cement and Concrete Research; Anthony Evans, James Clifton and Eric Anderson, "Fracture Properties of Unimpreanated and Polymer Impregnated Mortars," to be submitted for publication; a talk by James Clifton, "Polymer Impregnated Mortars and Concretes," talk given at the Institute for Applied Technology Pilot Project Review, June 12, 1974.

\section{Project Status \\ Concluded}

Project Leader James R. Clifton $301 \quad 921-3407$

Sponsor National Bureau of Standards

Project Number $4 6 \longdiv { 6 1 6 8 }$

Impact Keywords Construction: materials

Technical Keywords Polymer concrete. 
Project Status

Continuing

Project Leader

Robert G. Mathey

301 921-3407

Sponsor

$\mathrm{National}$ Bureau of

Standards

Project Number

$4 6 \longdiv { 1 6 1 6 4 }$

Impact Keywords

Construction;

materials.

Technical Keywords Roofs.
For over 70 years bituminous built-up roofing has been specified by prescriptive type of specifications. Little attention has been given to the mechanical and physical properties of the membrane. Criteria are needed that quantitatively state how the membrane should perform. Producers of roofing products also need criteria so that they can have quidance on what properties are needed for the products they manufacture. Shortages of materials have also shown the need for performance criteria since substitution of materials is often necessary.

The objectives of this project are to develop performance criteria for bituminous built-up roofing. This includes the development of test methods to measure the performance characteristics which effect the behavior of bituminous membrane roofing.

Twenty performance characteristics of built-up roofing membranes were identified; they include tensile strength, coefficient of thermal expansion, flexural strength, tensile fatique strength, flexural fatique strength, moisture expansion, effects of moisture on strength, shear strength (horizontal and vertical), impact resistance, notch tensile strength, creep, wind uplift resistance, weather test, fire resistance, ply adhesion, permeability, abrasion resistance, fungus resistance, tearing, and pliability. Test methods are being developed and conducted to measure the performance characteristics that were identified. The level of performance of built-up roofing for the various performance characteristics is also being determined. Development of some standards and test methods is being accomplished through participation in American Society for Testing and Materials Committees D8 and E6.

Test methods and performance criteria were developed for the following attributes: tensile strencth, thermal expansion, thermal movement, flexural strength, tensile fatigue strength, flexural fatique strength, punching shear strength, impact resistance, wind resistance and fire resistance. These criteria are described in the publications listed in Part II.

Also during FY 74 . comprehensive research plans were prepared to develop performance criteria for some of the attributes which were identified, especially for the effects of moisture on built-up roof systems. In addition, the following publications were the result of this project: "Proposed Method of Test for Coefficient of Linear Thermal Expansion of Roofing and Waterproofing Membranes," America Society for Testing and Materials Book of Standards, Part 15, 1974; "Preliminary Performance Criteria for Bituminous Membrane Roofing, "Proceedings of International Symposium of Roofs and Roofing, 1974, in process for Building Science Series; "Fatigue Tests of Bituminous Membrane Roofing Specimens," in process as a NBS Technical Note; "A Research Program of Effects of Moisture on Roof Systems," presented to sponsor, Naval Civil Encineerina Laboratory (NCEL); a letter report "Moisture Effects in Built-up Roofing Assemblies," sent to NCEL; and six letter reports on roof inspections were made to sponsor. 
Metals and alloys are important constituents of almost al1 structures (e.g. pipe, electrical wiring, reinforcing bars, steel beams, roofing, siding, etc.) However, the corrosion of metals and alloys is a major problem and the estimated annual loss attributed to corrosion amounts to several billions of dollars (considering all uses), causing the waste of energy and valuable materials. Therefore, protecting metals and alloys from corrosion and selecting the most cost effective materials is of national importance.

The objective of this project is to develop methods ${ }^{\circ}$ to predict and to improve the long-term durabilities of metals and alloys used in buildings.

The research approach is to assess (1) the protective orooerties of organic and metallic coatings on metallic substrates by use technical methods to measure rates of corrosion, nature of the interface between the substrate and coating, and cohesion and adhesion of the coating; and (2) evaluate existing methods and develop new methods to determine the corrosion state of coated and uncoated metals and to measure the rate of corrosion.

During FY 74 (1) different electrochemical methods (electrical resistance, electrical potential and linear polarization) to determine the corrosion state of metal surfaces and the protective qualities of coatings on metal substrates, were evaluated; (2) a study of the protective properties of zinc on steel rebars (galvanized rebars) embedded in concrete prisms, exposed to different concentrations of $\mathrm{Cl}^{-}$, was started (by Mr. Seng Hin Low, a guest worker from Singapore, under the sponsorship of the United Nations); and (3) test specimens of metal siding and roofing panels protected with commonly used and also newly-developed metallic coatings, for use in weather-exposure studies, were obtained from manufacturers.

During FY 75 (1) the study of the protective properties of zinc on steel rebars will be completed; (2) specimens of metal siding and roofing panels protected with metallic coatings will be placed at weatherexposure sites, and (3) problems associated with the durability of metals in buildings will be identified and appropriate solutions investigated.
Project Status

continuing

Project Leader James R. Clifton 301 921-3407

Sponsor

National Bureau of

Standards

Project Number $4 6 \longdiv { 6 1 6 7 }$

Impact Keywords Construction, materials

Technical Keywords corrosion prevention 


\section{NON-METALLIC COATING FOR CONCRETE REINFORCING STEEL}

\author{
Project Status \\ Concluded
}

Project Leader James R. Clifton

301 921-3407

\section{Sponsor}

Federal Highway

Administration

Project Number $4 6 \longdiv { 1 6 4 3 3 }$

Impact Keywords Construction; materials

Technical Keywords Electrostatic coatings
The premature deterioration of concrete bridge decks, in 5-10 years, has become a major problem during the past decade. The annual cost of such repairs was estimated to be more than $\$ 70$ million in 1972 . Much of this deterioration is attributed to corrosion of steel reinforcing bars caused by chloride ions from deicing salts. This project was performed under the auspices of the Federal Highway Administration (FHWA).

The objective of this project was to determine if oraanic coatings can protect steel reinforcing bars, embedded in concrete bridge decks, from rapid corrosion caused by deicing salts (sodium chloride and calcium chloride).

Organic coatings were selected on a generic basis with epoxy coatings being emphasized. The coatings were subjected to physiochemical screening tests to select the most promising materials. These tests assessed the following: chemical resistances; chloride permeabilities; flexibilities; film integrities; protective qualities; and resistance to physical damage. The most promising materials were included in structural tests to determine if coated rebars can be used in existing bridge designs without affecting the structural integrity of the bridge.

This project was terminated in FY 74 upon completion of the work specified in the contract with the FHWA. Four powder epoxies have been identified as promising coating materials for steel reinforcing bars. Specifications covering coatings to be used on rebars for experimental bridges were issued by FHWA in collaboration with NBS. On the basis of this study, experimental bridges are being constructed using epoxy-coated reinforcing bars. This project resulted in the following outputs: R.G. Mathey and James R. Clifton, "Bond of Coated Reinforcing Bars in Concrete", submitted to the Journal of the American Concrete Institute; James Clifton, Hugh Beeghly, and Robert Mathey, "Nonmetallic Coatings for Concrete Reinforcing Bars," in process as a Building Science Series; talks by James Clifton, "The Creep Characteristics of Epoxy Coated Reinforcing Bars", American Concrete Institute Fal1 Convention, Ottawa, Ontario, Canada, October 12, 1973; James Clifton, "Nonmeta11ic Coatings for Concrete Reinforcing Steel," NBS in Action Series, January 24, 1974, at NBS, Ga ithersburg. 
The work is, in part, sponsored by Tri-Service who have a continuing need to know the performance of new and improved coating systems; the preparation of specifications for these materials, and consultative and advisory services related to coating problems. The development of test methods to evaluate the performance of coatings may be directiy related to improved coating performance and reduced maintenance.

The objective of the project is to provide (a) continuing support for Tri-Service investigations for the development of performance standards for surface protection (b) improved coating performance and reduced maintenance and (c) continuing development of test methods applicable to the evaluation of coating performance.

Laboratory tests and field inspections to assess the performance of new organic coatings. In order to measure the "degradative chemical and physical changes occurrina durina accelerated/natural aqina of coatings, gas and liquid chromarography, infrared and atomic absorbance spectrophotometric methods are used. Test methods are developed to determine performance characteristics applicable to America Society for Testing and Materials (ASTM) standard test methods, Federal Test Methods Standard 141, test methods and coatings specifications. During FY 74 the following were completed: "Analyzing Liquid Latex Paint," Paint Varnish Publication, September and October, 1973; Revision to Manua1, "Paints and Protective Coatinas," submitted to the Air Force for publication; and revisions to Federal Specifications TT-P-001510, TT-F1098, TT-P-29 which were submitted to GSA.

Consultative services have been provided as requested. The Tri-Service manua] "Paints and Protective Coatings" was revised. Specifications have been submitted to General Services Administration. Laboratory and field testing were established to examine the performance of latex primers for wood and mercury-free fungicides. In cooperation with ASTM D-1, CBT participated in test methods for mold resistance, aloss and reflectance measurements porosity, stain removal, analysis of heavy metals in low concentration, etc. Methods of resin analys is have been applied to coatinas specifications. Literature on the effects of air pollution on coatings has been reviewed and laboratory studies initiated.

During FY 75 the following are expected to be completed: specifications for lead-free latex primer for wood; specification for latex coating system for metal; specification for lead-free corrosion inhibitive primer; final report (2 year study) on performance of coatings containing nonmercurial funcicides; and a report on effects of atmospheric pollutants on the performance of coatings.
Project Status

continuing

Project Leader

Paul G. Campbe11

301 921-344T

Sponsor

National Bureau of

Standards, Tri-

Services of the

Department of

Defense

Project Number $4 6 \longdiv { 1 6 1 6 5 }$

Impact Keywords construction; materials.

Technical Keywords organic, general. 


\author{
Project Status \\ Continuing \\ Project Leader \\ James R. Clifton \\ 301 921-3407
}

\section{Sponsor}

National Bureau of

Standards

Project Number $4 6 \longdiv { 1 6 1 6 1 }$

Impact keywords Materials utilization.

Technical Keywords construction materials.
The performance of inorganic building materials (concrete, polymer impregnated mortar and concrete, gypsum, lime, brick, stone, etc.) can be improved by knowledge of the relationships between compositions and microstructural features, and performance. This knowledge will provide a basis for the establishment of performance criteria, which will benefit the building industry and consumer. Furthermore, these performance criteria should lead (1) to effective material substitutions (ex. polymer impregnated concretes to replace steel and wood); and (2) to the utilization of only the necessary amount of material in structures, thereby resulting in material conservation and reduced energy consumption.

The objective of this project is to determine the influence of chemical and phase compositions, and important microstructural features of inorganic building materials upon their mechanical properties and durabilities.

The effects of variations in composition and microstructure on the performance of inorganic building materials is being ascertained in various parts of this project. Technical methods are being used to determine the porosity, phase composition, mechanical properties and durabilities of materials. Typical methods used include: optical and scanning electron microscopy; porosity determinations; tensile and compressive strength measurements; fracture mechanics techniques; thermal analysis; and x-ray diffraction. The durabilities of materials to freeze-thaw cycles, water, a wide range of temperatures, etc. are also being investigated in this project.

During FY 74 (1) a 14-year weather exposure study on the dimensional stability of masonry walls was completed; (2) results of the study on the durability of a series of over 450 concrete specimens fabricated from 199 different cements have been evaluated; (3) the bond strength between epoxy-coated bars and concrete have been measured by pullout tests, and submitted for publication in the Journal of the American Concrete Institute; and (4) a 10-year study performed at NBS on the performance of concrete at high temperatures has been assimilated to publish in the open literature, as requested by many material scientists. The following were also presented: James R. Clifton, Bruce Foster and Ray Clevenger, "Dimensional Stability of Masonry Walls," American Society for Testing and Materials (ASTM) Special Technical Publication, in process; and a talk presented by James R. Clifton, "Dimensional Stability of Masonry Walls," 1974 Annual Meeting of ASTM, June 25, 1974, Washington, D.C.

During FY 75 plans are to (1) study the effects of cure time and cement to sand ratio on the mechanical properties of polymer impregnated mortars; (2) study the stress-strain relationships for polymer impregnated fiberreinforced mortars; (3) continue a study on the creep characteristics of coated and uncoated bars in concrete; (4) draft the report on the weatherexposure durabilities of concrete and (5) draft the report on the performance of concrete exposed to high temperatures. 
The objective of this project is to develop a general methodology for the prediction of the durability of building components and materials and to apply the methodology to selected components and materials.

Short-term tests are seldom satisfactory for predicting long-term performance. Thus, there is a need to improve durability prediction techniques. A general methodology for durability prediction would be very valuable as an aid to the evaluation of the durability of innovative building components and materials. A methodology which is being developed in a companion project is limited to exterior building components and materials. It will fill a great need in the area of durability prediction and facilitate the acceptance of new building components and materials.

The first task of the project will be to outline a general methodology for durability testing and to identify properties, degradation mechanisms, and environmental factors of importance. The second task will involve preparing matrices to relate these various parameters. The third task wi11 consist of applying the methodology to existing durability related projects.
Project Status

New

Project Leader

Larry Masters

3n1 921-3371

Sponsor

National Bureau of

Standards

Project Number $4 6 \longdiv { 1 5 1 6 0 }$

Impact Keywords construction; materials.

Technical Keywords Durability and deterioration; wea thering. 
Project Status

Concluded

Project Leader

Paul G. Campbe1]

Sponsor

Tri-Services of the

Department of Defense

Project Number

$4 6 \longdiv { 1 6 4 4 0 }$

Impact Keywords

construction; materials.

Technical Keywords

Residential.
The use of vinyl wall covering materials is increasing and these materials are comparatively high-cost items expected to have superior performance characteristics. However, there is relatively little quantitative information available on their performance. Knowledge of the behavior of various backing fabrics, coating textures, color patterns, and protective overlays is also lacking. Some problems have been encountered in the performance of materials which meet the Federal Specification for Vinyl Coated Wallcovering, CCC-W-408A, which is the basis for government purchase of this type material.

The objective of this project is to establish performance criteria for vinyl wallcovering materials which relate to abrasion resistance, stain removal, washability, fungus resistance, etc. The data obtained will be used as a basis for revision of the vinyl wallcovering specification, Fed. Spec. CCC408 .

The approach has been to obtain selected wallcoverings from commercial suppliers and to test them for abrasion resistance, stain removal, washability and mildew resistance. The data have been used to develop performance criteria for wallcoverings. The results will be the basis for recommendations for a revision of Fed. Spec. $\triangle C C-W-408 \mathrm{~A}$.

The planned testing has been completed and the final report is being prepared. The report will be an NBSIR report to the sponsor and it will include recommendations for the revision of Fed. Spec. CCC-W-408A. With completion of the work, the project is being terminated.

\section{CORROSION CONTROL-DPIPING-- MILITARY FACILITIES}

\author{
Project Status \\ New \\ Project Leader \\ Ramon CiTimberg \\ 301 921-3441
}

\section{Sponsor}

Tri-Services of the Department of Defense

Project Number $4 6 \longdiv { 1 5 4 4 6 }$

Impact Keywords Defense; materials.

Technical Keywords Aqueous corrosion.
The cost of corrosion in the United States has been estimated at $\$ 8$ billion per year. Aside from the cost in dollars, corrosion definitely contributes to the depletion of natural resources and energy supply. Examples of this depletion are the iron ore required to replace corroded steel and the four tons of $\mathrm{COa} 1$ required to produce each ton of steel.

The objective of this project is to minimize corrosion of piping in military facilities by recommending feasible and economical corrosion control methods based on field and laboratory evaluation of problems with existing systems.

During FY 75 corrosion problems associated with piping in military facilities will be identified. Field inspections of preselected pipina facilities will be carried out and supported by laboratory tests and technical analysis. Methods for minimizing corrosion in existing military facilities will be recommended and design guidelines for future facilities will be provided. 
The Tri-Services (Army, Navy, and Air Force) requested that the National Bureau of Standards conduct a comprehensive study of roofing in the field to aive Headquarters engineerina personnel an opinion of the performance of roofing and to assist them in their decision making on the selection of roofina systems. In addition, information from a survey of roofind at military installations would assist engineering personnel in the repair and maintenance of roofs.

The objective of this project is to inspect various types of roofing in a variety of climates to determine in general the performance of roofing systems and the effects of various environments on the behavior of comparable roofing systems, to identify problems for various types of roofing systems, to recommend aeneral solutions to these problems and also, to recommend roofing systems that perform satisfactorily in various climates.

In cooperation with Headquarters U.S. Air Force; U.S. Army; and Navai Facilities, U.S. Navy, copies of a technical questionnaire on the performance of roofs and roof problems encountered were sent to 100 selected bases. Based on the results of the questionnaire, bases were selected for field inspection of roofing. Inspections were made at 16 military installations, including bases in the North East, Middle Atlantic, Midwest and offshore Pacific reqions.

A draft of a report was prepared on the findings of the roof survey and recommendations for obtaining improved roofing performance. The report is to be published.
Project Status Concluded

Project Leader Phillip A. Cramp $301 \quad 921-3371$

Sponsor Tri-Services of the Department of Defense

Project Number $4 6 \longdiv { 1 6 4 3 6 }$

Impact Keywords Construction; materials.

Technical Keywords Inspection; roofs.

\section{PORCELAIN ENAMEL INSTITUTE RESEARCH ASSOCIATESHIP}

The porcelain enamel industry has a continuing need for the development of ouality control tests related to porcelain enamel performance and durability. Through the PEI (Porcelain Enamel Institute) Research Associateship established at NBS, the industry could draw on the extensive resources of NBS to help with its test development program.

Porcelain enamel samples manufactured by various companies were evaluated in the laboratory and in outdoor exposures to provide data upon which quality control tests could be based. New test methods were developed and evaluated in collaboration with member companies of PEI.

Reports on "The Weather Resistance of Porcelain Ename1: 15-year Inspection of the 1956 Exposure Test" and "The Adherence of Porcelain Ename 1 to Aluminum" were completed and submitted for publication in the NBS Building Science Series.
Project Status Concluded

Project Leader Geoffrey Frohnsdorff $301921-3458$

$\frac{\text { Sponsor }}{\text { Porcelain Ename1 }}$
Institute
Project Number
$46 \frac{1677}{}$

Impact Keywords Construction; materials.

Technical Keywords Ceramic matrix. 


\section{HUD LONG RANGE RESEARCH--GRAFFITI}

Project Status

continuing

Project Leader James G. Gross

301 921-3126

Sponsor

Department of Housin and Urban Developmen

Project Number $4 6 \longdiv { 1 5 4 4 2 }$

Impact Keywords Construction; aesthetics.

Technica 1 Keywords Testing.
Graffiti removal is a costly maintenance problem for the Maintenance Engineering Branch of Housing Management of the Department of Housing and Urban Development (HUD) and for others. Potential advantages of the studies in the public housing area would include cost benefits by the reduction of maintenance costs, improvements in surface appearance and performance, and the provision of a basis for performance criteria which would serve as a guide for HUD and the general public.

The objective of this project is to evaluate currently available graffiti removal techniques and graffiti-resistant materials and to recommend performance criteria for their selection.

The initial approach involves preparation of a report on currently used graffiti removal procedures and an evaluation and identification of critical performance characteristics. This will be followed by laboratory evaluation of graffiti removal procedures and comparison of performance and durability characteristics using substrates and marking materials selected on the basis of field experience.

A letter report was prepared on critical performance requirements related to affected substrate, types of marking devices, and cleanability. The preliminary evaluation of graffiti removers and graffiti-resistant coatings was completed. Included were identification of products suitable for graffiti-removal and suitable graffiti-resistant coatings, compatability between remover and substrate, characterization of physical properties, and natural and accelerated weathering tests to measure durability of coatings.

The following achievements are planned for FY 75: (a) a letter report on the effectiveness of graffiti removal methods and level of performance of graffiti-resistant coatings; and (b) a final report including comparison of performance and durability characteristics of graffiti-resistant coatings, and recommendations for the development of performance criteria and measurement methodology. 
A general methodology will be outlined and then detailed by identifying materials properties, possible degradation mechanisms and environmental factors of importance. Matrices will be used to relate these properties, mechanisms and environmental factors. The use of the methodology will be demonstrated using selected structural sandwich panels comprised of various materials such as plastics, adhesives, metals and foam.

The objectives of the project are to develop a general methodology for durability prediction of exterior building components and materials and to demonstrate the use of methodology by applying it to selected structural sandwich panels.

Durability or long-term performance is frequently predicted on the basis of short-term tests designed for specific components in materials. However, the predictions are seldom satisfactorily accurate. There is a need to develop a general methodology for durability prediction so that all possible factors affecting the durability can be identified and considered in the tests. Completion of the project will have considerable economic impact by paving the way for durability evaluations of failures and will assist the sponsor, in evaluating durability.

During FY 74 methodology was outlined and numerous matrices prepared to assist in interrelating properties, mechanisms and environmental factors. The methodology was applied to two types of panels. A comprehensive study of existing climatoloqical and weather data for use in durability testing was completed. Samples of selected sandwich panels were erected at various outdoor exposure test sites to obtain natural aging data. Accelerated tests were begun on several materials comprising the panels. A publication by Larry Masters, "The Use of Climatological and Weathering Data in Durability Testing of Building Components and Materials," NBS Technical Mote, June 1974 was also completed.

During FY 75 the general methodology wi11 be improved by applying it to additional components and materials. Additional accelerated and natural aging tests will be conducted. Reports summarizing the laboratory and field studies will be prepared.
Project Status Continuing

Project Leader James G. Gross 301 921-3126

Sponsor Department of Housing and Urban Development

Project Number 4608490

Impact Keywords Construction; effective regulation.

Technical Keywords Aging, materials; test methods, materials. 


\section{HUD LONG RANGE RESEARCH--WATERPROOFING}

Project Status

Continuing

Project Leader

James G. Gross

301 92]-3458

\section{Sponsor}

Department of Housing and Urban Development

Project Number

$4 6 \longdiv { 5 4 4 3 }$

Impact Keywords

construction.

Technical Keywords

Testing.
Water damage to buildings or their contents is a serious maintenance problem. Use of clear waterproofing treatments on exterior masonry surfaces can provide protection from water damage without seriously affecting the original appearance. It can also affect maintenance cost economies. The results of this work will be directly applicable to maintenance practices in the public housing area.

The objective of this project is to evaluate the water resistance of proprietary clear coatings as applied to the various masonry surfaces encountered in the public housing area and to establish performance criteria.

Small scale laboratory tests for resistance to wind-driven rain will be applied to masonry units treated with proprietary clear waterproofing surface treatments. Treated masonry specimens will also be subjected to temperature cycling, Weather-Ometer exposures and water exposures to provide measures of treatment durability, water repellency and permeability.

During FY 74 a letter report on the range of comercially available clear waterproofing materials was prepared. Over 50 materials were included and the generic resin types and contents were identified. Water absorption tests on brick and concrete masonry block were completed.

During FY 75 plans are to write a letter report on laboratory studies on the initial effectiveness of waterproofing coatings, application procedures, and survey results and a final report covering durability characteristics, with recommendations for performance criteria and for improved measurement and application techniques.

\section{HUD LONG RANGE RESEARCH--INNOVATIVE COATING SYSTEMS}

\author{
Project Status \\ Concluded \\ Project Leader \\ James G. Gross \\ $301 \quad 921-3458$
}

Sponsor

Department of Housing and Urban Development

Project Number 4608403

Impact Keywords Construction; quality control.

Technical Keywords Paint, general.
Laboratory tests were conducted to determine the performance characteristics of representative quick-drying, interior latex paints. Comparison of performance and durability characteristics of this material with other interior coatings were utilized for the application of performance criteria and the basis for the preparation of a coatings specification.

The advantaqes, potentially, to the use of such a paint in the Maintenance Engineering Branch would produce cost benefits relating to application, clean up, and improved performance and durability of the coatina.

A proposed specification for quick-drying, interior latex paint was submitted to HUn and published as HUD-HM Specification No. 4. The project was completed with its publication. 
Premature failure of sealants in buildings results in damaged interiors followed by costly repairs and continuous maintenance, as well as efficiency loss in heating and cooling systems.

The objective of this project is to obtain basic laboratory, performance, and exposure data on building joint sealants; to develop performance requirements and test methods for specifications; to issue guides for recommended practices which will help designers select the proper sealant as related to joint design, joint movement and level of performance; to advise sponsors on all problems. related to sealants.

The need for durable sealants is critical because of curtain wall designs, large thin panels, modular construction and use of high expansivity materials. Large dimensional changes occurring in buildings create situations where the joint sealant is most important in leakage control. Also, the present use by architects of large deck areas which serve as roofs for habitable areas, garages, cor storage rooms, etc. has emphasized the need for better sealants.

The sponsor is kept fully informed on the latest developments on sealant test methods, specifications, practices, etc. This information is obtained by laboratory and field evaluation of new sealants and by participation in leading standards-making organizations, e.g. American Society for Testing and Materials, American Concrete Institute, Canadian Government Specifications Board, etc. Cooperation with architects, government agencies, producers, organizations such as Adhesives and Sealants Council, National Paint and Coatings Associations, also universities, and foreign groups relating to sealant research is maintained on a continuous basis; consultation is continuously provided to the sponsors.

During FY 74 researchers conducted and completed a second round robin test with 4 labs for peel adhesion of a elastomeric sealants; completed final versions of 3 standard ASTM test methods - Effect of UV, Effect of Heat Aging and Peel Adhesion of Chemically Cured Sealants; submitted all tests for ASTM Society ballot; completed second draft of Recommended Practices for Chemically Cured Sealants (ASTM); continued cooperation with 2 producers in evaluation of new high range sealants capable of resisting $\pm 50 \%$ joint movement and continued evalution of numerous sealants to guide sponsors in their procurement. A one-day Federal Workshop was sponsored March 5, 1974.

During FY 75 plans are to complete evaluation of new $+50 \%$ class of sealants followed by recommendation for inclusion of such class $\bar{s}$ in Federal and ASTM specification; attempt completion of ASTM specification on Recommended Practices for chemically cured sealants; and revise and upgrade Federal Specifications on sealants. 


\section{ALUMINUM WIRE AND GROUNDING}

Project Status

Continuing

Project Leader

WiTTiam C. Cullen

$301921-2196$

Sponsor

Consumer Product Safety

Commission

Project Number $4 6 \longdiv { 1 5 3 7 0 }$

Impact Keywords Consumer protection; fire research; housing.

TechnicaT Keywords

Power transmission system.
A number of fire marshalls and consumer groups have reported that aluminum wiring used in electrical circuits may lead to overheated receptacles and switches and, subsequently, to fires. Thus, there is a need to determine the magnitude of the problem and to identify the failure mechanisms so that techniques for reducing the hazard can be recommended. The successfuT comoletion of the project will benefit homeowners who have aluminum wiring and will help fulfill the mission of the sponsor, the Consumer Products Safety Commission. Other NBS aroups are conductinn research to identify the manitude of the problem and the acceptability of proposed fixes.

A number of factors have been identified which may be important in leading to overheated devices, and oossible failure mechanisms have been hypothesized. Laboratory studies have been conducted to determine the effects of screw torque, screw composition, wire composition, salt environment, and polyviny chloride wiring insulation decomposition. Overheated devices from a burned home and from Taboratory tests have been studjed metallographically. Studies have also been conducted to identify the conditions necessary to start fires from an overheated electrical device. Although most tests have been short-term, long-term tests have been started.

During FY 75 the factors which could lead to overheated devices wilT be identified and possible faiTure mechanisms hypothesized. Laboratory and field studies will be conducted to determine the importance of the various factors. The studies will be conducted to confirm the hypothesized fai1ure mechanisms. The laboratory tests will emphasize the comparisons between results obtained with aluminum and copper wire, and with stee and brass binding head screws.

\section{CONSUMER PRODUCT SAFETY COMMISSION-- ARCHITECTURAL GLASS}

\author{
Project Status \\ Continuing \\ Project Leader \\ Sanford C. AdTer \\ $301 \quad 927-2796$
}

Sponsor

Consumer Product

Safety Commission

Project Number $4 6 \longdiv { 0 3 7 2 }$

Impact Keywords consumer protection; environmental hazards; hazards in the home.

Technical Keywords Architectural; safety; windows.
The Consumer Product Safety Commission (CPSC) has found that architecturaT glass products present an unreasonable risk of injury to consumers and has asked NBS to give them technical support in the development of a Nationa] Standard.

During Fy 74 a "Background Report on Architectural Glass" was completed which included: (a) a historical perspective on the Tife safety problems associated with architectural alass products; (b) a review of accident data and identification of principle causes of "glass" accidents; (c) a survey of nearly 100 qlass-related standards and identification of 35 unique test methods; and (d) a suggested guide for the evaluation of offers to use an existing standard or develop a new standard for architectural glass.

During FY 75 NBS will provide technical support to the CPSC which has chosen the Consumer Safety Glazing Committee to develop a National Standard for ArchitecturaT Glass. NBS support wiTT include monitorina the development of the standard and verification of the suitability of test methods developed. 


\section{SAFETY IN CONSTRUCTION AND OCCUPANCY OF BUILDINGS}

The creation of Occupational Safety and Health Adminstration in the Department of Labor as well as the Consumer Product Safety Commission in recent years is ample evidence of the affirmative action position the Federal government has taken to reduce accidents for workmen and for people engaged in ordinary activities. Safety during building construction and occupancy is a natural concern of the Center for Building Technology. Human lives can be saved.

The objective of this project is to conduct research both in the laboratory and in the field in order to develop test methods, criteria and standards to reduce death and injury losses in building and construction accidents.

Work will be carried out in cooperation with Federal organizations concerned with construction, building and fire safety, (including but not limited to the Occupational Safety and Health Administration and the Consumer Products Safety Commission) as well as recognized code and standards-making bodies and concerned industries. The purpose of this work will be to identify research needed to develop a technical base for current and proposed standards in the areas of accident, fire and life safety during construction and occupation of buildings and structures.

Field and laboratory studies will be conducted to develoo test methods, and criteria which can be incorporated into standards concerning accident, fire and life safety requirements in the construction and occupancy of bujldings, including residences.

Support and technical assistance will be provided to orqanizations in both the private and public sectors to assist in the development of useful, meaninaful and economical safety standards for construction of buildings and for the building's occupants after construction.

During FY 74 office and laboratory facilities were set up. Three staff members were hired. Six reports were prepared under this project in Fy 74, three were from outside consultants by contract and three were by in-house staff. Technical assistance to the Consumer Product Safety Commission was provided.

Plans for FY 75 are to continue development of the Building Safety Section's capability to conduct research and provide technical assistance primarily to federal oraanizations. Performance yardsticks will be formulated for building safety, and studies for safety standards will be initiated for formwork for concrete construction and for shoring for excavations.
Project Status

Continuing

Project Leader

James 0. Bryson

$301 \quad 921-3851$

Sponsor

National Bureau of

Standards

Project Number $4 6 \longdiv { 1 5 2 0 0 }$

Impact Keywords Housing; safety.

Technical Keywords construction, aeneral; safety. 


\section{SLIP RESISTANCE OF FLOORING}

\section{Project Status Continuing}

Project Leader James 0. Bryson 301 921-2196

\author{
Sponsor \\ Nationa 7 Bureau of \\ Standards \\ Project Number \\ $4 6 \longdiv { 1 5 2 0 0 }$
}

Impact Keywords Consumer protection; housing; occupationa 1 safety

Technical Keywords Floors; safety.
The study is needed because slippery floors are a large contributor to high casualty figures resulting from falls and no well established or generally accepted slipperiness standards are presently available. Slipperiness standards will help reduce these casualties and wi11 assist in the fulfil1ment of the goals of the Building Safety Section.

The objective of the project is to develop the technical bas is and test method for a safety standard for floor slipperiness.

The approach will be to obtain a reliable, portable device to measure a fundamental property of fioors and flooring materials that can be related directly to slipperiness and then use this device to establish standards for this fundamental property. The device will either be selected by evaluating available models or, if necessary, will be developed.

In FY 74 the state-of-the-art was determined by searching the 1iterature and by visiting several testing laboratories currently active in floor slipperiness studies. Preliminary laboratory evaluation of the three most promising test methods were completed, using three commonly used types of flooring material.

A report of these activities "Preliminary Study of the S1ipperiness of Flooring" has been prepared and will be issued as an NBSIR report.

In FY 75 the program is addressed to the four areas that follow: (1) the existing literature on human locomotion is being studied and researchers in that field are being polled to establish which coefficient of friction (static or dynamic) should be measured and under what conditions it should be measured, (2) two new slipperiness testers are beina developed: a portable version of the James Tester and a wholly new torque type tester. These along with existing testers, will be evaluated to arrive at a tester suitable for meeting the requirements of Item 1 , (3) several svnthetic shoe sole materials will be evaluated to see if they are more consistant than leather and if they can be reconditioned by merely washing with a suitable solvent, (4) several representative samples of bathroom and swimming pool surfaces will be studied to determine the coefficient of friction between them and bare feet (dry, wet and soapy). Also, several synthetic materials will be evaluated for possible simulation of bare feet in a standard slipperiness tester. 


\section{SAFETY RESEARCH ON STAIRS, RAMPS AND LANDINGS}

The aim is to reduce the frequency and severity of stair and landing accidents--particularly among yound children and the elderly, who share an inordinate number of the 356,00n hospital-treated injuries last year. The ultimate benefactor will be anyone who uses stairs and is thereby subject to an accident and disabling injury. Finally, it extends CBT's application of the performance concept into the interface between the built environment and human behavior.

The objective is to determine the relative contribution of stair design and of human errors in behavior associated with stair, ramp and landing accidents and to develop performance criteria and user quidelines to reduce the frequency and severity of such accidents.

The approach is to (1) review literature on epidemiology, biomechanics, slip-resistance, and perception; (2) analyze stair, ramp, and landing accidents surveyed by the National Electronic Injury Surveillance System and others; and (3) analyze video tapes on stairs in public settings against a working model of stair and ramp behavior and accidents which has been developed. The model posits direct relationships between (1) user expectations, sensations, reflexes, and movement habits; (2) the physical attributes of stairs and their settings; and (3) potentials for severity of accidents. Analys is of qait orientation, synchrony, and channeling using video tapes and films are being used to identify the critical design and construction tolerances conducive to successful stair and ramn use. A survey of stair and ramp use patterns and accident histories by age, sex and socio-economic status and an inventory of the physical quality of stairs and ramps are also being conducted. These behavioral and physical analyses will be used in preparing user guidelines and for performance criteria for stairs and landings.

During FY 74 a 1 iterature review, annotated bibliography, and glossary, were completed. Two iterations of the accident behavior report were submitted. Preliminary analyses of the NEISS data on stair accidents and a review of model codes and minimum property standards were completed. Detailed video tape data has been collected. A contract for the stair use survey and stair quality inventory has commenced.

During FY 75 plans are to complete stair usage and accident analysis of first video tapes; attend code agency and Federal agency conference on stair safety; complete user guidelines for stair usage; draft of Interim Performance Criteria; and revise Interim Performance Criteria. 


\section{Project Status \\ continuing}

Project Leader John S. Stroik

$301921-3595$

\section{Sponsor}

National Institute of Law Enforcement and Criminal Justice of the Department of Justice

Project Number $4 6 \longdiv { 3 7 4 0 2 }$

Impact Keywords Construction; crime prevention; persona 1 security.

Technical Keywords Architecture and desian; codes and standards; doors; residential buildings; testing
In order to reduce the number of buralaries, the National Institute of Law Inforcement and Criminal Justice (NILECS) has funded this project to develop performance standards and quidelines for door and window security. The standards will be used in building codes to insure that doors and windows standards will be used in buified performance level. The guidelines will be used by the public to improve existing doors and windows.

Analys is of burglary techniques and historical data, result in a breakdown of burglary attacks into categories and classes. Tests are then developed corresponding to, and duplicating, the attacks so categorized. Doors, windows, and components, passing tests can then be rated at a level corresponding to the class of burglary attacks resisted. In addition, adequate numbers of doors, windows and components, including add on devices will be tested in order to prepare guidelines for use by the general public. This guideline will provide information to enable residents and shopkeepers to establish the class ratinas for their doors and windows and if necessary, intelligently improve these ratings.

In FY 74 the following were completed: (1) final draft of the "Performance Standards for Physical Security of Door Assemblies and Components"; and (2) rough draft of the "Performance Standards for Physical Security of Window Assemblies and Components"; talks - John S. Stroik, "Development of Security Standards," Boston, American Society for Testing and Materials Committee F-12, October 17, 1973; John S. Stroik, "Door and Window Security Standards," National Woodwork Manufacturers Association Annual Meeting, Mexico City, February 6, 7, 8, 1974; John Stroik, Robert Kapsch, John Archea, Thomas Reichard and others, "Security for Buildings," NBS Federal Workshop on Building Science and Technology, February 5, 1974; various news reports in newspapers, madazines and television.

Durina FY 75 plans are to complete reviews and publish NILECJ Door Standard I; complete Uindow Standard draft; and complete reviews and publish NILECJ Window Standard. 
Doorways have been identified by the Consumer Product Safety Commission as the third leading consumer product directly involved in accidents. Approximately 135,000 persons received emergency room treatment in the U.S., during 1973, for injuries associated with doorways. The Consumer Product Safety Commission (CPSC) has funded and directed that this project investigate the nature of "door accidents" and provide means to reduce them. This project's output of standards, guidelines and reports will be used by CPSC to remove dangerous doorways from the market, insure that new doorways meet prescribed standards, and provide data for the public to enhance existing door safety.

The objective of this project is to develop criteria, standards and guidelines which, when used, will consequently result in the reduction of both frequency and severity of accidents related to doorways.

Two classes of causal factors converge for doorway accidents, namely, behavior and environment. The approach, then, is to first identify those aspects of doorway systems or environment that cause or encourage behavior resulting in accidents. In order to do this it is necessary first to examine as distinct the behavioral patterns of users, and the specific dimensions and properties of doorway settings involved in accidents. Then it is possible using data collected through various methods, to assess specific factors that will reduce accidents. Finally this assessment can be translated into the form of recommendations, standards and guidelines.

A contract has been let out and work is presently under way to review and assess interviews with doorway accident victims.

Plans for Fy 75 include a preliminary review of doors and door accidents to establish a behavioral model; and initial report on door accidents for both physical and human aspects; expansion of this report to include analysis of video taping and field observations of doors, door usane and door accidents; and interim performance criteria for door design and construction.
Project Status continuing

Project Leader Carl A. Johnson 301 921-3595

\section{Sponsor \\ Consumer Products Safety Commission}

Project Number $46 \overline{30411}$

Impact Keywords Consumer protection; construction; hazards in the home.

Technical Keywords codes and standards; doors; buildings, general. 


\section{MODULAR INTEGRATED UTILITY SYSTEMS PROGRAMMATIC SUPPORT}

\author{
Project Status \\ New
}

Project Leader Clinton W. Phi Ti7ips

Sponsor

Department of Housing and Urban Development

Project Number $46 \overline{06375}$

Impact Keywords

Construction

management.

Technical Keywords
Accomplishment of HUD-MIUS program objectives requires close coordination and monitoring of the diverse efforts of the eight agencies involved in addition to continuous technical overview and development of the program.

NBS, as a designated key agency in the HUD-MIUS program, is best suited to provide this coordination, monitoring and overview to the extent delegated by HUD. An effort to achieve the programmatic support objectives has been implemented at NBS.

The objective of this project is to provide HUD with management support, technical overview and program representation capability; and to implement, operate and maintain a management and technical information system for HUD.

The on-noing programmatic support activity includes operation of management information systems and other program support, interagency coordination, consultation and representational activities. Examples of the specific tasks involved in the management information systems include: implementation and maintenance of information systems for interagency technical task monitoring for the monthly interadency HUD-MIUS 1 eve] II proaram management and review board meeting; preparation of a MIUS technical reference file including abstracts of up to 10,000 reference technical articles, books, etc. concerning all aspects of utility systems design, planning, analysis and installation; implementation and maintenance of a monthly clip-sheet services for all members of the HUD-MIUS project technical and non-technical news items are included in this service; and implementation and maintenance of a control room including an interagency management information system for technical, fiscal and schedule monitoring of the overall HUD-MIUS oronram. Examples of tasks involved in the other aspects of pronrammatic upport include: presenting the MIUS concept in talks, discussions and articles prepared for professional societies, trade organizations, community aroups, etc.; assisting and/or representinn HUD in mananement meetings with other agency participants to further plan, define, implement, and schedule new and on-going MIUS program task efforts; coordinating industry/government meetings relative to program.

During FY 74 7 evel II information systems were developed, accepted by HUD, refined and continuously maintained; literature searching for data and final organizing of the MIUS technical reference file was completed. The monthly clip-sheet service was implemented and maintained; and an initial program control and monitoring information system was developed and maintained.

Key support to HUD in development of MIUS participating agency roles, tasks and schedules was provided. HUD was represented in presenting the MIUS program and concept to various outside technical groups.

Plans are to maintain 7 evel II information systems and the clip-sheet service-continuing task; to duplicate and distribute the reference file to HUD-MIUS participating agencies (August, 1974) to refine and expand the initial program control and monitoring information system into a MIUS control room display technique at NBS - October, 1974; to continue other programmatic support tasks. 
Although the principal technical study resources of the Department of Housina and Urban Development (HUD) MIUS program have been lodged in participating anencies, technical study efforts are needed at NBS to perform certain studies not being undertaken by other participating agencies, to knit toqether the technical output of diverse groups, to assist HUD in the technical direction of the program and to review other participatina documentation for publication.

The objective of this project is to analyze and evaluate all aspects of the MIUS concept particularly with reqard to providing HUD technical data for the p.lanning of the overal] HUD-MIUS Program, to provide analytical and experimental basis to support other MIUS projects, and to provide to HUD an overall technical overview and review function for the technical activities of the other participants in the HUD-MIUS Program.

Three efforts have been identified under the Design, Analysis and Technical Support Program: Performance Specification, Economic and Institutional Studies and Technical Studies and Reviews. In addition, the Design, Ana 1ysis and Technical Support element will coordinate and manage these individual efforts and provide a broader level of input to HUD for proaram planning purposes.

The Performance Specification effort is to describe the performance of a properly designed, installed and operated MIUS of any size and type. The Economic and Institutional Studies effort is to determine cost/benefits, economic feasibility and marketing studies, to develop methodologies for such analysis and to identify, quantify and develop solutions to institutional, legal, and governmental factors which constrain, delay or prevent the implementation of the MIUS concept. The Technical Studies and Reviews effort is to (1) conduct laboratory investigations, technology evaluations and systems studies of MIUS components, subsystems and system, and (2) conduct coordinated technical reviews of all MIUS program documentation.

A MIUS Performance Specification document is being written that will contain the minimum nerformance quality levels for the MIUS products and services, reliability, energy efficiency, control, environmental impact, natural hazards resistance, occupational safety, and community impact.

Three economic and institutional studies are currently underway. They are "A Methodology for Comparing the Economic Cost and Benefits of MIUS to Conventional Utilities," "A Methodology for Determining the Institutional Constraints to Building a MIUS," and "Economic Incentives for the Implementation of a MIUS." Further efforts have been initiated to develop a standardized economic methodology for MIUS participating agencies.

Two technology evaluations are nearing completion with written publishable products to be delivered later this year. These evaluations are investigations of utility load profiles and software programs that may be used in the methodologies described in (b) above. Reviewers of all (written publication candidate material) will be accomplished by the Coordinated Technical Review (CTR) process. This process requires all MIUS participating agencies to review subject written material, to transmit these reviews to NBS, to construct a CTR document containing all these reviews, to deliver the CTR to the original author(s) of the material, to monitor the resolution of the comments contained in the CTR, and finally to make recommendations to HUD regarding publication.

Plans for FY 75 are to send draft of "Economic Incentives for the Implementation of a MIUS" to MIUS agencies for CTR; develop a plan to study the institutional constraints involved in locating, building and operating the demonstration MIUS; develop a plan to complete the methodology for comparing the economic costs and benefits of MIUS to conventional utilities; complete economic comparison methodology study; deliver for CTR process and publication, "Technology Evaluation of Heat Pumps," "Summary of HUD-MIUS Program Building and Consumer Load Characterization Effort," (water, electric load

\author{
Project Status \\ Project leader \\ John D. Ryan \\ $301 \quad 921-3741$
}

Sponsor

Department of Housing and Urban Development

Project Number $46 \overline{06370}$

Impact Keywords Conservation; construction.

Technical Keywords Energy conservation; utilities; waste heat utilization. 
profiles) (solid waste load profile), "An Evaluation of Computer Software Applicable to the MIUS Program," complete eight scheduled CTR's of documents; and complete final draft of MIUS Performance Specifications; send Performance Specification for CTR; and resolve comments generated from CTR process and prepare for publication.

\section{MODULAR INTEGRATED UTILITY SYSTEMS FEASIBILITY DEMONSTRATION}

\author{
Project Status \\ New \\ Project Leader
} C] inton W. PhiT1ips 301 921-3741

Sponsor

Department of Housing and Urban Development

Project Number $4 6 \longdiv { 0 6 3 9 0 }$

Impact Kewords Construction; distribution and storage

Technical Keywords

Eneray conservation, utilities; waste water treatment and disposa]
To verify the energy, environment and social cost/benefit posture of the MIUS concept, it has been determined by Department of Housing and Urban Development that a full-scale demonstration of the concept similar to, but separate from, the Modular Integrated Uti]ity System Total Energy Demonstration needs to be undertaken. NBS involvement in this demonstration is a direct extension of the involvement under the on-going, HUD-sponsored Total Energy Demonstration and HUD has requested a similar level and type of support in both. The measurement, collection and evaluation of utility service data relative to performance specifications and user needs is the key element of the demonstration and is the basis for the HUD-requested NBS involvement in the demonstration.

The objective of this project is to (a) insure the proper initial development of the demonstration by assisting HUD in the management of the pre-demonstration activities; (b) insure a proper technical demonstration by developing performance specifications, conducting tests and evaluating data and providing the lead technical role in the demonstration; and (c) insure a proper programmatic demonstration by preparing and disseminating technical documentation, and presenting technical results to the public.

The approach will be to (a) provide key assistance to HUD for the selection of a site for the Feasibility Demonstration and to manage certain aspects of the initial demonstration activities as requested by HUD; (b) develop an overall demonstration evaluation plan and to prepare bid packages for the design and installation 
of a monitoring/information system; (c) review and evaluate contractor Modular Integrated Utility System designs and conduct tests of MIUS equipment; and (d) collect, analyze, evaluate and disseminate data collected from the MIUS plant and to conduct a long-term test program and evaluate results.

During FY 74 researchers participated in the planning laskj and review and evaluation of responses for a HUD advertisement to developers for initial expressions of interest in participating in the MIUS Feasibility Demonstration; assisted HUD in the preparation of an RFP for the Feasibility Demonstration including preparation of a model MIUS Performance Specification; identified a team to directly support HUD in the proposal evaluation effort and initiated planning for the evaluation task itself.

Plans for FY 75 are to assist HUD in the selection of a site for the Feasibility Demonstration by participating as members of the HUD Source Evaluation Board and conducting energy, environmental and economic analyses to evaluate candidate proposals; plan, develop and implement the overall evaluation and test effort for the Demonstration. Develop bid packages for the design and installation of a monitoring and instrumentation system (MIS) for data collection at the MIUS plant. Conduct special tests and plan additional demonstration activities as needed; monitor and evaluate the Feasibility Demonstration contractor's MIUS design efforts via incremental design reviews relative to the Performance Specification using architectural/ engineering contract personnel expertise as necessary. Submit Technical Review Reports (TRR's) to HUD for each incremental design review. 


\section{MODULAR INTEGRATED UTILITY SYSTEMS PROJECT MANAGEMENT}

\author{
Project Status \\ Continuing
}

Project Leader clinton W. Phillips 301 921-3741

Sponsor

Department of Housing and Urban Development

Project Number $4 6 \longdiv { 2 4 3 7 0 }$

Impact Keywords

Conservation;

construction.

Technical Keywords Energy Conservation; utilities; waste water treatment and disposal.
The objectives of this project are to demonstrate the technical and economic advantage of providing the basic utilities for a residential/ commercial community in an integrated plant. The objective of the MIUS project management efforts are to plan, direct, organize, monitor, and report to the Department of Housing and Urban Development (HUD) and NBS/CBT al1 aspects of the subprojects of the NBS Team of the HUD-MIUS Project. Present means for providing community utilities are energy wasteful (in most electric generating plants as much as 70 percent of the energy inout is rejected as waste (heat) and resource-intensive (remote incineration or landfilling of solid waste does not usually permit either energy or resource recovery and is wasteful of land area). Isolated liquid waste plants are, in many cases, not capable of meeting proposed standards and do not provide for process utilization of treated effluent. Separate maintenance and operating labor is required for separate plants; and individual plants require excessive land area. The MIUS concept provides remedy or improvement in these several areas, and the program provides means for stimulating implementation of the concept. The diverse and expansive nature of the NBS Team and assigned tasks in addition to the need for accurate and timely reporting to HUD, require the establishment of a strona, cohesive project management function. HUD has, in addition, indicated a stronn desire for centralized project management of the NBS-team efforts. HUD has sourht the cooperation and technical assistance of several government agencies, each interested in the benefits of MIUS either from a different technical aspect or from a different implementation need. In addition to HUD and NBS, these agencies include the Atomic Energy Commission, Environmental Protection Agency, National Aeronautics and Snace Administration, Department of the Interior (Office of Coal Research), Department of Health, Education and Welfare, and Department of Defense. The National Academy of Engineering has appointed under contract to HUD, an Integrated Utility System Board to assess the program progress. NBS serves to provide technical support to HUD and to coordinate the inputs of the several agencies.

The management approach for the NBS team of the HUD-MIUS Proqram is to identify, orqanize and manage a project "team" under the Center for Building Technology's Energy Conservation in Communities effort. This team consists of discipline specialists in economics, energy transfer, modeling, mechanical, electrical, and control systems, as well as subsystem specialists for each of the MIUS utility services-electrical, HVAC, water, and wastewater and solid waste management. Establishing internal procedures for the operation of this team and its interfaces with other MIUS program participants is another element of the NBS program management approach.

The participanting agencies have thus far in the program, conducted technology evaluations, prepared documents covering these evaluations, designed potential demonstrations, begun design and construction of demonstrations, operated demonstrations, or prepared for contracting of demonstrations. Demonstrations range from a pilot MIUS demonstration (at NASA's Johnson Space Center, Houston, Texas) to a major MIUS installation (now out for proposals, and include several individual subsystem technology demonstrations (such as incineration of solid waste in Hennepin County, Mo).

At NBS, a team has been as sembled to provide the several areas of technical and programatic support as outlined in the various subproject descriptions (Design Analysis and Technical Support, Programmatic Support, Total Energy Demonstration and Feasibility Demonstration). The team is multi-disciplinary and has provided technical gujdance and review to the several agencies cooperating in the HUD-MIUS program. One form of this support has been the preparation of Coordinated Technical Reviews of more than twenty technology-evaluation and technology-assessment documents intended for publication. Another form has been the preparation of several of the basic technoloqy-evaluation documents and special purpose documents such as the performance specification for the MIUS feasibility demonstration. The total energy demonstration measurement plan has been implemented. For specific details refer to the subproject descriptions. 
The project management progress has been to coordinate the functioning of these several subprojects and to provide technical and administrative leadership to the subproject and task leaders. Additional key progress has been the implementation and maintenance of effective periodic fiscal, manpower, and schedular mechanisms for reporting to the project sponsor.

The Project Management task will be to continue to (1) provide the liaison between the NBS Team of the HUD-MIUS Project and the sponsoring HUD-MIUS Program office; (2) provide the administration and technical leadership to the subproject and task leaders for accomplishment of the many related tasks outlined in the subproject descriptions; and (3) prepare and submit to the sponsor the required perjodic program, technical, and fiscal reports relating to NBS support activities. (Note: The Total Energy Demonstration at Jersey City wi11, in FY 75 , be incorporated in the MIUS program. It previously was implemented as an independent project).

\section{RETROFIT PLAN, ENERGY CONSERVATION, NBS CAMPUS}

NBS, along with all other Federal establishments, has been directed by the President to reduce its consumption of energy in carrying out the operations. It is anticipated that the current crisis will continue to cause additional reductions for the next several years. Also, since NBS is actively engaged in an extensive building energy research proqram, it is desirable that its own building be a model of conservation for other agencies and industry.

The objective of the project is to establish a plan which will determine the energy saved for dollars invested in the NBS buildings' systems and plant a)terations.

This project is a follow-on to a contingency study by an ad hoc task group under Dr. Hoffman to reduce energy by measures that could be implemented immediately. This study is considering how to reduce energy use by permanently incorporated alterations to the buildings' systems and plant operations.

A team has been orqanized which includes both plant and CBT engineers, and selection criteria and specific topics of study have been designated. Several subcontracts to outside groups have been let for specific studies. The buildings have been successfully modelled on the computer and parameters affecting system operations are under quantitative evaluation. An experiment to verify the computer model is to be carried out in four office modules.

Completion of a report to the NBS Executive Board is anticipated by September 30, 1974. This work is being carried out in FY 75 under another project, Existing Building Energy Analysis. 


\section{CONSERVATION OF ENERGY PROGRAM}

Project Status Continuing

Project Leader Jack E. Snell

301 921-3637

\section{Sponsor \\ National Bureau of Standards}

Project Number 4624101

Impact Keywords Conservation.

Technical Keywords Energy conservation.
Energy conservation is an important national goal. NBS projects in this area need to be coordinated and related to similar/complementary activities in industry, and in other agencies or levels of government. The ultimate beneficiaries of this program are the private and industry sectors.

The purpose of this project is to develop, maintain, and implement an effective energy conservation program plan that is compatible with and responsive to the NBS mission, the Federal Energy Agency (FEA) program, and national needs in the areas of buildings, community services, and industry.

Project activities consist principally of program planning, development, and management of Scientific and Technical Research Services (STRS); FEA, and other agency sponsored energy conservation programs; technical monitoring and coordination of laboratory, field demonstration, economic, and measurement technology phases with needs of the energy conservation program objectives through stimulating interdisciplinary research and development responses. Liaison work (usually thru FEA and the Department of Commerce) with Other Acency (OA) programs as well as private industry is of prime importance, as is an active program of activities to assure effective use and broad application of program findings.

The overal1 program plan and organizational framework were developed for management of the buildings and industry portions of the program during FY 74. Accomplishments include significant inputs to the President's Report on Energy Conservation (Dr. Dixie Lee Ray's Report to President Nixon) and the FEA program plans for FY 74, FY 75, and the FEA 5-year R\&D plan. These efforts led to major increases in NBS program funding in FY 74 (STRS \$400K and FEA \$671K).

Major activities in FY 75 include development of an updated program plan for NBS activities in energy conservation, monitoring of in-house and contract studies and $\mathrm{OA}$ /industry liaison. 


\section{ENERGY CONSERVATION INFORMATION}

For maximum impact, research findings should appear in the most accessible or usable form for potential users. There is an urgent need for practical guidelines on energy conservation by building designers, the construction industry, and the financial and regulatory sectors of industry, as well as building owners and operators. This project is coordinated with Federal Energy Agency (FEA) to assure maximum effectiveness.

The purpose of this project is to disseminate research findings and other practical information on energy conservation to appropriate users in a timely fashion and in an effective form or format.

Technical information of two types is collected, developed, and prepared for dissemination to Government agencies, professional organizations, builders, designers, regulatory bodies, manufacturers, or the public, as appropriate. These are: (a) existing technical information scattered throughout the literature, manufacturers' brochures, or other sources that is applicable to enerqy conservation needs and has not been assembled before; (b) new technical information developed under energy conservation projects that is ready for application in the building industry. A number of publications were developed in FY 74.

A number of publications were developed in FY 74 - NBS Technical Note 789 , "Technical Options for Energy Conservation in Buildings," Ju7y 1973; NBS special Publication 403, Vo1. 1, "Energy Conservation Through Effective Energy Utilization," (Proceedings of the Workshop on Energy Conservation in Industry, Henniker, Vermont, 1974); "Energy Conservation in Buildings," Sweet's Catalog, 1974; "Round Table Discussion on Energy Conservation in Buildinas," Scientific American, eds. James R. Wright and Paul R. Achenbach, January 1974; T. Kusuda, "NBS Heating \& Cooling Load Determination Program," Automated Procedures for Enqineering Consultants Journal, p. 4, Winter 19731974; T. Kusuda, "Heat Transfer Studies of Underground Heat \& Chilled Water Distribution Systems," NBS-Buildina Research Institute-ASHRAE Symposium on Under fround Heat Distribution Systems. Nov. 26-27, 1973.

During FY 75 the staff of the Center for Building Technology will plan and/ or participate in workshops on design criteria for retrofitted buildings, potential for energy conservation in selected industries, and heat pumps; symposia on standards for environmental conditions and the performance concepts; conferences on solar energy, measurement technology, and energy conservation potential in packaged equipment; the development of guidelines and specifications for retrofitting buildings, mobile homes, and for State regulations; and issuance of publications on energy conservation in NBS media, American Society of Heating, Refrigerating and Air-Conditioning Engineers (ASHRAE) media, and technical press on various energy conservation projects being conducted under Scientific and Technical Research Services (STRS), FEA, and Other Agency (OA) programs. See individual project summaries. Other reports and survey publications of a more general nature will be issued.
Project Status

Continuing

Project Leader

Jack E. Snell

30? 921-3637

\author{
Sponsor \\ National Bureau of \\ Standards \\ Project Number \\ $4 6 \longdiv { 2 4 1 3 6 }$ \\ Impact Keywords \\ conservation.
}

Technical Keywords Energy Conservation. 


\section{INDUSTRIAL ENERGY CONSERVATION}

\author{
Project Status \\ Continuing
}

Project Leader

Kenneth G. Kreider

301 921-3637

\section{Sponsor}

National Bureau of Standards and Federal Energy Agency

Project Number $46 \overline{26406}$

Impact Keywords conservation.

Technical Keywords Energy Conservation.
Iridustrial and commercial uses account for well over one-half of the national enerqy use with perhaps one-third of that amount potentially conservable.

The project is planned around five major thrusts:

(1) A series of seminars and technolony transfer exercised utilizing the "Energy Conservation Program Guide for Industry and Commerce" developed in FY 74 which would assist some industrial firms to initiate and implement eneray conservation programs, aain feedback from those firms to augment and imorove the Eneray Conservation Proaram Implementation Guide for Industry and Commerce (EPIC) particularly through identifying additional opportunities for eneray conservation, and gain a statistical characterization of the current state of the art in enerny conservation in intermediatesize industrial plants

(2) The second major thrust is the development of simplified operator manuals emphasizina energy conserving practices for thermal process systems which may be operated by in-plant maintenance and encineering personnel (selection of these systems is part of the research but small steam generators, process equipment, heat treating furnaces, and cooking equipment are candidates for consideration)

(3) Systems analysis of thermal process systems with emphasis on simplified but generalized characterization of the systems and computer assisted analys is to permit ready evaluation of specific systems including calculation of potential for enerav conservation is also planned. The initial tarnet will be industrial heat treating furnaces as used for heat treating of parts.

(it) Data and methods for designing and analyzing devices and techniques for transferring and containing thermal energy. Initial work will be with fluidized bed augmentation of heat exchangers for use with heat pumps.

(5) Field and laboratory measurement of energy related flow in thermal devices and systems and the evaluation of device and system efficiencies. A survey of measuring requirements and available methods will be used to identify needed measurement research. Initial focus will be the field evaluation of industrial furnace efficiencies in typical applications which are statistically representative of industrial practice. Methods and criteria for evaluating thermal system efficiencies will be assembled in appropriate form for use in energy conservation programs. Specific attention will be given to the use of thermodynamic performance in energy conservation in terms of practical consideration.

NBS has developed the EPIC Guide for small and intermediate industrial and commercial plants. It is intended for use by operating managers and plant enqineers in implementing their eneray conservation programs. Material for it has been aathered from larqe industrial orqanization that have gained valuable experience in implementing their own eneray conservation programs. It includes program develooment quidelines; tested and validated energy conservation opportunities, including technical details, sample calculations, examples and reference data; and information on various sources to contact for further assistance. The fuide, "Eneray Proaram Fuide for Industrv and Commerce (EPIC)," by R. Fatts, R.G. Massey and J.C. Robertson has been assembled and reviewed by a team consisting of NBS enninners, a Research Associate from Dow Chemical Corporation and a number of outside contractors.

The following talks were also niven: R. Gatts, "Energy Mananement Practice"; C. Berg, "Effective Utilization of Eneray and Other Natural Resources";

K. Kreider, "Applications of Thermal Process Technologies"; T. Kusuda and G. Kelley, "Potentials for Eneray Conservation in Build ina Environmental Equipment"--a11 presented at the Enaineering Foundation Conference Through Effective Enerqy Utilization, Henniker, N.H., Auqust 1973. 


\section{PERFORMANCE STANDARD FOR ENERGY CONSERVATION}

Shortages of electricity, gas and oil during the 1972-73 winter season created substantial popular demand for State regulations governing the distribution of energy. The National Conference of States on Building Codes and Standards (NCSBCS), an organization of building officials appointed by the Governors, sought the development of a voluntary standard to avoid a proliferation of different requirements by state and local regulatory jurisdictions.

The objective of the project is to develop performance oriented energy conservation criteria suitable for use as building design guidelines and as guidelines for evaluating the suitability of building designs prior to construction.

The design criteria are performance-based and are applied at the subelement level of buildings. The detailed requirements and criteria are directed toward the design of building envelopes with good thermal resistance and low air leakage, and toward efficient practices in the design of mechanical and electrical systems which conserve energy. To carry out its task, a team of fifteen NBS staff members were augmented by a group of advisors who met frequently over a period of three months. The advisors represented the American Consulting Engineers Counci1, American Institute of Architects, American Society of Heating, Refrigerating and Air-Conditioning Engineers (ASHRAE), and NCSBCS. After announcement in Commerce Business Daily, a public workshop was sponsored by NBS and NCSBCS on November 11-12, 1973 , to discuss the proposed format of the document and to solicit suggestions. During preparation of the document, numerous working meetings were held between the Task Group and officials of various industry associations. Early drafts of the document were reviewed by selected industry professional and governmental organizations. In addition, NBS contracted for economic and technical impact analysis of the draft from nine architectural and engineering firms and industry associations.

On February 27, 1974, NBS transmitted a performance based energy document, NBSIR 74-452 Design and Evaluation Criteria for Energy Conservation in New Buildings, to the National Conference of States on Building Codes and Standards (NCSBCS). These design criteria were prepared in response to a request by NCSBCS for a document which would serve as the bas is for a na.tional consensus standard on enerqy conservation. The American Society of Heating, Refrigerating and Air Conditioning Engineers (ASHRAE) is now developing ASHRAE Standard 90-P, of the same title, using the NBS document as a framework. ASHRAE issued proposed standard g0-P in July 1974 and seeks to issue a national consensus standard by year end.

NBS plans to formally publish the document as a research report in the Building Science Series (NBS). In addition to serving as a foundation from which the ASHRAE Standard g0-P was developed, the NBS document represents a worthy effort in its own right in applying the performance concept to an important national need. The document will continue to serve as a resource for energy conservation concepts that may not be incorporated in the first issue of a national consensus standard.

In addition to this the following also came out of this project: Workshop for Industry and Government on Energy Conservation in Buildings, November 11-12., 1973; "Design and Evaluation Criteria for Energy Conservation in New Buildings," NBS Interagency Report 74-452, February 27, 1974.

The National Fire Protection Association (NFPA) 501B Mobile Home Standard coordinating Committee (ANSI A119.1) has formed a Mobile Home Energy Conservation Task Force to develop a Tentative Interim Amendment. NFPA is seeking to incorporate energy conservation criteria into NFPA $501 \mathrm{~B}$ by January 1975. This is also based on NBS Interagency Report 74-452.
Project Status Concluded

Project Leader Jim L. Heldenbrand 301 g21-3512

\author{
Sponsor \\ National Bureau of \\ Standards \\ Project Number \\ 4621102 \\ Impact Keywords \\ Conservation: \\ construction.
}

Technical Keywords Codes and Standards. 


\section{CONTRACT MANAGEMENT (ENERGY CONSERVATION)}

\author{
Project Status \\ Continuing \\ Project Leader \\ Jack E. Snel] \\ $301 \quad 921-3637$
}

Sponsor

Federa] Energy Agency

Project Number 4626405

Impact Keywords Conservation.

Technical Keywords Building components; heating and cooling devices.

\begin{abstract}
The purpose of this project is to demonstrate through a contract field study involving a statistically significant sample of residences the poteritial for energy savings from a vigorous campaign to maintain residential oil burners at maximum efficiency and the practicability of this and other related home improvement actions.
\end{abstract}

A major portion of the Federal Energy Administration (FEA) FY 75 program in energy conservation in buildings deals with existing buildings, and NBS is a principal participant in this effort. Thus, FEA has requested NBS to develop a request for proposal (RFP) and monitor the resulting contract for the subject evaluation. It is not clear whether a residential oil burner adjustment campaign would be cost-effectively energy saving. The principal beneficiaries of such a program, if warranted by the results of this study, would be the northeastern states, and benefits would accrue possibly as early as the coming winter.

NBS will develop an RFP and let a contract for this work. The project wi11 involve training teams of technicians, who will visit a sample (possibly as many as 1000) of homes to determine furnace efficiency, to conduct minor maintenance, to make needed adjustments, and to determine the maqnitude of the resulting changes in furnace efficiency. The results of this study will be used in developina recommendations to FEA for a residential furnace efficiency pronram, if warranted.

\section{INDUSTRY ENERGY USE RESEARCH ASSOCIATESHIP, DOW CHEMICAL COMPANY}

\section{Project Status \\ Concluded}

Project Leader

Kenneth Kreider

$301 \quad 921-3324$

Sponsor

Dow Chemical Company

Project Number $46 \overline{24572}$

Impact Keywords Conservation; productivity enhancement.

Technical Keywords Industrial methods.
The potential for significant energy savings through energy management programs within industry is very great. An industry input is essential in developing effective and usable guidelines for small and intermediate-sized firms. The NBS Research Associate Program provides a mechanism for this

The objective of this project was to provide a vital industry input and perspective in development of the initial version of the NBS Energy Conservation Program Guide for Commerce and Industry. The Guide, MBS Handbook 115,
was completed.

Researchers will advise and assist NBS engineers in the development of an Energy Conservation Kit and in initiating other projects in the NBS Eneray Conservation in Industry program.

The Research Associate participation by John C. Robertson, Dow Chemical Company, who headed the energy management program within his firm (Dow Texas) has been an invaluable input to the program. Mr. Robertson's associateship is scheduled to be concluded in August 1974. 
Standardized testing and rating procedures for solar HVAC components in a form similar to those published for fuel burning equipment, air conditioners and heat pumps are needed for several reasons. A number of different kinds of solar subsystems are being developed at various universities and research laboratories and there is an urgent need to be able to compare their performance on some conmon basis. In addition, as the commercial models of various components become available, the procedures would provide an equitable basis for design and selection of equipment. Due to the large number of solar heating and cooling demonstration facilities being planned, there is also an urgent need to develop a common methodology or philosophy for the evaluation of full-scale integrated total systems as well as to document the performance of specific systems such as the one being constructed at NBS.

The objective of the project is to develop standard methods of testing and evaluation specific components of a solar heating and cooling system, and to evaluate the performance of a state-of-the-art full-scale integrated solar heating and cooling system designed to be retrofitted onto a four-bedroom single family residence in Washington, D.C.

The approach to accomplish the objectives above are respectively:

a. A preliminary version of standardized testing procedures for solar collectors and thermal storage units will be completed during the early part of the fiscal year 1975. These procedures will be based on the experience of solar researchers in the field and preliminary analys is on the behavior of solar components and experience in testing conventional equipment at NBS. A test stand for conducting outdoor tests of solar collectors and another for laboratory testing of storage units will be constructed and the procedures will be essentially verified or modified if appropriate by the middle of FY 1976. A round robin test program will be started during the latter part of FY 1975 and will consist of testing a series of solar collectors at NBS as well as at least four other independent outdoor and indoor testing facilities at judiciously selected sites around the United States. The purpose of the round robin test series will be to determine the feasibility of the established test procedure and to compare the results of tests conducted in different geographical locations and as well as both indoors and outdoors.

b. The design and procurement of a retrofitted solar energy heating and cooling system has been carried out for a four-bedroom house that is now located on the NBS grounds. The solar system, consisting of flat plate collectors with water/ethylene glycol as the transfer fluid, water storage, and an absorption air conditioner integrated into the existing forced air system of the house, will be operational by the early part of FY 1975. The approach will be to evaluate the performance of this system during typical summer and winter operation and compare it to the performance of the gas-fired furnace and electric air conditioner in this same structure determined during the previous two years. Emphasis will be placed on (1) evaluating the performance of the system in a variety of modes of operation, and (2) developing the procedures, methodology and recommended instrumentation for evaluating the performance of full-scale integrated heating and cooling systems.

A major part of the analysis was done for writing the standard test procedures for solar collectors and the thermal storage devices and preliminary draft of the thermal storage unit procedure was completed. In addition, the solar heating and cooling system for the four bedroom house was designed and al1 major components of the system were procured.

During FY 74 a draft of both the solar collector test procedure and thermal storage unit test procedure will be sent to the National Science Foundation; an interim report including the test procedures and the basis for their establishment will be sent to the National Science Foundation; a proposal will be sent to the National Science Foundation requesting funds to construct
Project Status

continuing

Project Leader
James E. Hi11
$301921-3503$

Sponsor
Nationa1 Bureau of
Standards, Federa1 Energy
Agency and Nationa 1
Science Foundation
$46 \frac{\text { Project Number }}{26401}$
Impact Keywords
Conservation.
Sochnical Keywords


the appropriate test facilities and to manage and conduct the round robin test program; the retrofitting of the solar collector array onto the house will be completed and preliminary testing of the solar collectors will begin; the retrofitting of the complete integrated solar heating system onto the house will be completed and testing of the system under winter conditions will berin; and cooling equipment and special high performance solar collectors will be added to the house and testing of the system under summer cooling conditions will begin.

\section{ENERGY DEMONSTRATION OFFICE BUILDING}

\section{Project Status \\ continuing \\ Project Leader \\ Tamami Kusuda \\ 301 $921-3521$}

Sponsor

General Services Administration, National

Bureau of Standards

Project Number $4 6 2 \longdiv { 2 4 1 3 7 }$

Impact Keywords

Construction;

distribution and

storage.

Technical Keywords $\mathrm{High}$ rise buildings.
The objective of this project is to perform energy consumption analys is during the design stage and to show energy savings by comparing alternative constructions, and mechanical and electrical systems.

It was estimated that $20-40 \%$ less energy would be needed in an office building that was designed to conserve energy while providing needed services, as compared with conventional buildings.

The approach was to use the computer program NBS Load Determination to compare and optimize the several design options to save energy both in the building shell and in the mechanical and electrical systems.

Computer runs (more than 40 ) simulating hourly enerqy consumption patterns covering a one year period were comnleted. The results of these calculations were transmitted to FSA and the architectural/enaineering designers and they were incorporated into the final plans and specifications. Comparative energy savinas were about 50 nercent. A performance specification for obtaining a computer controlled measurement system was prepared and used for procurement.

Hork on this project will continue under New Building Eneray Desian. 
The objectives of this project is to assist General Services Administration and the New York City School Board in designing energy conserving buildings by providina energy analyses during the design stage and evaluating energy utilization by measurement after the buildings are completed.

Accordinn to a pretiminary study conducted under this project, combined floor area of commercial and school buildinas in the United States constitutes approximately 50 percent of the total non-residential building floor area. necreased enercy consumption by improvina design or operation of these two types of buildings would have a significant impact on the nation's eneray consumotion.

The approach is to work with architects and engineers employed by the respective agencies in such a manner that the various design alternatives with respect to buildings shells and heating, ventilating and airconditioning (HVAC) systems can be evaTuated by the comprehensive computer program called NBS Load Determination (NBSLD) to attain the optimum configuration from the standpoint of the Tife cycle cost. Extensive instrumentation will be installed to evaluate the performance of various subsystems from an energy use or cost standpoint.

For the General Services Administration (GSA) Manchester office buiTding more than 40 computer runs simulating hourly energy consumption pattern over the one year period have been performed. The results of these calculations were implemented in the final design. In addition, a detailed performance specification for the procurement of computer controlled energy instrumentation system was provided to assist GSA in evaluating the proposals. A construction contract was let in June 1974. For the NYC School project, eneray consumption data from 19 typical schools were analyzed to yield the base energy consumption value. The annual energy consumption profile of one school building was simulated by NBSL.D. In addition, thermal performance and ventilation patterns of several schools were observed during FY 74.

During Fy 74 the final design of a solar utilization system and the initial desian of an instrumentation system of the Manchester office buildinq will be completed. As these are beinq completed, an in-depth analys is of the systems will be done and study reports will be prepared.
Project Status continuing

Project Leader Tamami Kusuda 301 921-3522

Sponsor NationaT Science Foundation, Federa 7 Energy Agency

Project Number $4 6 \longdiv { 2 6 4 0 4 }$

Impact Keywords Conservation; construction.

Technical Keywords Components, genera T; educational facilities; high rise buildings. 


\section{HUD LONG RANGE RESEARCH THERMAL PERFORMANCE OF WHOLE BUILDINGS}

Project Status Concluded

Project Leader
James G. Gross
$301921-3126$

Sponsor

Department of Housing and Urban Development

Project Number $4 6 \longdiv { 2 8 3 8 3 }$

Impact Keywords Construction; distribution and storage.

Technical Keywords Residential.
The need to accurately predict the thermal performance of housing and energy requirements is desired to allow architects and engineers to design housing and their mechanical and electrical systems more efficiently and to examine the energy economic trade-offs concerning first costs and owning and operatirig costs. By such a procedure the necessary energy to maintain health and comfort could be defined and supplied in terms of optimized systems.

The objective is to conduct thermal performance and energy consumption tests on full-scale houses in a 70,000 $\mathrm{ft}^{3}$ environmental chamber and to compare the results with the prediction capability of a sophisticated computer program suitable for housing or any type of building.

The approach is to erect ful1-scale houses in an environmental chamber where outdoor temperature profiles could be simulated and controlled allowing data to be gathered efficiently and less expensively than long-term fie]d tests.

The experimental work in the environmental chamber was completed at the end of FY 73. The funds for FY 74 were used to dismantle and move the 4-bedroom townhouse to a site on the NBS grounds and to complete publications. An excellent correlation between actual thermal performance and thermal performance predicted by the National Bureau of Standards Loads Determination computer proqram (NBSLD) was obtained for this lightweight townhouse: The following publications also resulted: Bradley Peavy, Frank Powell and Douglas Burch, "Dynamic Thermal Performance of an Experimental Masonry Building," NBS Building Science Series, No. 45, July, 1974; Bradford Peavy, Frank Powell and Douglas Burch, "Experimental Validation of the NBS Computer Prediction Model for Heating Loads and Indoor Temperature of Buildings," Transactions, American Society of Heating, Refrigerating and Air-Conditioning Engineers, 1974; Bradley Peavy, Douqlas Burch. and Frank Powe11, "Comparison of Measured and Computer-Predicted Thermal Performance of a Four-Bedroom Wood-Frame Townhouse," NBS Building Science Series (in process); Tamami Kusuda, "NBSLD - Heating and Cooling Load Calculation Program" NBS Building Science Series (in process); Tamami Kusuda, "NBSLD National Bureau of Standards Heating and Cooling Load Determination Program," Journal, Automated Procedures for Engineering Consultants (APEC), Winter 1973-1974, p. 4; NBS Technical Bulletin, "Dimensions," Apri1 1973. 
NBS is committed to a program of appliance energy labeling and the personnel, facilities and data available from CBT will be applied to implement this program as a contribution to the overall effort of the nation to conserve energy.

The objective of this project is to provide consultation and laboratory tests for the NBS effort in appliance energy labeling.

Staff experience and data will be made available through consultation. Laboratory energy performance tests on freezers, domestic refrigerators, furnaces, hot-water heaters and other appliances will add to and fill gaps in existing data for the purpose of preparing energy labels for these appliances to guide consumers.

During FY 74 consultation was provided on window air-conditioners . Laboratory tests of performance and energy consumption were done on freezers and domestic refrigerators and letter reports submitted to the NBS Proqrammatic Center of Consumer Products Safety.

During FY 75 laboratory tests on hot-water heaters and furnaces will be performed.
Project Status

Continuing

Project Leader

John W. Grimes

301 921-3521

\author{
Sponsor \\ National Bureau of \\ Standards \\ Project Number \\ $4 6 \longdiv { 2 4 1 4 4 }$ \\ Impact Keywords \\ Effective Regulation; \\ distribution and storage. \\ Technical Keywords \\ Thermal tests.
}

\section{ATTIC VENTILATION}

It was hypothesized that power ventilation of hot attics with cooler outdoor air will reduce the heat gain to rooms below sufficiently to allow a reduction in energy consumption of the building air conditioning system. The Tri-Services are interested in saving energy in existing buildings, as well as the 40 million $\mathrm{ft}^{2}$ of buildings they expect to build in the next 20 years.

The objective of the project was to measure the value of energy savings balanced against the cost of providing power attic ventilation equipment as a quantified input into a decision to equip all Department of Defense attics with summer attic ventilation fans.

The approach was to measure the energy consumption of air conditioning equipment when operated in a building with and without powered attic ventilation. A military barracks at Ft. Myer, Virginia, was used for tests.

Measurements were made and it was determined that energy can be saved by ventilation if the attic floor is not insulated, but savings are negligible if the attic floor is insulated with 6-inch-thick insulation.

These findings were reported in NBS Interagency Report, "Experimental Study on the Effect of Various Modes of Attic Ventilation on Energy Consumption of a Central Air-Conditioning System in a Buildinn," in review.
Project Status

\section{Concluded}

Project Leader
Tamami Kusuda
$301921-3522$

Sponsor

Tri-Services of the Department of Defense

Project Number $4 6 \longdiv { 2 4 4 1 0 }$

Impact Keywords construction; distribution and storage.

Technical Keywords ventilation. 


\section{RETROFIT OF HOUSING TO SAVE ENERGY-- MOBILE HOMES}

Project Status Continuing

Project Leader

Bradley A. Peavy

301 92]-3503

Sponsor

Federa] Energy Agency

Project Number $4 6 \longdiv { 2 6 4 0 2 }$

Impact Keywords Construction; distribution.

Technical Keywords Residentia].
Mobile home sales during 1973 represented approximately $40 \%$ of the sales for single-family dwelling units. For this reason, it is imperative that criteria be established in regards to energy conservation practices for construction and operation of mobile homes. A test plan to achieve this goa] has been implemented at NBS.

The objectives of the project are: (a) to develop design and evaluation criteria for energy conservation in mobile homes; (b) to establish performance and/or design standards for mobile homes, usina eneray conservation technology and its interface with cost, size, weight, and other performance aspects of mobile homes and (c) to compare measured thermal performance with predictive mathematical models.

The proposed study is concerned with energy utilization in heating and cooling a mobile home. The test plan includes the instrumentation and measurement for thermal performance of a full-scale furnished mobile home in the large NBS environmental laboratory. Laboratory measurements wi]l include the determinations for: (a) heating and cooling loads under various outdoor ambient conditions; (b) heat and mass flow paths in the envelope of the mobile home; (c) comparison of measured and predictive results; (d) effect of the moisture accumulation in building elements; (e) effects of retrofitting.

Concurrently, coordination will be maintained with an Industry Advisory Group and with the American National Standards Institute (ANSI) Committee on Mobile Home Standards that is revising current standards.

During FY 74 preliminary air infiltration tests were made on a mobile home scheduled for fire testing. Several meetings with industry and industry associations were held. A test plan was submitted for consideration by NBS staff and industry. Procurement for instrumentation and equipment was initiated. A mobile home on loan for testing was placed in the NBS high-bay environmental laboratory.

Plans for FY $75 \mathrm{call}$ for completion of the single-width mobile home tests in the environmental test chamber; completion of the double-width type mobile home tests in the environmental test chamber; preparation of test report for the single-width mobile home; maintenance of coordination with an Industry Advisory Group to this project; attendance at meetings and active participation in the ANSI Mobile Home Committee currently revising and up-dating ANSI 119. 


\section{GSA ENERGY PROFILE FOR FEDERAL BUILDINGS}

General Services Administration prepared a survey form to gather energy consumption data on Federal Buildings scattered over à wide geographic area and covering several types of buildings such as office buildings, post offices and court houses.

The object was to develop a typical energy consumption profile by comparing a number of buildings of the same type.

NBS was asked to computer input the survey data to determine whether correlation of the enerqy parameters could be deduced. Correlations to a common base unit such as Btu/ft2 per year or per month for energy consumed as electric power, 0il, gas, steam, chilled water were desired.

During FY 74 an analysis was performed on about 100 buildings that had sufficient input data that would allow correlation plots to be obtained and a report was drafted. The range of energy consumption was from 32,000 to over 1,000,000 Btu/year (gross $\mathrm{ft}^{2}$ ) with the average for the buildings at 179,000 Btu/year (gross $\mathrm{ft}^{2}$ ).

A letter report, James P. Barnett, "Energy Analysis of a Federal Buildings Survey for the General Services Administration," was submitted to the General Services Administration.

\author{
Project Status \\ Concluded \\ Project Leader \\ James P. Barnett \\ 301 921-3503
}

\author{
Sponsor \\ General Services \\ Administration \\ Project Number \\ $4 6 \longdiv { 2 4 4 1 5 }$ \\ Impact Keywords \\ Construction; \\ distribution and storage. \\ Technical Keywords \\ Utilities.
}

The objective of this overall study is to establish a measured performance of selected retrofit actions to act as a verification of the different conservation models being used for policy decisions.

Of the many estimates of expected energy savings resulting from specific modifications to houses, few if any are based on controlled measurements. This effort is necessary as a data base upon which generalizations may be built.

The Bowman House's performance is to be measured as is. Selected modifications, such as additional insulation, solar shading, storm windows, and exchanging the oil furnace with a heat pump, will be carried out with intermediate measurement periods to evaluate individual actions.

Baseline winter tests establishing the performance of the house "as is" have been completed. Modifications for the first series of retrofit actions, including installation of the heat pump, have been completed.

In FY 75 this research will be included in the Federal Eneray Agency project, Retrofit of Housing to Save Enerqy--Bowman House. 


\section{RETROFIT OF HOUSING TO SAVE ENERGY, BOWMAN HOUSE}

Project Status

Continuing

Project Leader

Douglas M. Burch

$301 \quad 921-3521$

Sponsor

Federal Energy Agency

Project Number $4 6 \longdiv { 2 6 4 0 0 }$

Impact Keywords

Construction;

distribution and storage.

Technical Keywords

Residential.
This study will experimentally quantify several energy saving modifications on a nearby, instrumented, residential dwelling, the Bowman house.

Approximately one-fifth of all energy used in the U.S. is used in housing. If a 20 percent reduction in energy use in 10 percent of the existing housing were attained each year for five years, the saving in the fifth year would be 2 percent of the current annual energy use. Since over half of this residential energy is used for space heating and cooling, it is logical to approach this goal through reducing heating and cooling loads and improving the efficiency of mechanical heating and cooling equipment.

The objective of the present study is to quantify the seasonal energy savings that may be achieved by implementing energy saving measures on existing domestic dwellings.

Energy requirements for existing housing could be reduced 10 to 40 percent by adding insulation, tightening up air leakage cracks around door and windows, using storm windows and doors, and using heating and cooling equipment efficiently. Guidelines need to be developed to assist the consumer to evaluate economic trade-offs and to make judicious decisions concerning reduction of residential energy consumption.

The approach is to measure the winter heating and summer cooling energy for an instrumented residential dwelling in an "as is" condition under a variety of weather conditions. Energy saving modifications will be performed in stages, each followed by a winter heating energy measurement. This will permit the separate energy savings for each stage of retrofitting to the quantified. And finally, a summer cooling energy measurement will be performed after retrofitting. A heat pump for heating and cooling will be used to replace the oil-fired warm air furnace now present in the house.

During FY 74, thermographic and smoke techniques were used to locate and identify specific heat and air leaks in the test house in an "as is" condition. A winter heating energy test was performed on the test house and prior-to-retrofit winter data base was established. Separate air infiltration measurements, using a tracer gas technique, were performed. Measured rates of air infiltration were correlated with outdoor wind velocity and the inside-to-outside temperature difference. The thermal behavior of the test house is currently being simulated with National Bureau of Standards Heating and Cooling Load Determination Program(NBSLD). A heat pump system was installed in the test house. The following publications have resulted from the project: Charles Hunt and Douglas Burch, "Air Infiltration Measurements in a Four-Bedroom Townhouse Using Sulfur Hexafluoride as a Tracer Gas," American Society of Heating, Ventilating and Air-Conditioning Engineers (ASHRAE) Transition Paper in Progress; Bradford Peavy, Douglas Burch, Charles Hunt and Frank Powel1, "Comparison of Measured and Computer-Predicted Thermal Performance of a Four-Bedroom Wood-Frame Townhouse" ; NBS Building Science Series in progress; Douglas Burch, Bradford Peavy, and Frank Powell, "Comparison Between Measured and Computer-Predicted Hourly Heating and Cooling Energy for an Instrumented Wood-Frame Townhouse," ASHRAE transition paper in progress.

During FY 75 the following items should be completed: (a) summer cooling test; (b) summer air infiltration measurements; (c) Phase 1 Retrofit (caulking, weather stripping, and sealing leaks); (d) winter heating test; (e) air infiltration measurements; (f) Phase 2 Retrofit (addition of storm windows); (g) winter heating test; (h) air infiltration measurements: (i) Phase 3 Retrofit (addition of awnings, thermal insulations); (j) winter heating test; and $(k)$ air infiltration measurements. 


\section{NEW BUILDING ENERGY DESIGN - AIR SIDE SYSTEM CONTROLS AND PLANNED AIR DISTRIBUTION}

This project was bequn essentialiy to explore ways to minimize energy consumption by treating ventilation and recirculating air.

Since approximately $3 n$ percent of energy used for heating and cooling a building is soent for processing ventilation air, it is very important to desian and operate ventilation systems to attain comfort conditions with minimum consumption of eneray.

The approach is to determine the minimum amount of outdoor air needed for the well-being of the occupants and to develop methods of controlling ventilation rate according to the needs (where and when) of the occupants.

Computer simulation of a planned ventilation scheme to shut off the ventilation air supply in the unoccupied office and laboratory spaces was performed in Building 226 on the NBS campus under three different climate conditions. Results show that important parameters for assessing ventilation are average outdoor temoerature and humidity ratio during the occupied hours. Literature studies for the minimum outdoor a ir reauirement from the standpoint of $\mathrm{CO}_{2}$ and odor have been completed. The following output has also resulted from the project: Input to "Technical Options for Energy Conservation in Buildings," NBS Technical Note 789, JuTy 1973; Tamami Kusuda, prepared request for proposa T, "Energy Instrumentation System for GSA/Manchester Federal Office Building," Tamami Kusuda and John Bean, "Computer Graphics Analysis of Psychrometric Data," 1974, publication in process; Tamami Kusuda, James Hi11, Stanley Liu, James Barnett, and John Bean, "GSA/Manchester Building, An Energy Conservation Demonstration Project." 1974. publication in process; Tamami Kusuda, "NBSLD, National Bureau of Standards Heating and Cooling Load Determination Program," Automated Procedures for Engineering ConsuTtants, Inc. Journa1, Dec.-Jan., 1974; Frank Powel1, "The Manchester, N.H., "Experimental Enerqy Office Building," Proceedings, Energy Conservation Seminar, Orlando, Florida, March 1974; publication in process; "Office Building to Slash Fuel Use," NBS "Dimensions," March 1974, p. 56; Frank Powe11, "A Fresh Look at Fundamental Energy Design Parameters," Energy Conference Proceedings, State of Illinois, Chicago; Tamami Kusuda and John Comerford, "Building Floor Area of the U.S., NBS Interagency Report in review; George Kelly, Tamami Kusuda, James Hill, "Potential Options for Energy Conservation in Building Environmental Equipment," Enqineering Foundation Conference, Aug. 19-24, 1973, Henniker, N.H.; Tamami Kusuda, "Psychrometric Landscape for HVAC Design," 2nd Symposium on Computer for Environmental Design; Tamami Kusuda, "Solar Water Heating in Japan," presented at National Science Foundation Solar Workshof: Tamami Kusuda, CharTes Hunt and WaTter ETTis, "Heat Loss Measurement of Underground Steam Mains," letter report to the Genera 1 Services Administration; Tamami Kusuda, "NBSLD--Heating and Cooling Loads Calculation Program of the National Bureau of Standards," NBS Interagency Report in process; Stanley Liu, Charles Hunt, Theodore Ray, and Jacqueline Elder, "Research, Design, Construction and Evaluation of an Energy Conservation School Building in New York City," Phase I, Pre-Design Analysis, letter report then NBS Interagency Report.

Plans for FY 75 are to draft a summary report on the simulation modeling, and studies on $\mathrm{CO}_{2}$ and odor, to develop averaqe outdoor temperature data during occupied hours for detailed evaluation of planned ventilation schemes; and to quantify alternative schemes in terms of sample comparative case studies to indicate simultaneously optimum balance between reduced energy use, comfort and hei.Tth safety and mutual and long term costs.
Project Status Continuing

$\frac{\text { Project Leader }}{\text { amami Kusuda }}$ 301 921-3522

Sponsor National Bureau of Standards, Federa 7 Energy Agency

Project Number $4 6 \longdiv { 2 4 1 3 7 }$

4626403

\author{
Impact Keywords \\ Conservation; \\ construction
}

Technical Keywords Components, general; educational facilities; high rise buildings. 


\section{EXISTING BUILDINGS' ENERGY ANALYSIS}

\section{Project Status \\ Continuing}

Project Leader David A. Didion $301921-3742$

\section{Sponsor}

National Bureau of Standards, Federal Energy Agency

Project Number 4626133

Impact Keywords Computer utilization; construction; distribution and storage.

Technical Keywords cooling; heating.
Selected buildings are being measured for their energy performance and comparison with a computer model. The data is expected to assist in the planning of retrofit actions for these specific buildings and to some extent, existing buildings of these types in general.

In order to support the Federal Government's Building Energy Conservation Program, it is necessary to establish a data base of existing building energy. As part of this data base, selected buildings and contents should be thoroughly analyzed to determine those factors which may be best altered to have an effect on energy consumption.

The objective of this project is to carry out an energy analysis on several buildings, as a contribution to the data base as well as an evaluation for retrofitting of the special building.

The approach is to model the building with a computer energy program (NBSLD Merriwether) and predict the energy expenditure of the various subsystems (e.g. lighting, cooling, heating, etc.). These predictions are then verified by comparison with grossly metered data as well as subsystem metering (e.g. reheat, thermographic walls, air infiltration).

The NBS campus buildings have been modelled and compared favorable with gross eneray consumption. Specific subsystems alterations are presently being evaluated both by model and experiment. The experiment, which is to measure the enerqy within a given office module, should have summer data verification by September 1974, winter data by December 1974. In addition, an evaluation as to the advantaqes of a computer controlled heating, ventilating and air-conditioning system for the campus is being carried out with Honeywell and Plant Division. These results will be put into final form by September 1974. If these study results indicate significant energy savings, as is expected, it will be recommended that such a control system be installed in one building for measured evaluation. A talk, "Building Energy Analys is," was given June 6, 1974 at the Charleston Naval Shipyard by David A. Didion.

A report of action item evaluations is anticipated for September 30, 1974. However, additional testing on the modules is expected through part of the winter. Also it is hoped that the computer control system will be installed in an NBS building and that an experiment on an entire building will be run to evaluate the advantages of the system. This latter experiment may run into FY 76. 


\section{NEW BUILDING ENERGY DESIGN EVALUATION OF COMPUTER PROGRAMS FOR ENERGY CALCULATIONS}

There are a number of computer programs each of which differs from others in some respects and claims to be useful for estimating annual energy consumption. The objective of this is to evaluate several typical energy analys is programs in terms of accuracy and consistency, not the intrinsic calculation methodology, for the use by Tri-Services.

Since the Proposed ASHRAE Standards "90P-..-" allows energy analysis as an alternative procedure to designing the new building according to detailed guidelines, it is necessary for building officials to be able to choose the energy analysis program which best suits their need from the standpoint of accuracy, cost and deqree of sophistication.

In consultation with Tri-Services engineers, a set of building constructions and heating, ventilatina and air-conditioning systems will be selected. The buildings wiTl be chosen so that recorded monthly enercy consumption data of several years are also available. These data will then be applied to various energy analysis programs to compare their calculated results against the observed energy consumption data.

During FY 75 a contract will be awarded for an architectural/engineering firm to run computer proqrams on the sample buildina.

In addition a comparison of several energy analysis proqrams will be made.
Project Status

New

Project Leader

Tamami Kusuda

301 921-3522

\section{Sponsor}

Tri-Services of the Department of Defense

Project Number $46 \overline{26479}$

Impact Keywords Conservation; construction

Technical Keywords Components, generaT; educational facilities; high rise buildings.

\section{INSULATION IN REFRIGERATED WAREHOUSES}

According to the survey made by the Building Research Advisory Board of the National Academy of Sciences, the majority of the nation's cold storage warehouses are experiencing difficulties in keeping the insulated wall from becoming waterjogged, because of continued water vapor condensation from outside. If the method proposed in this project proves to be successfuT, a large saving of energy is possible for the operations of refrigerated warehouses, in addition to substantial reduction in warehouse deterioration.

The object of the project is to explore the feasibility of drying out wet insulation in cold storage warehouse walls and ceilings by forced circulation of warehouse air.

The IBS apparatus for testing air, moisture, and heat transfer through walls will be used for the conventional glass fiber type warehouse wall with conventional vapor barrier as constructed by the manufacturer's recommendation. First the vapor barrier of the test wall will be intentionaliy punctured in accordance with a predetermined pattern to bring the moisture into the insulation. Then the cold side air will be forced into the insulation by local as well as overall pressurization to see whether condensation in the insulation can be prevented or removed expeditiously.

A test wall was constructed and installed in the ajr-moisture-heat transfer test apparatus and is currently undergoing the condensation phase of the test.
Project Status continuing

Project Leader
Tamami Kusuda
$301921-3522$

Sponsor

Tri-Services of the Department of Defense

Project Number $4 6 \longdiv { 2 4 4 1 1 }$

Impact Keywords

conservation; construction.

Technical Keywords Improvement of buildings; refrigeration. 


\section{EFFICIENCY OF HVAC EQUIPMENT}

\author{
Project Status \\ continuing \\ Project Leader \\ David A. Didion \\ 301 921-3742
}

\section{Sponsor}

National Federal Energy Agency, Nationa] Bureau of Standards

Project Number 4626132

Impact Keywords Construction; distribution and storage.

Technical Keywords cooling; heating.
For the purpose of offering the energy conscious designer a better data bank of heatina, ventilation and air-conditioning (HVAC) performance, the objective of this effort is to establish the relative efficiencies of the existing HVAC systems and selected components. An additional objective is to establish a new test method for evaluating the performance of specific equipment so that the manufacturers data will be a more accurate representation of field performance.

The state of the art of HVAC systems today is such that the inherent performance of a given design is not known. A measurement of a system in the field will not allow for a clear distinction of the system performance from the building shel] performance. Therefore a laboratory evaluation with controlled simulated loads is necessary. For the case of selected component testing, the static performance of HVAC equipment in the lab is not an adequate representation of the actual dynamic load operations they are subjected to in the field. An evaluation method of a more exact simulation is required as well as specific component data.

The primary thrust of this effort is one of engineering quantification and intercomparison of the major types of building HVAC systems in use today. Also since it is desirable to minimize the energy consumption, technical efforts are to be extended to an evaluation of specific pieces of equipment (e.g. heat pumps) which show particular promise for greater efficiency.

The approach is primarily a laboratory effort with hard data and test methods as the product. A HVAC "Tower" in which various types of building systems can be fabricated will be constructed. Performance of these systems will be compared so that system inherent efficiencies independent of the building shell will be known for the first time.

Heat pump studies will be carried on simultaneously both to evaluate test method for part load performance and to optimize heat pump systems (e.g. engine driven, storage system, etc.).

At present the heat pump has been installed within the laboratory and another in the Bowman House.

The HVAC Tower Design is expected to be completed so that the basic equipment can be ordered this fiscal year. The heat pump house winter tests will be completed by March 1975 while the laboratorv evaluation tests are to be completed by the end of the fiscal year. This project is expected to continue for several years. 


\section{MEASUREMENT OF INDOOR RADIATION - PILOT}

Designers of buildings use six primary variables to define the feelina of comfort or discomfort in indoor spaces occupied by humans. These variables are air temperature, relative humidity, air velocity, level of metabolic activity, amount of clothing and mean radiant temperature. Use of the mean radiant temperature as an indication of the entire thermal radiation environment as an intenrated effect does not account for asymmetrical aspects where a person might suffer as a result of one given "cold" or "hot" surface. Sufficient technology to improve the methods by which the radiation environment is evaluated appears to be available.

The purpose of this.project is to analyze the problem and devise an instrument for measuring the indoor radiation environment with a view of future changes to the current theory of human comfort.

During FY 74 a contract was let to Dr. Theodore Benzinger, a private consultant and physician. He conducted the analysis and showed in four progress reports that an instrument for measurement was feasible. A prototype instrument was made in the NBS shops and preliminary tests of its measurement capability were made. In addition four proaress reports on the project were written. $\frac{\text { Project Status }}{\text { Continuing }}$

Project Leader

James E. Hill

$301921-3503$

\author{
Sponsor \\ Nationa 7 Bureau of \\ Standards \\ Project Number \\ $4 6 \longdiv { 2 4 1 4 5 }$ \\ Impact Keywords \\ construction; \\ distribution and storage. \\ Technical Keywords \\ Environmental.
}

\section{HEAT PUMP SPECIFICATION}

The Department of Defense and the United States Air Force is a major builder of housing. Because of the high potential of heat pump equipment for saving energy, an updated specification for procurement was requested.

The object of this project was to update a previously prepared 1969 specification developed by NBS to assure reliability and other beneficial features available in today's technology.

The approach was to prepare an updated draft and coordinate a review by both military users and industry suppliers to insure a reliable and available product for the Air Force.

During FY 74 a draft specification was prepared and it was coordinated with the military and the industrial producers. In addition an NBS Interagency Report by Clinton Phillips, "Unitary Heat Pump Specification for Military Family Housing," is in review.
Project Status Concluded

Project Leader Clinton W. PhilTips 301 921-3741

Sponsor

U.S. Air Force

Project Number $4 6 \longdiv { 2 4 4 1 3 }$

Impact Keywords construction; distribution and storage.

Technical Keywords Heating and cooling devices. 


\section{UNDERGROUND PLASTIC PIPE SYSTEMS}

\author{
Project Status \\ Continuing \\ Project Leader \\ Tamami Kusuda \\ 301 921-3522
}

\section{Sponsor}

Tri-Services of the Department of Defense

Project Number $4 6 \longdiv { 2 4 4 1 2 }$

Impact Keywords Effective regulation.

Technical Keywords Piping systems.
There are several underground pipe systems which do not follow the existing Tri-Service criteria as to their drainability, driability and air-testability. Some of these non-Tri-Service systems will te evaluated for their thermal performance under simulated as well as in-situ test conditions.

The objective of this project is to evaluate new underaround pipe systems which have not yet met the existing Tri-Services criteria that the pipe insulation be driable, drainable and air testable. The evaluation objective is to determine if these non-Tri-Service systems will stay dry under specified test conditions particular to each pipe system.

The existing Tri-Service criteria are applicable only to a conduit system which has air space between the insulation and the conduit. There are, however, many new underground systems, especially the plastic pipe systems, which do not have the air space. The representations are that these systems are so completely water tight that there is no need for the requirement of drainability, driability and air testability. It is the interest of TriService as well as other government agencies to verify these claims.

Each different underground pipe system requires different testing procedures. Appropriate tests will be devised for each of selected pipe systems to see how reliable is the water tightness performance and to determine if the water, once brought in, can effectively be removed by the circulation of air or other inert gases.

So far three non-Tri-Service pipe systems have been tested in the laboratory and two systems were studied in the field by excavating and taking an insulation sample from the pipe system. Of the systems studied in the the laboratory, one used hygrophobic powder to fill in the space around the pipe in the trench; the second cellular glass insulation around the carrier pipe in the conduit; and the third calcium silicate insulation around the pipe encased in the cement asbestos conduit with polyurethane intermediate layer.

In November 1973, NBS sponsored a symposium for underground heat and chilled water distribution systems which attracted eleven technical papers and 100 participants throughout the country. The proceedings for this symposium will be published during the fiscal year.

The following output resulted: Tamami Kusuda and Halter Ellis, "Laboratory Investigation of Three Underground Pipe Systems," letter report to TriServices; Tamami Kusuda, "Heat Transfer Studies of Undercround Heat and Chilled Hater Distribution System," Symposium for Underqround Heat and Chilled Water Distribution System, NBS, November 1973; Tamami Kusuda, Walter Ellis and Chock Siu, "Heat Transfer Study on a Heated and Uninsulated Underground Pipe," report to the Tri-Services, General Services Administration, Veterans Administration and Atomic Energy Commission; Tamami Kusuda and Chock Siu, "Report on the Field Investigation Made on Underaround Condensate and Chilled Water Lines at Five Military Bases," Letter report to the Tri-Services.

During FY 75 reports on three non-Tri-Service Systems will be completed.

Design of pipe test apparatus where the heat transfer, thermal stress and external force systems will be studied together.

It is expected during FY 75 that several field trips will be made to observe the onsite performance of non-Tri-Service underground systems. 
This work is needed by industry and the public to provide a reliable technical base for standards and specifications and to fulfill the primary measurement mission of NBS. The methods developed and the performance results achieved find immediate application in the solution of national problems such as the conservation of energy and control of pollutants while maintaining a reasonably comfortable and clean environment.

The objective of this report is to simultaneously develop several methods of measurement through applied research that can be used in NBS research projects and by others in the field of building technology. To conduct tests to determine the mechanical and electrical performance of systems as used in buildings of all types and to determine the heat and moisture transfer characteristics of the shell of a building.

Mechanical and electrical performance tests will also be conducted on prototype refrigeration components and systems for the U.S. Army Natick Laboratories to determine the provisions for specifications used in mass procurements of these items.

During FY 74 the construction (by NBS machine shops) of the hot and cold plates and part of their supporting elements of a new guarded hot plate apparatus was initiated; an infrared thermographic system was used to identify heat leaks in a four-bedroom townhouse; to survey inside and outside temperatures in the Bowman house; to investigate temperature distribution on the external side of an inflatable building; and to relate heat leaks to the thermal quality of newly built buildings at Twin Rivers, New Jersey; ASTM draft standards on measurement methods and testing procedures for insulating glass units were completed incorporating the dewpoint measuring instrument invented and developed at NBS in this program. A Targe roundrobin testing program was initiated to evaluate the draft standards; and at the request of Natick a series of performance tests on prototype refrigeration compressors, self-contained refrigeration systems and portable walk-in size freezer rooms were completed. Performance tests were also completed on several prototype ice-making machines and on a mobile selfcontained kitchen. The following publications and outputs resulted from this research: "The Robinson Line-Heat Source Guarded Hot-Plate Apparatus," Manhee H. Hahn, H.E. Robinson, and Daniel R. Flynn, American Society for Testing and Materials (ASTM), Special Technical PubTication (STP), 1974; "What Property Do We Measure" and ASTM C-1630 Committee paper (William L. Carrol1 of 462.01 participated in its preparation) ASTM STP, 544, 1974; Dimensions, NBS Technical News Bulletin, March 1974. The following papers have been prepared and currently in NBS review. C.I. Siu, W.L. Carro]T. and T.W. Watson, "Thermal Conductivity and Electrical Resistivity of Six DiTute Copper ATToys and Comparison with the Smith-Palmer Equation." For submission into: Transactions MetaTTurgical Society of American Institute for Metallurgical Engineers; Charles M. Hunt and Douqlas M. Burch, "Infiltration Measurements in a Four Bedroom Townhouse Using SF6 as a Tracer," for submission into ASHRAE Transactions; Charles M. Hunt "Air Infiltration Measurements on the Four Bedroom Townhouse" as part of a paper by Bradford A. Peavy, DougTas M. Burch, Frank J. Powe11, and Charles M. Hunt, "Thermal Performance of a Four Bedroom Wood-Frame Townhouse" prepared as a Building Science Series Publication; Tamami Kusuda and James Hil1, "Dynamic Characteristics of Air Infiltration," NBS paper; George E. Kelly and David Didion, "A Laboratory Test of the Modular Concept as Applied to Fas-Fired BoiTers," NBS paper; Tamami Kusuda, and Chock Siu, "Earth Temperature Data for Underground Installations in the United States," NBS Building Science Series.
Project Status

Continuing

Project Leader

Frank J. PowelT

301 921-3501

Sponsor

National Bureau of

Standards, American

Society for Testing

and Materials, Department of Housing and Urban

Development and U.S. Army Natick Laboratories

Project Number $46 \overline{24140}$

Impact Keywords Construction; distribution and storage.

Technical Keywords Thermal test. 
During FY 75 a new and improved guarded hot plate apparatus for use as an absolute method of measurement of the thermal conductivity and thermal conductance of thermal insulation and building materials will be developed. This apparatus is to replace the present apparatus (circa 1937) currently defined in American Society for Testing and Materials (ASTM) Standard C177. Current methods and equipment are used as the national reference for supplying calibrated specimens to other laboratories in the U.S. and in several foreign countries and are used to measure materials for NBS and other governmental agencies. Techniques for applying an infrared thermographic system to determine temperature patterns and energy leakage paths on the inside and outside surfaces of the exterior walls of buildings, an instrument to scan the rooms of a building to determine acceptability for human occupancy in terms of human thermal comfort, and methods of measurement and draft standards via the ASTM Research Associate programs on the integrity of sealed insulating glass units for long-term use in buildings will be developed. Measurement of the dewpoint of the air in these units is used to indicate integrity and durability of the seals when subjected to the accelerated tests and in-situ tests.

\section{INTEGRATED SOLAR ENERGY SYSTEMS}

\author{
Project Status \\ Continuing \\ Project Leader \\ James E. Hi]T \\ $301 \quad 921-3503$
}

\section{Sponsor \\ National Bureau of \\ Standards \\ Project Number 4624141 \\ Impact Keywords conservation}

Technical Keywords Solar heat radiation
Efficient and economical collection, storage and use of solar energy can make a substantial impact on the ever increasing demands for energy in the U.S. and thus better distribute the existing supply of energy.

The objective of this project is to obtain technical information concerning the amount and freouency of solar radiation, to devise means to determine the performance of solar collectors, storage devices and equipment as parts of an integrated system for distributing collected energy in order to compare techniques, to perform system economic analysis and to estimate the impact solar energy can make in satisfying our national need for energy in buildings.

The planned approach is to devise a system of measurement to quantify and qualify performance of solar energy systems for buildings, retrofit an existing 4-bedroom townhouse with the solar eneray systems, and study the economy implications.

During FY 74 the four-bedroom townhouse was moved from the laboratory to a field site on the NBS grounds. Instrumentation was reinstalled and check measurements under winter weather conditions were made including air infi]tration tests and infrared photograph. An addition was built to house instrumentation and to serve as a simulation of a next-door neighbor's house. A solar eneray measurement system, and test plans, were devised. A specification for a solar energy collector and storaqe system was prepared and purchase orders were placed. Plans for performing the experiments were also completed. The following publications resulted: Tamami Kusuda, NBSLD National Bureau of Standards Heating and Cooling Load Determination Program," in process; Bradley Peavy, Douglas Burch, Frank Powe11, Charles Hunt, "Comparison of Measured and Computer-Predicted Therma1 Performance of a Four Bedroom Wood-Frame Townhouse," in process; Frank Powe1], James Hil1, 
Tamami Kusuda, Stanley Liu, "An Approach to Determining the Need for Air Conditioning by Using Building Thermal Responses"; Frank Powe11, Douglas Burch, Bradley Peavy, "Experimenta] Validation of NBSLD, NBS Computer Prediction Model for Heating Loads and Indoor Temperatures of Buildings," NBS publication in process; Douglas Burch, Bradley Peavy, Frank Powell, "Masonry Building Heat Transfer Experiment," American Society of Heating Ventilatina and Air-Conditioning Engineers (ASHRAE) Transaction Paper; Stanley Liu, "Survey and Analys is of Building Data for Classification of Buildings," NBS Interagency Report in process; James Hi11, Tamami Kusuda, Stanley Liu, Frank Powel], "Air Conditioning Criteria," NBS Building Science Series in process; Douglas Burch, Bradley Peavy, Frank Powe]], "Town House Tests, "ASHRAE Transaction Paper in process; NBS "Dimensions," March 1974.

\section{PEOPLE AND BUILDING FIRE SAFETY-OMONITOR}

Fire safety research has been very much a "hardware" and physical science activity. Our recent work indicated the importance of considering the human element as well--especially the occupant. Considerable gains in safety can be achieved when a meaningful and timely input can be provided by behavioral scientists. To some extent, this is a problem of information transfer--much useful data is avajlable but unfortunately not applied to fire safety problems.

The objective of this project is to provide behavioral science expertise to the Center for Fire Research in their research programs--assist in proaram development, contract monitoring and coordination of NBS programs with other ongoing programs concerned with occupant safety in building fires.

We will be responsive to the needs of the Center for Fire Research for monitoring, coordination, participation in meetings and providing behavioral science input to their programs as required.

A number of proposals were reviewed and evaluated, and one contractor selected, to perform work this fiscal year. Assistance was provided to General Services Administration (GSA) in the development and testing of the communications systems in the Seattle Federal Building. A NBS Technical Note 818, "Occupant Behavior in Building Fires," by Arthur Rubin and Arthur Cohen, was completed.

We will monitor a contract recently awarded to Dr. Bryan of the University of Maryland. We will maintain close contacts with GSA engineers responsible for fire safety and continue to be responsive to requests for research and design assistance. $\frac{\text { Project Status }}{\text { Continuing }}$

Project Leader Arthur I. Rubin $301 \quad 921-2177$

Sponsor
National Bureau of
Standards
Project Number
4620766
Impact Keywords
Disaster mitigation;
fire research.
Technical Keywords
Behavioral science;
man-machine system.




\author{
Project Status \\ Continuing
}

Project Leader Charles A. DougTas Robert L. Booker

30] 921-2177

Sponsor

Federa] Aviation Administration

Project Number $2 2 \longdiv { 1 5 1 7 }$

Impact Keywords Aeronautics; safety

Technical Keywords Air to ground cormunications;
Transportation as an element of our national life is of ever-increasing importance. Each increase in size, speed, or number of aircraft increases the risk of accident. Accidents have not increased more rapidly than they have in part because of continual improvement in the visual signalling systems which are an essential element in the control systems governing air transportation.

The objective of this project is to provide the sponsor with technica] assistance on all aspects of visual signalling as related to air transportation.

NBS has been directly involved, for over 39 years, in the development of instrumentation and concepts relating to Runway Visual Range (RVR). Much of the NBS work has never been sufficiently documented. The sponsor has requested that a manuscript be prepared on the Development and Application of the Runway Visual Range Concept.

Sometimes NBS is required to respond to the sponsor's needs and initiate a task on very short notice, for example the problem of color desaturation of the orange paint used for marking tall towers.

Approximately one-half of RVR manuscript has been completed in draft form. Acceptable limits of fade (color desaturation) for the orange paint used in marking tall towers and structures has been investigated. A test report on partial findings has been issued. The relative annoyance of different flickering/flashing light patterns of gaseous discharge lights under development for marking the presence of towers has been investigated and a test report issued. In addition, a talk, "A Computer Program for Computing Effective Intensity," was given by Gerald L. Howett, at the Symposium on Visual Signallina, Washington, D.C., April 1974.

During FY 75 plans are to complete draft of RVR manuscript; establish definitive limits of fade for orange paint; draft NBS report; evaluate recent German work in color recognition of flashing lights for possible effects upon present visual signalling systems; and plan and conduct further investigative work if necessary. 


\section{LIGHT QUALITY: VEILING REFLECTANCE}

One of the most important determinants of lighting quality is the geometric distribution of light flux and the resulting veiling reflectance (reflection that partially obscures the details to be seen by reducing contrast). A high quality lighting system at lower 1uminance levels can be more effective visually than a system with poor geometric distribution at higher luminance levels. The current most popular technique to measure lighting quality relies on a human observer as the measuring instrument. A purely physical technique should be developed. The literature cites 3 instruments that were proposed, but evidently did not receive wide acceptance because of inherent weaknesses.

The objective of this project is to develop an instrument that can be used in the field to measure the relative amounts of veiling reflectance resulting from the lighting system.

Rather than measuring the geometric distribution falling on a surface, the light flux reflected from the surface wi71 be measured. Two sets of measurements will be taken. In the first, a totally diffusing and totally reflecting surface will be placed at the work surface under the lighting system to be tested. The value will be the total luminous flux falling on the surface from all directions. In the next step a porcelain or black glass sample having high specular reflectance will replace the diffusing surface, in order to obtain the directional light flux. The ratio of directional flux to total flux will give a relative measure of veiling reflectance. Funds will be transferred to the Institute for Basic Standards (IBS) for calibration of reflecting samples and to provide assistance in solving theoretical and practical problems associated with applying reflection photometry principles to veiling reflection measurements.

The feasibility of the technique described above was' discussed with experts at IBS. They are interested in the problem and feel that the technique looks promising. The use of integrating spheres instead of reflecting samples were discussed and the former approach will a 7 so be pursued.

During FY 75 plans are to design a measurement instrument, test a mock-up of it and have it constructed by the Shops Division. 


\section{NOISE IN AND AROUND BUILDINGS (CBT)}

\section{Project Status Continuing}

Project Leader Arthur I. Rubin $301921-2177$

\section{Sponsor \\ Nationa 1 Bureau of Standards}

Project Number 4624162

Impact Keywords Environmental hazards; hea 1 th; housing.

Technical Keywords Behavioral science; building acoustics; design, other.
Government agencies such as Environmental Protection Agency, Department of Housing and Urban Development and Department of Transportation have indicated that noises experienced by building occupants are the most widespread problem faced by noise researchers. Attitude surveys have indicated that impact noises particularly are a major source of complaint in residences. At present, there is considerable controversy concerning the appropriateness of the most widely used test method employed to measure impact sound. Many researchers and designers want another procedure to be developed--one which can readily be associated with normal use conditions and is substantiated bv human response data. The current method is judged to be weak in both of these respects.

The human response data base is questionable in the area of impact sounds. Very few studies have been performed to test the adequacy of the widely used methods of rating materials (sound transmission classes - STC) or spaces (noise classifications, NC curves). As a result, rating schemes are in widespread use, which are subject to criticism from the standpoint of performing the function that they were designed for.

The objective of this project is to develop an improved procedure, employing physical and human response data, to evaluate impact sounds, and acoustical rating schemes now in general use.

Psychophysical studies of impact and other household sounds will be initiated using recorded sounds from actual buildings. Physical and human response measurements will then be made, and the findings correlated. An analysis of the characteristics of the sounds will be performed to identify the "basic" human response parameters. Analyses will also be conducted to evaluate several acoustical rating schemes with respect to their accuracy and consistency in describing human responses to building noise.

A state-of-the-art report on impact sound was prepared under contract. An "impact sound" test chamber was designed and constructed. Initial investigations were performed to determine the acoustical properties of the chamber.

During FY 75 a report is being prepared which summarizes the design of the chamber as well as the initial acoustical findings. The first of the noise studies correlating physical and behavioral data, will be performed. 
The basic objective of the overal] project is to improve the effectiveness as signals, of warning lights and sirens used on police and other emergency and semi-emergency (service) vehicles. CBT activity is more involved with lights.

Emergency vehicles making high-speed runs sometimes have (or cause other vehicles to have) accidents while trying to make their way through traffic. Frequently, these accidents could have been avoided if the flashing lights and sirens of the emergency vehicles had alerted the "civilian" drivers at a great enough distance. Drivers frequently do not hear the sirens or see the lights until it is too late to take evasive action. Improving the effectiveness of these warning devices should reduce these accidents and also reduce the time needed to complete emergency runs. This project was the product of police concern, but will also be useful to all the fire departments and ambulance corps throughout the nation.

Three types of documents are to be published and widely distributed as part of the effort to achieve the objective. These are voluntary performance standards for warning lights and sirens; guidelines explaining the standards and giving advice on selecting equipment of superior effectiveness; and state-of-the-art reports summarizing knowledge in all phases of the subject, but emphasizing the perceptual factors entering into the determination of device effectiveness. A limited number of physical and perceptual tests were conducted.

All three planned documents, with respect to lights, were in various stages of editorial review at the end of FY 74 . These include a standard for lights, a state-of-the-art report on lights, and a guideline covering both lights and sirens. Because of the quite limited scope of the testing program carried out in earlier years, it seemed inappropriate to prepare reports of these tests for public distribution. An informal report on the physical tests of lights was communicated to the sponsor, and an informal report of the exploratory perceptual tests of the lights is in preliminary review. With the issuance of the formal reports and the transmittal to the sponsor of the informal psychophysical test report, the project will be completed. The project's major accomplishments are embodied in these final reports, plus an earlier, preliminary state-of-the-art report on both 1 ights and sirens, which has proved quite popular since its publication.
Project Status Concluded

Project Leader Avery T. Horton 301 921-2177

\section{Sponsor}

Law Enforcement

Assistance Agency

Project Number $40 \overline{094} \overline{10}$

Impact keywords Automobile; highway; law enforcement.

Technical Keywords Emercency communications; signal devices; signal lights; vehicular communication. 


\section{THERMAL "COMFORT" MEASURES IN BUILDINGS}

Project Status

Continuing

Project Leader Arthur I. Rubin

301 921-2177

Sponsor

National Bureau of

Standards

Project Number $4 6 \longdiv { 2 4 1 6 5 }$

Impact Keywords Conservation; health; housing.

Technical Keywords Environmental; residential; ventilation.
The growing acceptance of the performance concept has identified the need for upgrading the available data base associated with user requirements in buildings. As an initial step in the process of improving these data, a state-of-the-art survey was made of measurement techniques in the human sciences which might be applied to this problem. An evaluation of these techniques has indicated that an important area needing further study (especially from the standpoint of energy conservation) is that of thermal comfort. Past investigations have concentrated primarily on laboratory measurements of physiological responses. However, it is also necessary to collect behavioral data, both in the laboratory and in the field, in order to supplement these physiological findings. This project is designed to develop improved methods of obtaining psychological data which can be then correlated with the physical and physiological findings available. Initially, the emphasis will be on field investigations.

The objectives of this project are to develop and test field methods of collecting psychological data associated with the thermal environment.

An understanding of "thermal comfort" consists of the

integration of three sets of measurements--physical, physiological and psychological. Up until very recently, most investigations in this study area have been directed toward collecting physical and physiological data. The objective seemed to be to treat human subjects as "black boxes" where thermal comfort could be explained in terms of a simple input (physical) and output (physiological) device--with some rather simple transformation within. Within the past few years there has been a recognition among researchers that behavioral data are also required if we are to understand how people respond in realistic settings. Current building design recommendations related to the thermal environment are almost entirely based on these earlier physiological data. The concern for energy conservation has raised questions about the adequacy of thermal design associated with ventilation, among other parameters. Very limited field validation data has been collected to evaluate current practices. It is therefore difficult to determine whether these practices ought to be modified, and if so, on what basis.

During FY 74 a report, "User Requirements in the Home-Data Collection Methodology: A State of the Art Report," was completed by Arthur Rubin and Jacqueline Elder and is now in review.

During FY 75 a review and analysis of laboratory and field research dealing with thermal comfort will be undertaken based on field visits with researchers, correspondence, and a literature review. Working closely with the Feneral Services Administration and the Federal Energy Agency, a field survey investigation will be planned. The approach will be to collect physical and behavioral data concurrently, to the extent possible. The evaluation study of methodologies initiated last year will be completed. 
Color coding is a commonly applied method for rapidly communicating safetyrelated information. Many government agencies and trade associations have developed over the years their own sets of colors for use in identifying different cateqories of traffic signs, warning labels, etc. Most of these color codes contain, for example, a red, but the exact "shade" of red prescribed is not the same in all the codes. This project aims at encouraging all these groups to choose their colors from a sinq]e, limited set of precisely defined colors with explicit meanings. Widespread adherence to the single combined safety-color code will progressively improve the rapid and universal recoanizability of these colors in all contexts, thereby resulting in fewer accidents, injuries and death. It has long been known that the standard procedure (used in photometers) for calculating the total luminous output of a light lead to errors that are sometimes quite serious. Development of a more accurate formula, and instruments based on it, will not only advance photometric science, but will permit realistic comparisons by lighting engineers of the outputs of different types of light sources, and possibly will permit energy savings by encouraging the replacement of lights now overrated in visual effectiveness by fewer liahts of greater true effectiveness.

The long-range objective is the continued development and application of color science and technology with the aim of optimizing the use of color in the promotion of safety, communication, visual comfort, and esthetic satisfaction. There is a division into two basic sub-areas: surface color and illumination color. Current medium-term project objectives in these respective sub-areas are: (a) development of a master set of surface colors for all safety-coding applications, including cooperation with standardizing and user organizations; and (b) evaluating current standard method for measuring amount of light, which is being questioned by technical and industrial orqanizations as well as standards bodies.

In cooperation with the orqanizations interested in using the combined code, exact colors will be included. A decision will be made as to how much deviation in hue, saturation, and lightness is considered an acceptable match for the standard colors by the principle cooperating groups. Charts will be painted for each color in the set, showing the standard color and colors representing the summaries of the reqion of acceptable match to the standard. The long-range effort will be divided into several phases. These will include investigation of brightness difference between equally luminous lights (by present standards) of different chromaticities; "brightness" differences on task performance; measures of acceptable color saturation; development of a formula for "equivalent luminance" which agrees with perceptual data. In the current phase, equipment permitting direct side-by-side comparison of the brightness of different lights will be designed and built. Lights of several colors will be intercompared in brightness. The order of magnitude of the error in present luminance assessment wi]l be specified for current available light sources.

Specifications for the colors in the new combined safety-color standard were drawn up, and technical cooperation in the production of actual color samples was carried through to completion. Technical collaboration was provided to several government agencies and American National Standards Institute committees in drawing up standards referencing the combined safety colors. A first draft of a revised article on the Universal Color Lanquage, to be included in a new edition of NBS Circular 553, the InterSociety Color Counci]/NBS Color Names Dictionary, was prepared by Kenneth L. Kelly. A paper, "Uniform Perceptual Scales of Color: Relation Between Munseil and Swedish 'Natural Color System Scales, " was submitted to the Journal Optimal Society of America for publication. The work on illumination color is new in the current fiscal year. Encouragement from the NBS photometry aroup to undertake the proaram was extended last year. In addition, an NBS Special Publication 393, "Colorimetry and Spectrophotometry: A Biblioaraphy of NBS Publications January 1906 Throuah January 1973," was completed by Kenneth L. Kelly and published in April 1974.
Project Status

continuing

Project Leader

Gera]d L. Howett

$301 \quad 921-2177$

Sponsor

National Bureau of

Standards

Project Number $46 \overline{24161}$

Impact Keywords communications; safety.

Technica] Keywords Behavioral science; design, other; illumination. 
During FV 75 several technical publications and an NBS report to consumers, "Color and the Consumer," is planned. Brightness-comparison equipment will be desianed and constructed.

\section{EXTERIOR ENVELOPE DESIGN-FENESTRATION}

Project Status

\section{Continuing}

Project Leader Arthur I. Rubin $301 \quad 921-2177$

Sponsor

National Bureau of Standards

Project Number $46 \overline{24164}$

Impact Keywords Esthetics; conservation.

Technical Keywords Architectura], cost; solar heat radiation; windows.
The heat transfer characteristics of the exterior envelope of a building is a major determining factor of the amount of energy consumed within the buildina. An examination of the typical building shell from the standpoint of energy efficiency indicates that windows have the least desirable heat transfer characteristics among the various components of the she11. In order to save energy therefore, it is desirable to minimize window size. However since windows are generally desired by building occupants, it is necessary to first determine in a systematic way what functions they perform and then estimate what size is consistent with meeting necessary window raquirements. It is anticipated major energy savings will be possible when objective criteria for windows are developed.

The objective of this project is (a) to make an initial estimate of the costs (economic and energy) and the benefits (psycholoqical and architectural) of windows in office buildings; (b) to estimate the minimum and maximum sizes of office windows from an architectural and psychological standpoint; and $(c)$ based on architectural and psychological criteria of window size, and economic information on window glass, calculate energy usage employing the NBS Load Determination (NBSLD) for a range of exterior envelope designs, and life cycle costs associated with the proposed design.

An interdisciplinary investiqation is underway to achieve the stated objectives. The research strategy is to first concentrate on those subject areas least understood-psychological and architectural criteria for windows which ultimately can be translated into window size. When window sizes can be estimated, NBSLD program will be employed to determine energy usage associated with proposed designs. 
During the first phase of the program, a literature search of the psycholoqical aspects of windows was performed. This provided an overview, but little quantitative information that could be used in design. Since little systematic work has been performed on window design--which differs considerably in accordance with building usage--we are concentrating our effort on office buildings. A literature search of the architectural concerns for windows and the identification of "window parameters" will be performed. These parameters will submitted to thermal engineers and economists to be incorporated into their investigations of energy and dollar costs (respectively). While this work is being performed, there will be a periodic assessment of the NBSLD program to determine whether the architectural and economic data requirements dictate any modification of the existing program - - if so, it will be modified accordingly. Pilot and field investigations will be performed to collect information on the psychological requirements for windows. During these studies, close cooperation will be maintained between the psychologists and architects working on the problem. Questionnaire surveys will be administered and physical measurements taken concurrently (to the extent feasible). The field investigation will entail outside contracting if a "sizable" study is to be performed.

At the conclusion of the field study, a first quantitative estimate of office window size will be made, permitting an energy analysis employing the NBSLD. Concurrently, an economic analys is will be performed. Both the psychological and architectural estimates will be on the basis of the literature searches performed, the field study and judqment. It is quite conceivable that the psycholonical and architectural estimates will differ from one another.

Several calculations were prepared to provide basic data needed for estabblishing criteria for energy conservation by varying the area ratio and thermal resistance values of various elements of the exterior envelope. A table of annual profiles of monthly averaqe sol air temperatures was prepared for use in economic analyses; a general architectural guide was prepared which outlined some of the major oarameters to be considered when desiqning windows in office buildings, an initial step in the follow-up study to be undertaken this year; a state-of-the-art review of psychological studies of windows was drafted and is now in section review.

During FY 75 a literature review of architectural design of windows will be completed. A number of pilot investigations will be performed to identify "window variables" and refine a questionnaire to be used in a field survey. An economic analysis of windows will be performed with major variables being identified with the assistance of architects. A field investiqation will be planned, and conducted. The design of both the pilot and field studies will employ psychological research techniques combined with architectural insights. 


\section{Project Status Continuing}

Project Leader Gary T. Yonemura 301 921-2177

\section{Sponsor \\ $\mathrm{NationaT}$ Bureau of Standards \\ Project Number $4 6 \longdiv { 2 4 1 6 0 }$}

Impact Keywords Conservation; housinq; safety.

Technical Keywords Behavioral science; illumination; residential; windows.
To validate an earlier study which suggests that currentiy recommended illumination levels in buildings are based on an inappropriate experimental approach

Artificial illumination consumes a substantial amount of the total power requirements in buildings. The levels of illumination now recommended for buildings are largely the result of investigations employing one particular methodology. At present many architects and building managers are questionino the appropriateness of the illumination levels in common use--they think that they are too high. The "hard data" available does not support this assertion. Our initial study suggests that the lighting levels might be too high, but verification of these findings is required before these results can be expected to have widespread acceptance. If follow-on studies do demonstrate that lower lighting is appropriate, major savings in terms of eneray and costs are Tikely to occur when these findings are transformed into design specifications and building codes. The most immediate impacts might be through the General Services Administration, Federal Eneray Adencv and the National Conference of States on Codes and Standards.

The stimuli in the study currently underway are alpha-numerics instead of the gratings used in the earlier NBS study. Observers will be asked to equate Lebenson Charts (alpha-numerics) at different luminance and contrast levels for equal clarity, the procedure used in the earlier study with gratings. The results will be presented as equal clarity contours, the physical variables plotted being contrast and Tuminance. Two additional parameters, font size and initial contrast levels, will also be investiaated. The fol Towing research phase will employ images produced on a cathode-ray-tube. This technique greatly simplifies manipulation of the parameters. The visual targets (sine-, square-, and sawtooth waves) will be generated by two independent signal generators and fed to a high resolution television monitor via a control console. The control console will linearly vary the contrast and luminance of each of two grating patterns independently, at several frequencies.

During FY 74 the stimuli for the validation study, photographic reproductions of the Lebenson Eye Charts (alpha numerics) were reproduced and calibrated at 36 levels of contrast for each of two levels of background reflectance. A viewer which permitted experimental control of view, viewing distance and luminance levels was constructed and calibrated. Preliminary experimental trials were run and minor apparatus difficulties were identified and corrected.

"Clarity of Grating" is being reviewed for publication as an NBS Interanency Report and "Imaqe Quality Criterion for the Ientification of Faces" is heinn reviewed as an article for the Journal of Photographic Science and Encineering, in review.

During FY 75 plans are to complete experiments, analyze and interpret data, and submit manuscript for editorial review. An apparatus to electronically produce arating patterns being developed by the Measurement Engineering Division, IAT, should be welT on the way to completion. 
The long-range objectives of the project are to develop (a) realistic performance criteria and test methods, and (b) general computational methods for design and performance evaluation. The most important current objectives are (a) the development of recommended test methods and reporting formats for discharge characteristics of plumbing fixtures and appliances, and (b) the development and analys is of fundamental performance data for the dynamic flow phenomena in multistory drainage stacks of various designs.

The work is needed to provide a scientific basis for criteria and evaluation techniques that will (a) facilitate the acceptance of innovative hydraulic designs, and (b) significantly reduce quantities of materials or consumption of water and/or energy. Regulatory groups, contractors, designers and manufacturers are interested in the output from this program, and the achievement of adequate performance with reduced cost and minimum resource consumption will benefit the building owner and occupant. The results will significantly contribute to effective NBS input in national and international standards and into the national model codes and the specifications used by other governmental agencies.

During FY 74 an approach for studies during FY 75 has been formulated. Mathematical models, reproducible test methods, and user-oriented/based performance criteria will be developed from laboratory experimentation under controlled conditions. From this information, computer aids will be developed to facilitate the computational prediction of hydraulic performance of a broad range of designs based on a minimum of testing. For example, recent work has involved laboratory trials to formulate methods for measuring and reporting: (a) the most significant performance characteristics of plumbing fixtures/appliances in terms of their loading effect on the drainage system, and (b) the quality of the hydraulic performance of several types of drainage systems in terms of fluid emissions, design parameters, and construction or site-related variables. The laboratory results are to be compared, where feasible, with predictions by a computer program, and the computer program is to be improved and expanded on the basis of the laboratory data.

During FY 74 results from laboratory tests made on systems with reduced size vents at CBT and Stevens Institute were reported. Significant data were obtained in preliminary experiments at CBT to develop reproducible test procedures and reporting formats for the discharge characteristics of a drainage system representing a non-proprietary, innovative design. Preliminary exchanges were made between CBT, Stevens Institute, and the Building Research Establishment comparina computer-aided predictions and actual measured performance in selected drainage systems, and comparing a]ternative measurement techniques for representive transient, two-phase flow.

The findinas have shown that: (a) satisfactory hydraulic performance is attainable with venting reduced significantly below current code requirements, (b) performance is affected by the discharge profiles of the fixtures and by the geometry of the traps, and (c) present code criteria need to be modified to realistically address the fundamental needs of the user and to correlate the measures of these needs with the system design and installation parameters.

The following outputs resulted: publications, (1) R.S. Wyly and M.J. Orloski, "Studies of Reduced-Size Venting of Sanitary Drainage Systems in the USA," CIB W62 Commission, Stockholm, Sweden; (2) J.E. Sne11, "Comments on Drainage System Performance," CIB W62 Commission, Stockholm Sweden - talks, (1) R.S. Wyly, "Plumbing Research Activities at the National Bureau of Standards," American Society Civil Engineers, Los Angeles, California; (2) R.S. Wyly, "Some Relationships Between the Physics of Plumbing Systems and a Workable Performance Code for Plumbing," Texas State Association of Plumbing Inspectors, Dallas, Texas; (3) J.E. Snell, "Evaluation of Gravity Drainage Systems," American Society Sanitary Engineering, Oak Brook, I llinois. (4) M.J. Orloski, "How NBS Programs Facilitate the determination of Acceptance of Innovative Approaches in Plumb-

\author{
Project Status \\ Continuing
}

\author{
Project Leader \\ Robert S. Wyly \\ 301 921-3293
}

Sponsor
National Bureau of
Standards

Project Number 4624190

Impact Keywords Construction; qua 1 ity control.

Technical Keywords Design, other; piping systems; sanitary service; innovative systems evaluation. 
ing," Virginia. Plumbing Inspectors Association, Martinsville, Virginia - other, (1) on request by the American Society of P] umbing Engineers, by the Copper Development Association and by ANSI A40 substantive presentations were made at IIBS on four occasions by L.S. Galowin, M.J. Orloski, and/or R.S. Wyly; (2) talks no. 1 and 3 above were submitted for review as publications, (3) substantive exchanges were completed between CBT, Stevens Institute, and the Building Research Establishment of the United Kingdom, pursuant to a collaboration agreement between CBT and CRE; and (4) R.S. Wyly, assisted by J.E. Snell and L.S. Galowin, actively participated in a task group effort that produced a Position Paper of the U.S. Counterpart Commission to CIB W62, entitled "Water Distribution and Supply within Buildings - National Research Needs."

With the aid of a capital equipment funds, significant progress was made in completing needed improvements in the laboratory facilities.

Largely through CBT leadership, a U.S. Counterpart Commission W62 (to the Internationa] Counci] for Building Research, CIB) on Water Supply and Drainage for Buildings was established, and CBT personnel are actively participating in the work. The II.S. Counterpart Commission is making significant progress in identifying U.S. research needs and activities in this area, and in preparing quidelines useful in evaluating research proposals.

FY 75 plans are to publish certain significant FY 74 results and to proceed further with the development of suitable methods for hydraulic calibration of fixtures and appliances, and for the determination and prediction of the quality of hydraulic performance of multi-story drainage systems.

\section{CRITERIA FOR BACKFLOW PREVENTERS}

\author{
Project Status \\ continuing
}

Project Leader

Robert W. Beausoliel

$301 \quad 921-3293$

Sponsor

Environmental Protection Agency

Project Number $4 6 \longdiv { 2 4 4 7 2 }$

Impact Keywords Test methods; laboratory evaluation.

Technical Keywords Backsiphonage; back pressure; backflow; cross-connection.
The object of this study is to prepare laboratory evaluation criteria for back flow presenters.

The approach is to review U.S. standards and test methods for backflow preventers used in buildings and interstate water carrier systems, visit laboratories and evaluate laboratory test methods and equipment, test laboratory devices as deemed necessary to evaluate device/test methods, develop Guide Criteria for laboratory evaluation of devices, circulate the Guide Criteria to several testing laboratories and professional societies for their comment, collate comments and report to the Environmenta] Protection Agency (EPA).

FY 74 results consisted of completion of the State-of-the-Art Report and Guide Criteria drafts. The State-of-the-Art Report was reviewed at EPA. Both reports are presently undergoing revision at NBS.

During FY 75 approval of the State-of-the-Art Report and Guide Criteria by EPA is expected. Reports will be sent to labs and professional societies for their critique. The level of financial and technical input required to develop new test methods will be identified. The reports will be completed and published in FY 75 . 


\section{CRITERIA FOR REDUCED-SIZE VENTING}

The principal motivation is potential savinas of materials and labor in family housing systems. This is of interest to Federal Construction agencies such as those in Department of Defense, as well as to the model code aroups, contractors, and plumbinq encineers. The findinas are expectted to contribute to NBS input into codes and standards, and into the specifications used by other government agencies such as DOD.

The objective of the project is to develop and confirm criteria for the design of reduced-size drain-waste-vent systems for military housina, through laboratory and field work.

During FY 74 laboratory work on a two-story townhouse system installed in the Center was completed and a report is being prepared (see below). A comprehensive analys is of the data was carried out, leading to the recommendation of definitive criteria for reduced-size venting for one-and two-story housing systems. The data from Stevens Institute test of a ten-story high-rise system were evaluated, and the test methods used reviewed. The following output also resulted: R.S. Wyly, G.C. Sherlin, and R.W. Beausoliel, "Laboratory Studies of the Hydraulic Performance of One-Story and Split-level Residential Plumbing Systems with Reduced-Size Vents," NBS Building Science Series (BSS) 49; T. Jackson and T.P. Konen, "An Investigation of the Adequacy of Performance of Reduced-Size Vents Installed on a Ten-Story Drain, Waste and Vent System," Report SIT-DL73-1708, Stevens Institute of Technology (for NBS); M.J. Orloski and R.S. Wyly, Hydraulic Performance of a Full-Scale Townhouse DWV Systern with Reduced-Size Vents, NBS BSS (in review--approved for publication as BSS 60 in September, 1974). R.S. Wyly and M.J. Orloski, "Studies of ReducedSize Venting of Sanitary Drainage Systems in the USA," Paper 13, 1973

Symposium Proceedings, CIB W62 Commission, Stockholm obtainable as Document D14:1973, Svensk Byggtjanst, Box 1403, S-177 84, Stockholm Sweden (SwK.38); R.S. Wyly and M.J. Orloski, "Report on Recommended Redesign of Venting Systems for Andrews Air Force Base Housing Units," letter report to Family Housing Division, Directorate of Civil

Engineering, Headquarters, U.S. Air Force. 


\section{COMPUTER EVALUATION OF BUILDING PLUMBING SYSTEMS}

New

Project Status

Project Leader Lawrence S. Galowin $307 \quad 927-32.93$

\author{
Sponsor \\ $\mathrm{Na}$ tiona 7 Bureau of \\ Standards \\ Project Number \\ $4 6 \longdiv { 2 4 1 9 6 }$ \\ Impact Keywords \\ Computer utilization; \\ construction.
}

Technical Keywords Computer-aided design; computer graphics; sanitary service.
A major constraint to the implementation of advanced and innovative technologies for the providing of building services such as plumbing, electric distribution, heating and cooling is the lack of standard user-oriented techniques for use with available computer programs needed to evaluate the performance of such technologies. Visual display permits very rapid assesment of dynamic effects. Plumbing systems have been chosen as the first application of this technique since there is a specific need to implement such methods in order to satisfy the goals of a NBS agreement with the British Research Establishment.

The objective of this project is to provide modern computer graphical techniques in conjunction with numerical computations for evaluating various engineering studies conducted in the section. The initial applications will be directed towards the performance of innovative plumbing systems.

High speed computers and computer graphics will be used during FY 75 to physically describe the installation within the building. The information required to dimensionally describe the building, empirical data relations required to describe loads, fixture location, system design and use patterns will be catalogued and processed to produce standardized inputs for computer programs under development for evaluating building plumbing systems at NBS and BRE (as well as other studies conducted elsewhere, e.g., Massachusetts Institute of Technology). This new project requires intensive research and review efforts to synthesize available technology and developments. Consequently, the first year will be limited to attaining the implementation for combining a computer computational capability with display equipment.

During FY 75 plans are to: (a) evaluate input requirements of available computer graphic programs for application to plumbing systems; (b) develop standardized input requirements; (c) initiate development of computer-graphic techniques for building plumbing systems by development of systems of governing equation; and (d) initiate development of a computer Tibrary of building plumbina data. 
At present there is no commercially available instrumentation package for the determination of utility loads in general and plumbing systems in particular. The successful completion of other section projects and interests such as water conservation, the British Research Establishment agreement, and reduced-sized venting need such instrumentation to meet objectives.

The objective of this project is to design, construct and test in the field a small, compact data logging system for determining real time flow and usage patterns in plumbing and drainage systems.

The approach of this project has been to develop a monitoring system consisting of a digital cassette recorder, a signal output of flow meters, flow switches and temperature transducers installed in a plumbing system in a single family residence. The system will operate in real time and record the actual occurrence of significant events and the effect on the operation of the plumbing system. Data analysis software package will be developed using available section equipment.

Assembly of a prototype field-portable data acquisition system for monitoring water usaqe in residences is 90 percent completed. A contracted agreement was established with Princeton University to install and field operate the system in a residence at Twin Rivers.

\author{
Project Status \\ Continuing \\ Project Leader \\ Richard A. Grot \\ $301921-32.93$
}

\author{
Sponsor \\ National Bureau of \\ Standards \\ Project Number \\ $46 \overline{24192}$ \\ Impact Keywords \\ construction \\ Technical Keywords \\ utilities
}

The plans for the current fiscal year are to fjeld test the developed system and to develop the software analysis package.

\section{RESIDENTIAL AEROBIC WASTE WATER TREATMENT}

Some municipal waste treatment facilities are overtaxed and are unable to service new construction sites, and most urban area lot sizes are too small for septic tank use. An estimated 20,000 to 30,000 aerobic waste treatment systems have been installed, but little is known of the performance, safety, or reliability of these household systems.

The goals of this project were: (a) to develop generic performance quidelines to evaluate individual household sewage treatment units; and (b) to develop a prototype household sewage sampler suitable for field testing of individual household sewage treatment units.

The approach used to obtain project objectives consisted of the following: (1) a literature survey and review of present methods to evaluate individual household sewage treatment plants such as National Sanitation Foundation Standard 40; (2) a full-scale test of a NSF Standard 40 certified aerobic treatment plant under NBS test conditions to determine the adequacy of NSF Standard 40: (3) development of Generic Performance Gujdelines to evaluate all types of individual household sewage treatment plants as an alternative or suggested modification of NSF Standard 40; and (4) devellopment of a prototype household sewage sampler unit to monitor individual household sewage treatment unit performance and to provide data on household effluent not available from existing technical literature.

Performance Guidelines for individual household sewage treatment units have been completed based on (a) a technology evaluation consisting of a 1 iterature survey and a review of present evaluation methods such as the N.S.F. Standard 40 "Individual Aerobic Waste Water Treatment Plants November 13, 1970;" and (b) laboratory investigation consisting of an eight week test of an individual aerobic waste water treatment plant,

\author{
Project Status \\ Continuing \\ Project Leader \\ David J. Mitche11 \\ $301921-3293$
}

Sponsor National Bureau of Standards

Project Number $46 \overline{24191}$

Impact Keywords Effective requlation; environmental hazards.

Technical Keywords Aerobic treatment; waste treatment, general; waste water treatment. 
certified by NSF, with random "live" hydraulic and biological loads.

A prototype household sewage sampler was desianed, constructed and tested in the Center for Building Technology Plumbing Research Laboratory. Present wastewater monitoring techniques were reviewed. Individual component and system simulation tests were conducted.

A limited laboratory capability was established to support the above. The latoratory can provide total organic carbon (TOC), biochemical oxygen demand ( $B O D)$, chemical oxygen demand (COD), and other determinations of household sewage "quality" using procedures specified by "Standard Methods" published by the American Health Association.

Environmental Protection Agency at the time of project initiation had no programs actively addressing individual household sewage treatment units. In contrast, today EPA is funding studies by the University of Wisconsin and other related programs. It is felt that this project has had a small part in this change in EPA priorities.

\section{HUD LONG RANGE RESEARCH- INNOVATIVE ELECTRICAL CONNECTIONS}

\author{
Project Status \\ Continuing \\ Project Leader \\ James G. Gross \\ $301921-3126$
}

Sponsor

Department of Housing and Urban Development

Project Number 4608403

Impact Keywords Construction; environmental hazards.

Technical Keywords Codes and Standards; connectors; contact resistance measurement.
This project results from the inability to properly evaluate innovative electrical connections proposed for use in the operation BREAKTHROUGH program. Code and other institutional restrictions, a serious fire hazard potential and the lack of technical data based on performance, coupled with beliefs that significant advancements and lower costs were possible in the methods of installing electrical wiring, led to the creation of this project.

The objective of this project is the development of criteria and test methods to evaluate electrical connections in residential branch circuit wiring (nominal 115-230 volt, 15-50 amps).

During FY 74 the approach to the project was to (1) make a study of the state of the art including code and other institutional constraints, (2) develop interim criteria based on performance, (3) develop technical data needed in the evaluation of electrical connections, and (4) develop and publish criteria and test methods for the evaluation of innovative electrical connections.

Progress reports on the state of the art and tentative performance criteria and research needs were written and placed into the NBS editorial process. Preliminary laboratory work was bequn. Technical data measuring connection quality including deteriorated connections and their overheating effects were obtained.

Plans for the current fiscal vear are to continue to study parameters and characteristics of various connector designs and materials and to continue to gather data concerning the effects of deteriorated connections and the reasons for deterioration. Also, based on preliminary laboratory work, 
an improved method for measuring the quality of a connection, particularly in relation to over-heating aspects will be developed. Criteria and test methods to evaluate electrical connections in residential branch circuits on a performance basis will be developed and published.

During Fy 75 plans are to complete editing of a report on state of the art, "Electrical Connections in Residential Branch Circuit Wiring"; complete editing of "Report on Tentative Performance Criteria and Research Needs for Electrical Connections in Residential Branch Circuit Wiring"; submit draft report on "Electrical Connection Failure Mechanisms"; and submit draft report on "Electrical Connection--Thermal-Electrical Relationships."

\section{ELECTRICAL SERVICE QUALITY MEASUREMENT}

Quality of electrical service effects the operation and durability of electrical and electronic appliances and other equipment. Representative data on variations from standard electrical service characteristics (e.g. brownouts - reduced voltage levels), is needed to establish elements of design requirements for electrical and electronic equipment in buildings. The lifetime cycle of equipment reliability may be improved by development of improved control and better regulated supply.

The objective of this project is to obtain and analyze data on the effect of electrical service currently available from conventional public service in homes and commercial buildings. The impact of on/off operations of appliances and enuipment upon the characteristics of the electrical service is to be assessed by collection and review of the data. Limited service suoply installation (such as Jersey City total energy plant and new MIUS developments) are also to be evaluated from instrumentation applications developed in this project.

The approach is to provide instrumentation at various field sites which continually record quality of electric service data (high and low voltages, high and low transient voltages and frequency stability), periodically collect and analyze the data, determine causes of electric service characteristics variations, and evaluate the impact upon lifetime cycles of equipment.

During FY 74 instrumentation was procurred and field measurements started. Even though enough measurements had not been taken to be statistically valid, the number of low voltage transient events indicate a need for in-depth studies. It has been determined that some low voltage events are
Project Status

Continuing

Project Leader

Adolfo A. Camacho

$301921-3293$

\section{Sponsor}

National Bureau of

Standards

Project Number $46 \overline{24193}$

Impact Keywords Distribution and storage; consumer data.

Technical Keywords Power generation systems, genera 1; power measureents; voltage measurements. 
caused by the on-off events of electrical equipment internal to the building.

During the preceeding fiscal year committee work was finished on 1974 National Electric Code (NEC).

Plans for FY 75 are to continue gathering and analyzing quality of electrical service data, to report on the quality of electrical service, and to start reviews for the 1977 NEC update.

\section{HUD LONG RANGE RESEARCH - INNOVATIVE PIPING MATERIALS}

\author{
Project Status \\ Continuing
}

Project Leader

James G. Gross

301 921-3293

Sponsor

Department of Housing and Urban Development

Project Number $4 6 \longdiv { 0 8 4 0 3 }$

Impact Keywords Construction; effective regulation.

Technical Keywords Materials, residential ; pipe, tube; piping systems.
The objective of this project is to develop performance criteria for innovative piping materials, subassemblies, and systems for residential plumbing, with emphasis on the thermoplastics.

The work is needed to provide criteria suitable for expeditious acceptance of innovative piping materials in terms of user/owner needs. In particular, thermoplastics have become attractive in terms of first cost and convenience of assembly; but on the other hand, the product standards do not directly address certain characteristics of installed thermoplastic systems that have been postulated as critical to safety or durability, e.g., combustibility, dimensional changes, stress corrosion, leakage.

Review of existing standards and industry data is first carried out to establish whether user-related measures of functional performance, of health and safety, and of durability for installed piping systems are effectively addressed in the existing piping materials standards. Laboratory tests are then conducted to examine the critical performance characteristics not specifically covered in the standards, and from these data suggested performance criteria and test methods are drafted as supplemental to, not instead of, the existing product standards. The approach employed endeavors to produce broad evaluation criteria that are not dependent on the particular material; however, the performance characteristics of the material may determine which criteria are critical and hence which test methods need to be developed.

Laboratory work was completed, supplementing the work carried out in FY 73. This (FY 74) work was concentrated mainly in the areas of fire performance and thermal properties, and involved a broader range of thermoplas- 
tics materials than was the case in the FY 73 work. Eight reports describing the findings in the FY 73 work were in preparation or in review at the close of FY 74. Three of these were nearing the end of the format review process.

The work indicates that a number of the potential concerns relating to the use of thermoplastic piping in above-ground residential plumbing systems can be significantly reduced or eliminated by a more careful application of existing knowledge in design, installation, and inspection. In other areas of potential concern, e.g., fire safety, stress corrosion, and quality of joints, additional work is needed to develop suitable evaluation methods. The criteria format and the rationale resulting from the FY 73-74 work has significantly reduced the difficulties in defining the needed new work and in the presentation of recommendations for development or modification

of specifications, standards, and codes of practice insofar as the means of acceptance of innovative piping materials are concerned.

New experimental work to develop needed test methods and performance data for parameters generally outside the scope of the FY 73-74 program may be started during FY 75, or in FY 76, depending on funding. Among such work may be experimentation on the functional performance and durability of joints and expansion fittings subjected to repetitive thermal loading and pressure shock, on the mechanisms of stress cracking and aging, and on the phenomenon of smoke and toxic gas emission into living spaces.

Based on such data, the criteria developed in the FY 73-74 program are to be reviewed. In addition, a review of guidelines for design and installation is to be conducted.

The emphasis in the research would be on those criteria potentially critical with thermoplastics, but the format of the recommendations would be such that other materials could be addressed, with the development of some additional test methods. The following outputs also resulted: Robert S. Wyly, "Performance Criteria for Piping Materials," and Daniel Gross, "Fire Research," both talks given at HUD Orientation Program for Area and Regional Officials, October 16, 1973; Richard G. Bright, "Review of Fire Programs" and "Detection and Suppression of Fire."

During FY 75 reports on the following subjects will be completed: review of performance characteristics of piping in residential plumbing

a state-of-the-art summary to be published in the Building Science Series; (2) fire endurance tests on walls and plumbing chases containing drainwaste-vent (DWV) systems--first series; (3) interim criteria for thermoplastic piping materials for above-ground use in water supply and drainage for residential buildings; (4) procedures for determination of thermal performance characteristics of plastic piping used in housing; (5) hot water and pressure-cycle tests of piping assemblies; (6) fire endurance tests on walls and plumbing chases containing drain-waste-vent systems composite summary of first and second series; (7) laboratory study of thermal properties of plastic piping used in housing; (8) summary of performance characteristics and criteria for DWV and water distribution piping for above-ground residential plumbing systems (final report, Building Science Series).

Reports on the FY 73-74 work will be completed during FY 75 and any funded new work carried out that is required as a basis for adequate criteria and test methods outside the scope of the FY 73-74 program. 


\section{SER VICE SYSTEMS DATA PROCESSING}

Project Status

New Project

Project Leader

Daniel E. Rorrer

$301921-3293$

\section{Sponsor}

Nationa] Bureau of

Standards

Project Number $4 6 \longdiv { 2 4 1 9 5 }$

Impact Keywords Distribution and storage; computer utilization.

Technical Keywords Data processing; reduction and analysis; sanitary services; utilities.
The objectives of the project are to (1) provide and develop laboratory control and data collection functions and analys is of multi-project activities at Twin Rivers, NBS plumbing laboratory, and Andrews Air Force Base (AFB); (2) provide general purpose mini-computer software to facilitate the use of existing instrumentation for field and laboratory test data analysis; (3) provide training necessary for section personnel to adequately operate the existing section (Data Acquisition Systems) mini-computer; (4) maintain the section mini-computer data acquisition and analysis software library on a timely basis.

Under a software service contract with the section mini-computer manufacturer, new and updated software is continually being supplied. Also, continuing modifications to the existing computer facility require changes in many programs in the existing software library. Where related reguirements for new computer software are identified, this project will support other projects in development of general purpose programs. This project will also coordinate data handling software development with other mini-computer users throughout NBS and other mini-computer user groups to enlarge section capabilities.

General purpose computer programs will be developed durina FY 75 in support of specific section and/or division projects. The system software library will be updated and maintained as required on a regular bas is and as supplied by the mini-computer manufacturer. Increased utilization for laboratory and field data analysis, empirical curve fitting, and development of predictive capabilities for section projects will be provided. Enlarged requirements for reading cassette tapes from field sites, such as Twin Rivers, Andrews AFB housing, water quality measurement, and appliance labelina are anticipated. A section user's group will be formally established to meet on a reqular basis in order to apply the available software descriptions for (1) enhancing the capability of section personnel to meet their project goals; (2) decreasing dependency on a single "computer specia1ist"; and (3) setting up training sessions for the purpose of instructing potential users in the rudiments of computer programming and use for laboratory and field data collection and processing. 
There is no recognized methodology to evaluate vacuum drainage systems. Furthermore all plumbing codes, including the four model plumbing codes do not recognize vacuum drainage. Seven installations of vacuum drainage have been completed on experimental permits.

The vacuum drainage industry is embryonic, highly competitive, and unwilling to form a trade association. Little or no technical data is available from the vacuum drainage industry. There is a growing demand for watertight and water conserving sewerage systems. The Defense Department (DOD) is finding it increasingly difficult to obtain off-base utility services such as potable water and sewage treatment for their military bases.

The scope of this project was to prepare general performance guidelines for vacuum drainage technology. The goal was to develop a tool for Tri-Services and local code officials to use in evaluating individual vacuum drainaqe systems designs.

The research approach consisted of three phases. Phase I, Technology Evaluation FY 72, consisted of reviewing 1iterature, visiting and evaluating existing installations, and identifying critical issues. Phase II, Preliminary Criteria Development, consisted of identifying functional requirements for a generic vacuum drainage system, determining the quantitative measures used to establish that all functional requirements are met, and developing an evaluation procedure to be used to test for compliance with the above criteria. Phase III consisted of installing a full scale vacuum drainage system marketed by industry in the NBS Plumbing Research Laboratory; attaching a full scale townhouse plumbing system complete with fixtures to the vacuum drainage system and investigating the input and output characteristics of vacuum drainage hardware, the pneunatics and hydraulics of in building vacuum mains, and other pertinent areas identified as unknown areas in Phases I and II.

Performance guidelines for vacuum drainage have been completed based on a technology evaluation of existinq literature, review of present related evaluation methods and site visitations to a limited number of vacuum drainage installations and test laboratories; and an NBS laboratory investigation of a series of selective tests concerning the pneumatic and hydraulic requirements of vacuum drainage and their impacts on health and safety.

In addition the following output resulted: NBS in Action Seminar (series VIII), "Water Conservation and Vacuum Drainage"; Technical Workshop was held at NBS for divisions of the Department of Defense, Department of Housing and Urban Development, the Environmental Protection Agency, Model Code Committee, and state public health deoartments (April 15, 1974).
Project Status concluded

\author{
Project Leader \\ David J. Mitchel1 \\ 301 921-3293
}

Sponsor

Tri-Services of the Department of Defense

Project Number $4 6 \longdiv { 2 4 4 7 0 }$

Impact Keywords construction.

Technical Keywords Sewage collection; transport of sewage; vacuum sewers. 


\section{UTILITY LOAD MEASUREMENTS}

\section{Project Status Continuing}

Project Leader Richard A. Grot 301 921-3293

Sponsor National Science Foundation

Project Number $46 \overline{24473}$

Impact Keywords Conservation; construction.

Technical Keywords Power measurements; utilities; voltage measurements.
The National Science Foundation - Research Applied to National Needs (NSFRANN) program is intended to establish an information data base for energy consumption and patterns of usage from sample residences in Twin Rivers, N.J. The goals reguire NBS participation with Princeton University for collection of reliable field data and then to provide for development of models to provide a predictive capability. Techniques for conserving energy and techniques for utilization of utility services will be developed. Special developments by NBS for thermographic studies of air filtration. and real-time/event data for assessing integrated time recording of energy consumption are required.

The rational planning of energy and water reducing strategies and the development of energy and water conserving technologies requires a firm understanding of energy and water use patterns in residences and of factors that influence their consumption.

NBS has participated in the project with Princeton University by supplying instrumentation equipment and technical assistance in four task areas; development of a semi-automatic air infiltration measuring system; (2) use of thermographic equipment in units at Twin Rivers to detect construction defects; (3) design and assembly of a real-time energy and hot water usage monitoring system; and (4) review and critique of the Princeton project design.

A prototype semi-automatic air infiltration measuring system using sulfur hexafluoride (SF6), a tracer gas, has been completed and tested in several dwellings at Twin Rivers. Three more versions of this system are being produced. Thermographic field work was undertaken during two one-week periods in February at Twin Rivers. The thermographic equipment clearly indicated the existence of heat leaks along the firewalls in the townhouses at Twin Rivers. Due to delays in the construction of the realtime data acquisition system, data collection was postponed to obtain usage profiles for energy and hot water in a residence at Twin Rivers.

During FY 74 the following talks were given: R. A. Grot, "Factors Influencing Energy Consumption in Planned Unit Developments, "American Society for Heating Refrigerating and Air Conditioning Engineers Meeting, Los Angeles, February, 1974; "Review of Twin Rivers Project: Eneray Use Patterns," American Gas Association Conference, Dallas, Texas, March 1974; "Energy Conservation in a Multi-Family Complex," Ohio State University, Columbus, Ohio, May, 1974.

The completion of the real-time data acguisition will be accomplished during August. It will be installed in a townhouse at Twin Rivers and data will be collected during September and November. 


\section{AMERICAN INSTITUTE OF ARCHITECTS/NBS RESEARCH ARCHITECT}

The objective of this project is to strengthen the link between the architectural profession and the CBT building research effort, in order to increase the relevancy and the applicability of CBT research.

The American Institue of Architects (AIA) and NBS selected a mature professional who will act as a link between the design professions and the buildinn research staff of CBT was selected. The vehicle of this linkina activity will be research on a subject of interest to NBS and the AIA, and will be cenerally directed toward the production of an improved built environment.

The candidate will be installed in the Center for Buildina Technolony during the fall of 1974. We anticipate developing with him a detailed plan of operation for subsequent years, puttinn into action with the AIA a recognized competition as a means of selecting future AIA/NBS Research Architects. In addition, the first AIA/NBS Research Architect will work with CBT staff in support of the goals of the pronram.

\section{CONSTRUCTION RESEARCH}

Most of current building research activity is directed toward the design and use phase of building construction, or toward the support of the design professions. It is believed that research activities directed toward the construction process phase, or toward the support of the contracting industry, could lead to significant advances in construction methods, material and labor savings, and rise in productivity of the construction sector.

The objective of this project is to improve the efficiency of the construction process through research. This process would include economics and finance, communications, coordination, transportation, the handling of men and materials, and the organization of on-site manufacturing and assembly.

Through an interdisciplinary approach it is proposed to simultaneously conduct research in a few well-defined areas and to coordinate related activities in other CBT units. Earlier work has identified specific research needs, and early in FY 75 appropriate priorities will be established.

An extensive study of prior art and of research needs in the construction process area was conducted; a role for CBT in this research area was established; specific research areas were identified. Based on the above study, plans for work in construction research were formulated. In addition a report, "Staff Study on Construction Research," was completed by Heinz Trechse T in March, 1974. 
Plans for FY 75 are to estabTish priorities for specific research project areas; select one or several projects for intensive study, such as methodology for quality control in on-site construction; coordinate and promote related research projects in other CBT units, i.e. the investigation of terms used in construction statistics.

\section{MEDICAL FACILITY DESIGN}

Project Status

concluded

Project Leader

Robert J. Kapsch

301 921-3595

Sponsor

National Bureau of

Standards

Project Number $46 \overline{37130}$

Impact Keywords HeaTth, research.

Technical Keywords Architecture and design; codes and standards; hospitals; interior design and equipment.
In a report to Conaress, the General Accountina office stated that the most pervasive issue in medical facility design was the multiplicity of Federal and non-Federal codes and regulations that often conflict. It was stated, furthermore, that the solution to this problem depends on the development of performance criteria for medical facilities. Rational, consistent design standards will benefit the Federal anencies and the design professions in addition to the ultimate facility users.

The objective of this project is to rationalize the many faceted regulatory standards for medical facility design presently existing amona many Federal agencies.

During FY 74 an evaluation technique for assessing three different designs for nursing units was developed. A Titerature search on planning and desian of hospital nursing units was conducted and a preliminary investiqation of nursina home designs, particularly with respect to Federal regulations in this area was undertaken. Consultation with Federal agencies on medical facility design including Veterans' Administration; Department of Health, Education, and WeTfare; Army; Air Force; and others, was provided and two Federal Agency Workshops on medical facility design were orqanized and conducted. A model was developed to allow for the comparative evaluation between different configurations of nursing units and patient bedrooms. In addition the following output was a result of this project: Robert J. Kapsch (ed.) "Health and Medical Facilities Design," NBS Building Science Series 54, JuTy, 1974; Robert Wehrlj "Evaluation of Types of Hospital Nursing Units," CBT Federal Aqency Workshop, october, 1973. 
The objective of this project is to disseminate consumer opinions on industrialized and innovative housing as compared with conventional housing; to develop monographs on metrication, computer aided design methods and related topics; to develop future architectural research projects.

Adequate housing is a major concern for everyone. This project reports on innovative and industrialized construction, a potential answer to supplying good homes at moderate cost. But is this type of home acceptable to residents? Answers to this question will be documented in detail for safety, security, privacy, comfort and many other attributes of quality housing. These answers will be reported to the qeneral public and to architects, engineers, designers, contractors, builders, code officials and housing managers and owners as well as 10cal, state, and federal officials interested in the housing problem. (See also Project Feedback.)

The consumer opinion study is based upon a survey of 1500 occupants of HUD's Operation Breakthrough industrialized housing and 500 occupants of comparison, conventional housing. Reports will be based upon an analysis of the computerized survey data. Monographs and research development will be based upon literature research and intuitive methods.

In FY 72 and 73 the Operation Breakthrough research was planned and commenced. In FY 74 three surveys were reported in an initial and second interation. These were the exit, visitors, and work order surveys. The fourth, consumer survey was conducted and technical reports were outlined and commenced. Finally, technical reports for all four studies will be completed in FY 75, as will a combined report which will integrate results from the four technical reports in a single document for public readership. In FY 74 we also prepared and presented a paper, "The Performance Concept as a Model Linking Research Design," Environmental Design and Research Association Fifth Conference (EDRA 5), Milwaukee, May 30, 1974; Prepared and presented a paper, "What Kind of Metrication for Building?" to the Building Research Institute on Metrication, Washington D.C. November 27 , 1973; and provided participation at numerous other conferences, conventions and symposiums.
Project Status Continuing

Project Leader Robert Wehrli $301 \quad 921-3595$

Sponsor

National Bureau of Standards

Project Number $46 \overline{37138}$

Impact Keywords Construction; consumer data; quality control.

Technical Keywords Architecture and design; codes and standards; housing demand; improvement of buildings; residential buildings. 


\section{URBAN DESIGN}

\author{
Project Status \\ New
}

Project Leader

Robert Wehrli

301 921-3595

\section{Sponsor}

Nationa 7 Bureau of

Standards

Project Number 4637140

Impact Keywords Housing; environmenta 1 impact.

Technical Keywords Architecture and design; codes and standards; environmenta 1 design; land use; urban planning.
The development of urban areas, despite the many legislative and administrative controls upon it, tends to be irrational and based upon whim, expediency and convention, rather than upon a rational analysis of data. One major reason for this is that these data are not pulled together in logical, consistent, and manageable arrays. This research will examine the content of environmental impact statements, building and zoning codes, design guides, topographic and utility maps, and other materials to attempt to make them more consistent and manageable.

The objective of this project is to provide a tool for managing urban design information to support more rational urban design decisions.

The approach is as follows: to continue the study of the nature of building code provisions as to type, content, scope, and coverage as described in "A Performance Indexing and Information System" and "Existing Architectural Indexing Systems" by Robert Wehrli and Robert Kapsch: to analyze existing computer systems for community planning data banks; to study and specify the nature of available generalized computer programs; to get hands-on experience with such a program as MUMPS, a generalized computer program used for hospital and medical applications; to show how pictures, words, and numbers needed for urban design can be implemented in such a program; to prepare a report on all these which would serve as a specification for the final research and development of a computerized urban design information system.

In FY 73 Section 463.01 prepared two papers on performance indexing to show how the performance statement can serve as the prototypical format for any design statement or building regulatory provision. In previous research Robert Wehrli, Section Chief, has outlined and partially developed a computer aided architectural design system suitable for urban as well as building design. In FY 74 a contract was let for preparing papers on (1) building design and (2) computer aided design. In FY 73 a series of symposia on interdisciplinary design decision making was conducted. These proceedings will be published in FY 75. 
Available codes and standards for fire safety design of buildings are arbitrary, not performance based. These codes and standards are not related to actual data on building fires, hence U.S. losses of life and property are inordinately high. Revised design criteria can provide innovation, reduce building losses, and mitigate the frequency and severity of fires and fire losses.

This research will examine theories of desian, fire safety provisions of building codes, and available literature of fire phenomena in buildings; it will establish and record the principles governing these phenomena. The research will propose a new set of fire criteria for a selected building type based upon the tenets of performance but incorporating prescriptive criteria where they are applicable. These criteria will be submitted to national authorities for review and will be tested in prototypical design projects for buildings not intended for construction. The building schemes will be compared with those designed according to conventional codes. Relevant research will be reviewed and recommendations made as to how future follow-on research can address and support the design theory.

In FY 74 pertinent 1 iterature was reviewed and contracts were let for studies of two specialized building types--tall buildings and nursing homes. The basis for a rational theory of fire design was established.

A series of informal conferences is planned with fire experts and the following schedule will be followed: complete literature search; select building type; ccinplete first version of theory; test theory on prototype projects; complete revised version of theory; reiterate testing; revise and print report; review; and prepare photo ready copy of manuscript.

\section{PROJECT FEEDBACK}

Social and psychological research is critical to our understanding of the built environment, which after all, is for people. This project not only reports consumer satisfaction or dissatisfaction with the industrialized and innovative Operation BREAKTHROUGH housing but in addition achieves the following: develops a competency for such research at NBS, provides a prototypical study as a model for other researchers, provides a methodology including procedures and instruments for other housing researchers, and establishes a data base on industrialized housing which can now be extended in further in-depth studies of housing or in researches of other (nonhousing) building types.

In an effort to better satisfy the needs of those who occupy, or use, the built environment, there is an increasing interest in polling just those persons. This project is securing the opinions, and behavioral reports of residents of Operation BREAKTHROUGH housing in an "occupant" survey of some 2,000 interviews. Two other surveys have sampled the opinion of visitors to model homes (visitors survey) and persons who have moved away from Operation BREAKTHROUGH homes (exit survey). A fourth survey has analyzed maintenance work orders for the dwellings (work order survey). These surveys, and related studies, will qive the public a detailed report on consumer "acceptance" of the BREAKTHROUGH industrialized homes.

Four main surveys have been conducted, the most important of which is the occupant survey which has covered some 1500 residents of 0peration BREAKTHROUGH housing and 500 residents of conventional, non-industrialized, homes. The questionnaire is based upon housing issues surveyed in depth at the 9 Operation BREAKTHROUGH sites. Typical issues were safety, security, manaqement, noise, amenities, livability, etc. These apply primarily to the dwelling and its parts, the building (for apartments)
Project Status Continuing

\section{Project Leader Robert Wehrli 301 921-3595}

\section{Sponsor \\ National Bureau of Standards \\ Project Number $4 6 \longdiv { 3 7 1 3 9 }$}

Impact Keywords Construction; disaster mitigation; hazards in the home.

Technical Keywords Architecture and design; codes and standards; fire considerations; general buildings; interior design and equipment.

\author{
Project Status \\ continuing \\ Project Leader \\ Stephen T. Margul is \\ 301 921-3595
}

\section{Sponsor}

Department of Housing and Urban Development

\section{Project Number $46 \overline{38404}$}

Impact Keywords construction; consumer data; quality control

Technical Keywords Architecture and design; codes and standards; environmenta 1 design; housing, general; improvement of buildings. 
and the site, and secondarily to the surrounding neighborhood. Demographic questions identify the socio-economic status of households and the number, age, sex, etc. of household members. All questionnaire data are computer ized to permit a wide variety of analyses and comparisons across sites, manufacturers dwelling size, housing type, ownership type, etc. Reports are written both for technical persons and for the general public.

Surveys were completed on 8 sites in FY 74 and reports were commenced. These will be completed in FY 75. The 9th site, Jersey City, New Jersey is the subject of another study in FY 75.

\section{METHODOLOGY HANDBOOK}

\author{
Project Status \\ New \\ Project Leader \\ Stephen MarguTis \\ 301 921-3595 \\ Sponsor \\ Department of \\ Housing and \\ Urban Department \\ Project Number \\ $4 6 \longdiv { 3 8 3 7 0 }$ \\ Impact Keywords \\ Consumer data; \\ construction; quality \\ control
}

Technical Keywords: Architecture and design; attitudes; buildings, genera 1; design, general; environmental design; improvement of buildings
The objective of this project is to disseminate to other survey researchers prototype instruments and supporting documents on four types of housing surveys. This will be helpful to these researchers since this type of detailed material is not readily available elsewhere. Moreover, if others use these materials, it may be possible to extend the housing data base (which CBT now has available) with the data of other researchers.

The Nation has no larne data base of opinions of people livina in industrialized housing and very few other user needs data on housing qenerally. Moreover, the techniaues and instruments for housing surveys are not readily available. This project aims at partially satisfying these housing research and information needs.

Four surveys were developed in FY 73, and tested in a large scale demonstration project, Operation BREAKTHROUGH, in FY 74.

The four surveys will be briefly described and published along with questionnaire and supporting documents. The resulting methodology handbook will be addressed to other housing researchers.

The survey descriptions, instruments, and supporting documents will be assembled in a methodology handbook in FY 75. 


\section{INTERDISCIPLINARY DECISION MAKING IN DESIGN}

The advent of the performance approach to building procurement, design, and regulation means that experts within a great variety of disciplines are needed for design decisions. This project provided final editing of a report on four symposia in which such experts discussed their experiences in interdisciplinary decision making in design. The report addressed those in the construction industry concerned with this aspect of changing practice.

Washington Editorial Review Board reviews, revisions, final editing, printing, and distribution will be completed in FY 75.

\author{
Project Status \\ concluded \\ Project Leader \\ Rohert Wehrli \\ $301 \quad 921-3595$
}

\author{
Sponsor \\ National Bureau of \\ Standards \\ Project Number \\ $4 6 \longdiv { 0 3 1 0 6 }$ \\ Impact Keywords \\ Construction; effective \\ regulation.
}

Technical Keywords Architectural design; architecture and design; environmental design.

\section{ARCHITECTURAL PSYCHOLOGY}

Privacy has been emphasized as an essential human right now jeopardized by invasions from both public and private sectors. People must be assured of environments which protect them from these and other threats to visual, aural and other threats to privacy. This research assesses the human component and identifies the important behaviors and attitudes related to privacy, and shows how these are legal aspects. Most importantly, the research examines how privacy is maintained and reinforced (or not) by the physical environment. Privacy is an intimate concern of everyone, and al1 will benefit from the research results. Privacy criteria for the design and management of buildings eventually will be made available to involved persons through this research.

Library research and critical review of available materials will provide the approach.

In FY 71 a draft of a state-of-the-art monoaraph was prepared. It covered most work done prior to 1971. In FY 74 two papers were prepared and another summarizing research subsequent to 1971. A symposium was conducted at the annual conference of the Environmental Design Research Association Fifth Conference, Milwaukee, Wisconsin, May, 1974 and the following talks were qiven and will appear in the published proceedinqs: Carl Johnson, "Privacy as Personal Contro?"; Stephen Marqulis, "Privacy as a Behavioral Phenomenon; Coming of Aqe"; John Archea, "User Evaluation Studies, Concepts and Theories."

\section{Project Status} Continuing

Project Leader Stephen Margul is $301921-3595$

Sponsor

Nationa $]$ Bureau of Standards

Project Number $46 \overline{37134}$

Impact Keywords Consumer protection; housing, environmental.

Technical Keywords Architecture and design; communication; correction procedures; family; locus of control; self disclosure presentation. 
Before commencing fruitful research in privacy it is necessary to prepare a report containing five elements (1) a state-of-the-art review of previous research through 1971, (2) a theory of privacy as a behavioral phenomenon, (3) a theory of the nature of privacy, definitions, and hypothesis, (4) a treatise discussing the environmental implications of privacy, and (5) a program of proposed research projects which would test the theory. In FY 75 , the first and third of these five elements will be completed as a prelude to the development of the other three. The state-of-the-art report will encompass the previous FY 71 report draft and the two reports of FY 74, and additional exploration into not fewer than four large segments of the literature on privacy. The remaining three elements will also be completed if possible. Completed reports witT be published in FY 75 and the other elements published separately in FY 76. (if not completed during this fiscal year).

The in-house portions of this research will be commenced when the HUD Feedback Research has been substantially completed. Plans are as follows: let contracts for literature reviews; begin NBS In-House literature reviews; begin report preparation; complete report manuscript; and complete WERB reviews and publish.

\section{FEEDBACK ON JERSEY CITY, OPERATION BREAKTHROUGH}

\author{
Project Status \\ New \\ Project Leader \\ Stephen MarguTis \\ $301921-3595$
}

Sponsor

Department of Housing and Urban Development

Project Number $46 \widehat{38371}$

\section{Impact Keywords Consumer data; construction}

Technical Keywords Architecture and design; codes and standards; design, general; environmental design; housing, general, residential buildings.
There is an increasing awareness in the U.S. of consumerism, the satisfaction of those who buy and consume (or use) the products of industry, and this applies to housing as well as other types of products. HUD, and in turn NBS, has a need to determine whether or not the nation's built environment satisfies those who occupy and enjoy this environment. The "determination" requires special competencies, techniques, and skills which CBT has assembled for this project and can apply to future projects.

The Architectural Pesearch Section has already developed the techniques for this study and tested them on the first 8 sites. These methods and instruments are a housing consumer's questionnaire, an instruction manual for interviewers, and a coding and editing manual together with computer analysis procedures. These will be used for Jersey city. In addition, the Architectural Research Section will rely upon on-site observations, photographs, and informal interviews to supplement the face-to-face interviews using the survey questionnaire.

Housing evaluation methods and instruments were prepared, tested, and applied in FY 72,73, and 74 on 8 of Operation BREAKTHROUGH's 9 housing demonstration sites.

The success or failure of a housing demonstration project can best be evaluated by those directly affected, the residents. Their opinions are awaited by the general public, public officials, the housing 
industry, and in fact, all who look toward improved technology as a way of solving human needs. This project reports consumer opinions on the 9th Operation BREAKTHROUGH site at Jersey City.

Housing evaluations for Jersey City will be scheduled to follow upon occupancy anticipated to near completion in Spring of 1975. The main survey is scheduled for Summer of 1975 with report publication in Fall of 1975 .

\section{ECONOMIC INDICATORS OF CONSTRUCTION COST TREND}

The Engineering Division, Department of the Army, needs data for forecasting military construction cost trends. The Building Economics Section (BES) has the capability of collecting such data. Providing periodic reports of economic indicators will help the Army generate better forecasts and will also help the BES in its own forecasting work on construction activities.

The objective of this project is to collect data on economic indicators relating to the building construction industry having significant influence on future military construction.

The approach is as follows: (a) conduct a literature search on existing economic indicators available from public sources; (b) conduct a literature search on existing economic indicators available from private sources; (c) tabulate the results of these searches of economic indicators.

Progress during FY 74 included a tabulation of economic indicators avai1able from nublic and private sources. Two interim reports to the sponsor have been made.

\author{
Project Status \\ Continuing \\ Project Leader \\ Phillip T. Chen \\ 301 921-3701 \\ Sponsor \\ office of the \\ Corps of Engineers \\ Project Number \\ $46 \overline{374} \overline{3}$ \\ Impact Keywords \\ Building design; \\ productivity enhancement \\ Technical Keywords \\ Projections and forecasts; \\ wages and salaries
}




\section{TECHNIQUES FOR ECONOMIC EVALUATION}

\author{
Project Status \\ Continuing
}

Project Leader Harold E. Marshal1 301 921-3701

\section{Sponsor \\ National Bureau of Standards}

Project Number $46 \overline{37160}$

Impact Keywords Building desian; consumer data; effective regulations.

Technical Keywords cost-benefit analysis; economic methods; housing, other; land use, value and planning.
The objective of this project is to develop and refine the theories and methods of benefit-cost analysis, risk-benefit analysis, and life-cycle costing for applications to building evaluations.

The Building Economic Section provides economics analyses for the Center for Building Technology and its clients. Benefit-cost, risk-benefit, and life-cycle cost analyses are examples of techniques that are needed for the evaluation of alternative building and equipment designs. Cost minimization has been recognized as an economic objective in choosing among building alternatives, but the maximization of net benefits is a more desirable objective for effecting an efficient allocation of building resources. By considering benefits and costs, the most efficient building technologies can be applied.

The approach is as follows: (a) conduct literature search for the state of the art on available evaluating methods and statistical data, both in the U.S. and abroad; (b) examine non-building applications of evaluation techniques to determine their applicability to building problems: (c) examine alternative methods for evaluating in dollar terms losses of life and personal injuries; (d) examine the appropriate techniques for evaluating alternative building design from preventing losses from fire, progressive collapse, and other disasters, and for reducing the consumption of energy; (e) examine alternative forms of cost-sharing rules as they impact on construction design and scale; (f) increase CBT awareness of the applicability of economics to building problems and facilitate the inclusion of economics into interdisciplinary research through seminars and workshops that describe economic applications.

Benefit-cost, risk-benefit, and life-cycle cost methods were refined for evaluating alternative building technologies. The staff participated in seminars, training, and research relating to applications of these methods. Drafts of two articles were completed for submission to professional journals. The first article concerns efficient cost sharing for plant and nonplant techniques for controlling salinity pollution of water; the second article concerns efficient cost sharing of various techniques for protecting shorelines from damages from high winds and waves.

These publications have resulted from this research - Robert E. Chapman and Peter Colwel1, "Economic Analys is of Proqressive Collapse Standards," NBS Interagency Report in progress; $f_{7}$. Thomas Sav, "Losses Due to Natural Disasters: Empirical and Economic Considerations," NBS Interagency Report 74-473; Harold E. Marshall commented on an article, "Cost Sharing for Recreation: Efficiency and Equity," Moler and Scherr, Land Economics, Vol. 50, No. 1, February 1974; Harold E. Marsha11, "Efficient Techniques of Shoreline Management through Cost Sharina," submitted to Land Economics; Joel Levy, "The Optimal Size of a Storage Facility," published in Naval Research Logistics Quarterly, Vol. 21, No. 2, June, 1974. 
A benefit-cost methodology is needed so that CBT can ascertain the external impacts of CBT activities. The nation, NBS and CBT will profit from a more efficient allocation of scarce resources in implementing improved technoloqy through the building requlatory system and the building industry. This project specifically deals with the NBS goal of improving the efficiency (a) in budget allocations, i.e., in selecting NBS projects, and (b) in documenting the impacts of past and future NBS projects.

The objective of these two microstudies is to derive and apply a methodology for measuring the impact of buildina technology as introduced through CBT on both the building regulatory system (Microstudy I) and the building industry in general (Microstudy II).

The approach is to develop a benefit-cost methodology for measuring the net social impacts of improvements in technology that are introduced through the building regulatory system and through the building industry on a voluntary basis. Impacts to be studied are social benefits and costs that result from the introduction of new technology. Both those who benefit and those who incur costs from the introduction of improved technology will be identified for case studies on reduced-sized venting for plumbing (Microstudy I) and on improved standards and practices for roofing (Microstudy II).

\section{Project Status New}

Project Leader Harold E. Marshal 1

Sponsor

National Bureau of

Standards

Project Number $46 \overline{33111}$

Impact Keywords Conservation; construction.

Technical Keywords Cost-benefit analysis; program planning, budgeting; technology assessment; technology innovation.

\section{BUILDING PRACTICES FOR DISASTER MITIGATION-- FINANCIAL LOSS}

Annual losses due to natural disasters have shown an upward trend through time and are expected to continue increasing in the future. Damages from natural disasters result from personal injuries and the loss of 1 ives and real property. Additional damaces to society include social disruption, human suffering, losses in productivity, and decreases in the tax base.

The objective of this project was to determine from existing research findings the extent and value of annual losses resulting from natural disasters in order to report the potential benefit that could be realized from mitigating the neqative economic impacts from natural disasters.

The approach was to conduct a literature search for statistics on the social costs (monetary and non-monetary) associated with various types of natural disasters.

Durina FY 74 the project was terminated as scheduled with the completion and publication of the report, "Losses Due to Natural Disasters: Empirical and Economic Considerations," NBS Interanency Report 74-473, by Thomas G. Sav.

\author{
Project Status \\ concluded \\ Project Leader \\ Harold Marsha1] \\ 301 921-3701
}

Sponsor National Bureau of Standards, National Science Foundation, Defense Civil Preparedness Agency.

Project Number $4 6 \longdiv { 3 5 1 9 0 }$

Impact Keywords Building design.

Technica 1 Keywords Benefit-cost analysis; economics, general; improvement of buildings. 


\section{ECONOMICS OF ABANDONMENT AND REHABILITATION}

\section{Project Status Continuing}

Project Leader Harold E. Marshall $301921-3701$

\author{
Sponsor \\ National Bureau of \\ Standards \\ Project Number \\ $46 \overline{37161}$ \\ Impact Keywords \\ Housing
}

Technical Keywords Housing demand, suppty, needs; housing rehabilitation; land economics; market adjustments; optimization and feasibility; rehabilitation, conservation.
Since housing is one of the most important factors in the quality of life, both individuals and governments are concerned that property owners maintain and rehabilitate their houses at optimum levels. Undermaintenance and premature abandonment of housing units generate excessive social costs, blight, neighborhood pessimism, further disinvestment and deterioration of property values. Both individual home owners and the community may benefit by higher levels of maintenance and rehabilitation.

The objectives of this project are to provide a description of factors that induce owners to abandon, maintain, or rehabilitate their units, and to identify incentives that will encourage property owners to make housing maintenance decisions that are socially efficient.

The approach is as follows: (a) conduct a literature search for any economic analysis of abandonment and rehabilitation: (b) determine an analytical framework to study property owners' motives for particular maintenance policies; and (c) evaluate the effectiveness of various incentives in inducing a socially efficient maintenance policy.

Research has been done to learn the extent to which abandonment and rapid declines in value lead to resource allocation problems. From this comes an understanding of the extent to which neighborhood conservation programs (i.e., programs which decrease abandonment and increase levels of maintenance and rehabilitation) may improve the allocation of resources.

A model has been used which explains behavior at the dwelling unit level and links this behavior to the aqqregate housing market. The focus has been on behavior which results in changes in the stock of housing through depreciation and rehabilitation. In addition, the divergence between optimal private behavior and optimal behavior from a social viewpoint has been emphasized.

An NBS Interagency Report by Peter F. Colwell, "The Economics of Residential Abandonment and Rehabilitation," is in progress.

The impact of the property tax on rehabilitation and abandonment, the impact of the income tax on rehabilitation and abandonment, the impact of land use controls (i.e., development standards) on rehabilitation and abandonment, and the importance of individual homeownership as a device to promote neighborhood conservation have also been studied. 
Twelve percent of the national energy supplv is consumed in residential space heating and cooling. Yet much of this energy is wasted due to inadequate thermal insulating qualities of the majority of houses in the U.S. If homeowners can determine how specific eneray conservation retrofitting techniques wi]l benefit them, in economic terms, they may respond faster and more accurately to national energy conservation requirements.

The objective of this project is to provide homeowners with a handbook, written at the layman's level, which will assist in determining that combination of energy conservation retrofitting techniques for residences which is optimai in terms of maximizing net savings in space heating and cooling operations.

Progress during FY 74 included the development of a methodology for determining optimal retrofitting strategies; research as to techniques avai1able, their costs and potential savings under a variety of climatic conditions; research as to fuel prices and growth rates; research as to appropriate discount rates for homeowners; and other facets of energy conservation opportunities for residential application.

The approach for $\mathrm{FY} 75$ is to assemble this information in such a manner that it can be easily interpreted by the layman interested in reducing the BTU requirement for heating and cooling his home. This methodoloqy will include allowances for climatic conditions, current fuel prices, the rate at which fuel prices are rising, and the cost of specific retrofitting techniques. A Building Science Series, "An Economic Analysis of Eneray Conservation Techniques for Retrofittina Existina Housing," by Stephen R. Petersen will be completed.

\section{ECONOMIC EVALUATION OF ROOF AND WALL SECTIONS}

The existing and anticipated shortage of energy for environmenta] conditioning of buildings requires designers of buildings to investigate and to select carefully building construction materials for optimum energy conservation. The recent history of significant increases in construction labor costs also requires investigation of labor-saving material selection.

The objective of this project is to develop criteria which can be used by designers of buildings to select building construction materials for optimum energy conservation and to select materials for their labor-saving properties in construction.

Complying with the latest Department of Defense Construction Criteria Manua 1 (DoD 4270. 1-M dated October 1, 1972) in general and the maximum allowable heat transmissions of roofs and exterior walls in particular, the approach will be to compile data on the construction (inplace) costs and energy consumption costs of roof and wall sections over a 25-year expected 1 ife for the following types of military construction: administrative facilities, housing facilities, morale and recreation facilities, and hospital facilities.

During FY 75 plans are to compile technical information on roof and exterior walls generally used in Washington, D.C.; compile technical information on roof and exterior walls potentially suitable for Washington, D.C.; and for the above sections, perform heat transmission calculation, calculate expected energy costs over a 25-year expected life, and estimate construction (in-place) cost.

Project Status Continuing

Project Leader Stephen R. Petersen 301 921-3701

\author{
Sponsor \\ National Bureau of \\ Standards \\ Project Number \\ $46 \overline{34747}$ \\ Impact Keywords \\ Consumer data.
}

Technical Keywords cost-benefit analys is; improvement of buildings; residential; ventilation.

\author{
Project Status \\ New \\ Project Leader \\ Phi 11 ip T. Chen \\ 301 921-3701
}

\begin{abstract}
Sponsor
Tri-Services of the Department

of Defense
\end{abstract}

\section{Project Number $4 6 \longdiv { 3 7 4 3 2 }$}

\author{
Impact Keywords \\ Building design; \\ conservation; \\ utilization
}

Technical Keywords cost-benefit analysis; improvement of buildings; military; roofs; value engineering; walls 


\section{ALTERNATIVE FINANCING METHODS, NON-PLANT SEWAGE TREATMENT}

\author{
Project Status \\ concluded \\ Project Leader \\ Harold E. Marsha11 \\ 301 921-3701
}

Sponsor

Environmental

Protection Agency

Project Number $46 \overline{37430}$

Impact Keywords Forestry and land management; quality control.

Technical Keywords Government expenditures; government programs; land use and development.
The Environmental Protection Agency was directed by Section 317 of the 1972 later Act to investiqate and study the feasibility of alternative financing methods for preventina, controlling, and abating pollution. This project provides backqround information to help EPA respond to this assinnment.

The ctjective of this project was to evaluate the impact of alternative cost-sharing rules on the choices of treatment technologies. This evaluation by the Buildina Economics Section provides the Environmental Protection Aqency (EPA) with information to help them to recommend financing methods to encourane adoption of the most efficient (leastcost) technologies for waste treatment.

The approach was as follows: (a) to examine current cost-sharing rules as described for both plant and nonplant waste treatment technologies; (b) develop the relationship between cost sharing and its incentive effects on nonfederal interests with respect to their choice of treatment technologies; (c) derive conditions for encouraging the selection of least-cost technologies; (d) examine current cost-sharing rules in terms of the derived conditions; (e) examine economic, legal, administrative, and other institutional conditions affecting the choice of nonplant treatment and ( $f$ ) discuss alternative cost-sharing rules.

A report entitled "Analysis of Cost-Sharing Programs for Pollution Abatement of Municipal Wastewater" was completed and presented to the sponsor. Preliminary research for two journal articles was completed. The project was terminated as scheduled.

\section{BUILDING TECHNOLOGY INFORMATION SYSTEMS}

\section{Project Status \\ Continuing}

Project Leader Morris Nimmo

$301921-3107$

\section{Sponsor}

National Bureau of

Standards

Project Number $46 \overline{32191}$

Impact Keywords Building design; construction.

Technical Keywords construction, general; design, general; improvement of buildings.
The Building Technology Information System program responds to inquiries about technical research in the Center for Building Technology.

The Building Technology Information Systems program utilizes direct correspondence, information referrals to other technical sources and a computerized information system to answer technical inquiries.

A computer-aided information referral system has been developed to assist in responding to direct mail and telephone inquiries for research information from CBT.

More than 2,000 written requests and telephone inquiries were filled with numerous referrals to other sources for information. Staff members attended the International Building Exposition and lational Association of Home Builders annual meetings. The CBT Reference Library has been maintained to serve the Center. Liaison has been maintained for the publishing of CBT research publications.

Plans for FY 75 are to continue responding to all requests for research information from CBT and to participate in relevent exchanges of research information at conferences and seminars. 
The objective of the project is to respond to requests for information from the Center for Building Technology.

Liaison will be maintained by tours, conferences and seminars to establish communications with practicing professionals in construction, technical organizations, schools of architecture and engineering, manufacturers and research groups primarity concerned with building.

During FY 74 CBT tours for more than 1,000 visitors were coordinated; extensive arrangements for the September 1973, CBT Advisory Committee meeting and arrangements for the January 1974, Technical Evaluation Panel meeting were made. The project leader acted as assistant Institute of Applied Technoloay Representative for NBS Open House and attended and heTped man NBS/CBT Eneray Display and Information booth at the International Building Exposition (INBEX) Conference, Chicago, 111 inois, November 1973.

During FY 75 plans are to continue responding to requests for CBT tours and conferences. Participation will also involve technical conferences, INBEX, National Association of Home Builders, Construction Specifiers Institute and American Institute of Architects national meetings.

\author{
Project Status \\ Continuing
}

\section{Project Leader Kenneth DeCorte $301921-3106$}

Sponsor Nationa 7 Bureau of Standards

Project Number $46 \overline{32193}$

Impact Keywords Building Design; construction.

Technical Keywords construction genera 1 ; improvement of buildings.

\section{INTERNATIONAL BUILDING RESEARCH}

This activity is for coordinating the international exchange of information from CBT and foreign research organizations involved in building research.

An international Building Research Coordinator serves as a single source for developing a more comprehensive program.

During FY 74 liaison with the U.S. French Cooperative Program and the U.S. National Committee/CIB (International Council for Building Research Studies, and Documentation) was continued. A joint research program has been established with the British Research Estabi ishment on plumbing, wind and fire detectors. The program provided tours of CBT for foreign visitors and arranged traveT within the U.S. for a French team. An extensive international correspondence file was also maintained. The annual report on international research activity, "International Activities, Center for Building Technology, National Bureau of Standards, "NBS Interagency Report 74-514, was published.

During FY 75 foreign research liaison will continue and response will be made to all foreign request for technical information. The foreign annua] report will be published and foreign correspondence files will be maintained. A tour of U.S. schools by a French research group will be arranged for October 1974 and a return visit wi 11 be made by a U.S. team in ApriT 1975.
Project Status

Project Leader Charles C. Raley 301 $921-3106$

\section{Sponsor National Bureau of Standards \\ Project Number $46 \overline{33104}$}

Impact Keywords Binational cooperation; technical assistance

Technical Keywords construction, genera 1 ; design, genera 1 ; improvement of buildings. 


\section{LIAISON WITH THE BUILDING COMMUNITY}

\author{
Project Status \\ Continuing \\ Project Leader \\ Roger A. Rensberger \\ $301921-3106$
}

Na Sponsor

Project Number $46 \overline{32790}$

Impact Keywords Building design; construction

Technical Keywords Construction, genera 1 ; design, generai; improvement of building
In order to insure relevant research in the building sciences, liaison must be maintained with the nation's building community.

Liaison will be maintained with scientific, academic, professional and technical organizations for the exchange of technical information on all aspects of building technology.

The approach is to maintain liaison with scientific, academic, professional and technical organizations for the distribution of technical research information from the Center for Building Technology and in turn provide feedback from the building community.

During FY 74 active liaison with the building community was maintained by participating in scientific and professional conferences and seminars. International Building Congress, Chicago, Illinois, November 1973; the National Association of Home Builders Convention, Houston, Texas, January 1974; and the 18th Annual Convention of Construction Specifications Institute, Portland, Oreqon, June 1974, were attended bv staff members. The following publications were the results of liaison participation: Sweet's McFraw-Hill "Energy Conservation for Buildinqs" catałoq insert; "Design and Evaluation Criteria for Energy Conservation in New Buildings"; Scientific American Roundtable, "Enerqy Conservation in Buildings," and Engineering News Record editorial on the Center for Building Technology.

During FY 75 liaison will be continued with scientific and professional oraanizations in the building community. Participation will be continuued at the annual meetings of Industrialized Building Exposition, National Association of Home Builders, Construction Specifiers Institute and other appropriate technical seminars. A series of building community seminars will be launched and new contracts developed to broaden CBT's role in the exchange of research in the building community.

\section{EDITORIAL LIAISON}

\author{
Project Status \\ New \\ Project Leader \\ Neil Gallagher \\ $301921-3106$
}

\section{Sponsor}

Nationa 7 Bureau of

Standards

Project Number $46 \overline{37190}$

Impact Keywords Buildina design; construction.

Technical Keywords construction genera 1 ; design, genera 1; improven of buildings.
The following items will be published to effectively carry out this important liaison: guarterly newsletter, annual report, project summaries, and papers offered to building publications.

The objective of this project is to produce printed materials as follows: one quarterly periodical, two annual publications, and intermittent editorial pieces, all of which would be tailored explicitly for the building community.

The Scientific and Professional Liaison Section accommodates the building community and the public generally with research findings; "feed-in" to the Center for Building Technology on building issues by establishing greater visibility for the Center; encourages collaboration in research ventures and positive rapport with the building community.

The approach is to develop narratives on research capabilities, activities, and findings, and to deploy these narratives in a coordinated strategy aimed at serving the building community and the public generally.

During FY 74 basic dissemination concepts and audience analys is was developed.

Camera-readies for the first quarterly periodical are in preparation, and a comprehensive and particularized audience for this and other outputs of the Center is being assembled. Planning for both of the annual publications (to be issued in the fal1) has begun, as has editorial research for the first of the intermittent editorial pieces, a paper directed toward construction specifiers. 
The objective of this project is to provide a central focus within the Center for Building Technology which will facilitate the exchange of information, maintain liaison activities, and insure that research activities remain applicable and responsive to the real world problems of the industry segment of the construction cummunity.

The processes of the building construction community experience dramatic changes in response to varying stimuli such as rising costs, manpower shortages, energy shortages, environmental controls, technological and regulatory changes. These changes influence nearly every participant in the building process such as the designers, developers, product manufacturers, builders, and material suppliers. Since the Center for Building Technology of the Institute for Applied Technology is the principal focal ooint in the Federal government for assuring the maximum application of the physical and engineering sciences to the advancement of technology in the construction industry, it is paramount that these changes be considered and accommodated by the building research activities of the Center.

The approach will be to establish and maintain the CBT Advisory Committee for the express purpose of providing a medium for consultation and to receive advice from the building commity, oovernment acencies, professional ormanizations, etc., relative to nolicy matters and needs in building research and technology. In addition, the committee will draw together the diverse personal contacts and technical relationships between the Center for Building Technology staff and industry representatives, and develop consultant contracts as needed to assist in identifying industrial research which influences and shapes the building process, and visit industry research directors for the purpose of structuring a model of an acceptable and efficient method for continued liaison with the industrial and federal building research programs.

The Advisory Committee was formed in mid-summer 1973. Durinn FY 74, three Committee meetings were held: September 1973, January 1974, and Apri1 1974. Minutes for these meetinas are on file at CBT headquarters. Four Specia] Task. Groups within the committee were appointed to consider these priorities: Eneray, Building Regulatory System, Environmental Standards, and the Performance Criteria.

Visits were conducted with the industrial research directors of six major companies, directly involved with the building construction process.

Two consulting contracts were completed which assisted in identifying areas of research which influence the building process.

An industrial distribution list was started for a CBT Newsletter and will also be used as the basis for a matrix which will bring together diverse personal contacts and technical relationships between the Center staff and industry representatives.

During FY 75 plans are to review, modify, and recommend new memberships as needed for the CBT Advisory Committee, (August 74 - January 75); to schedule and hold two additional Advisory committee meetings; (October 74 - to be determined 75); to receive completed reports and recommendations from the Advisory Committee Soecial Task Groups, (October 74); to establish a Task Group on Building Fires within the Advisory Committee, (October 74); Issue a CBT Newsletter for industry and other use, (August 74); visit approximately six major corporations within the construction community, to discuss research directions, approaches, and trends, (to be determined); and complete matrix of CBT staff/industry technical relationships, (Apri] 75).
Project Status Continuing

Project Leader James L. Haecker $301 \quad 921-3227$

\section{Sponsor}

National Bureau of Standards

Project Number $46 \overline{03108}$

Impact Keywords Construction; management.

Technical Keywords Components and equipment; manufacturing; public works. 
NBS. II AA IREV. 7.731

\begin{tabular}{|c|c|c|}
\hline $\begin{array}{l}\text { 1. PIBI I ATION OR REIPORT NO. } \\
\text { NBSIR 75-642 }\end{array}$ & $\begin{array}{l}\text { 2. Gov't Accession } \\
\text { No. }\end{array}$ & 3. Recipient's Accession No. \\
\hline \multirow{2}{*}{\multicolumn{2}{|c|}{$\begin{array}{l}\text { 4. TII1.E ANI SU13III.I: } \\
\text { PROJECT SUMMARIES } \\
\text { of the Center for Building Technology } \\
\text { National Bureau of Standards 1974-75 }\end{array}$}} & $\begin{array}{l}\text { 5. Publication l)ate } \\
\text { December, } 1974\end{array}$ \\
\hline & & 6. Performing Organization Code \\
\hline 7. AUTIIOR(S) Lillian T. Slovic, Editor & & $\begin{array}{l}\text { 8. Performing ()rgan. Report No. } \\
\text { NBSIR 75-642 }\end{array}$ \\
\hline \multirow{2}{*}{\multicolumn{2}{|c|}{$\begin{array}{l}\text { 9. P. FORMING ORGANIZATION NAME ANI) ADDRESS } \\
\qquad \begin{array}{l}\text { NATIONAL BUREAU OF STANDARDS } \\
\text { DEPARTMENT OF COMMERCE } \\
\text { WASHINGTON, D.C. } 20234\end{array}\end{array}$}} & 10. Projec:/Task/Work Unit No. \\
\hline & & 11. Contract/Grant No. \\
\hline \multirow{2}{*}{\multicolumn{2}{|c|}{ 12. Sponsoring Organization Name and Complete Address (Street, City, State, ZIP) }} & $\begin{array}{l}\text { 13. Type of Report \& Period } \\
\text { Covered } \\
\text { Final }\end{array}$ \\
\hline & & 14. Sponsoring Agency Code \\
\hline
\end{tabular}

16. A BSTRACT (A 200-word or less factual summary of most significant in formation. If document includes a significant bibliography or literature survey, mention it here.)

This document contains precis of more than 100 research projects recently concluded or underway at the Center for Building Technology, Institute for Applied Technology, National Bureau of Standards.

17. KEY WORDS (six to twelve entries; alphabetical order; capitalize only the first letter of the first key word unless a propet name; separated by semicolons)

Building construction; building research; building technology; Center for

Building Technology; improvement of buildings; research project descriptions.

18. AVAILABILITY Unlimited

[X. For Official Distribution. Do Not Release to NTIS

— Order From Sup. of Doc., U.S. Government Printing Office Washington, D.C. 20402, SD Cat. No.C13

— Order From National Technical Information Service (NTIS) Springficld, Virginia 22151

\begin{tabular}{|l|c|}
\hline $\begin{array}{l}\text { 19. } \begin{array}{l}\text { SECURITY CLASS } \\
\text { (THIS REPURT) }\end{array} \\
\text { UNCL ASSIFIED }\end{array}$ & 135 \\
\hline $\begin{array}{l}\text { 20. SECURITY CLASS } \\
\text { (THIS PAGE) }\end{array}$ & 22. Price \\
UNCLASSIIIED) & \\
\hline
\end{tabular}




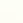



